
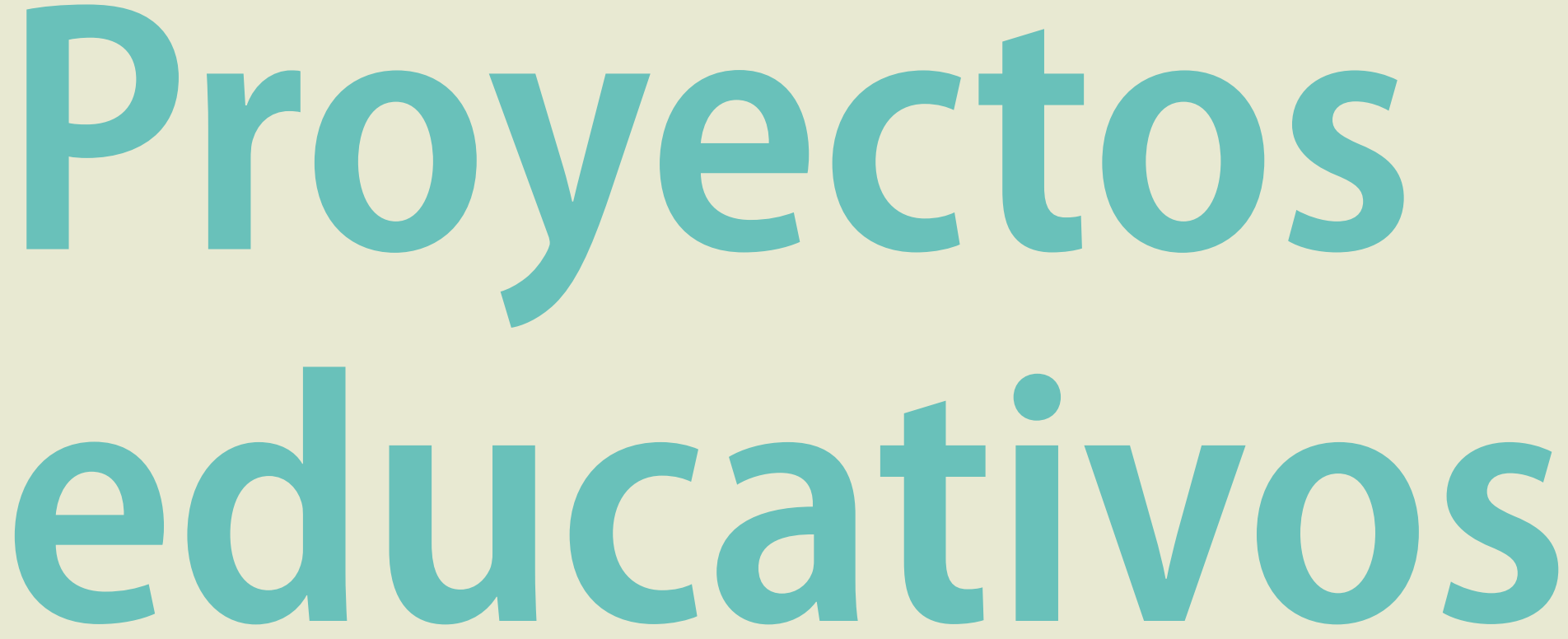

\title{
Propuesta de gestión y procesos formativos
}

Emilia Cristina González Machado Jesús Adolfo Soto Curiel (Coordinadores) 
(c) (i) (): ()

Esta obra se edita bajo una Licencia Creative Commons

Atribución-NoComercial-Compartirlgual 4.0 Internacional. 


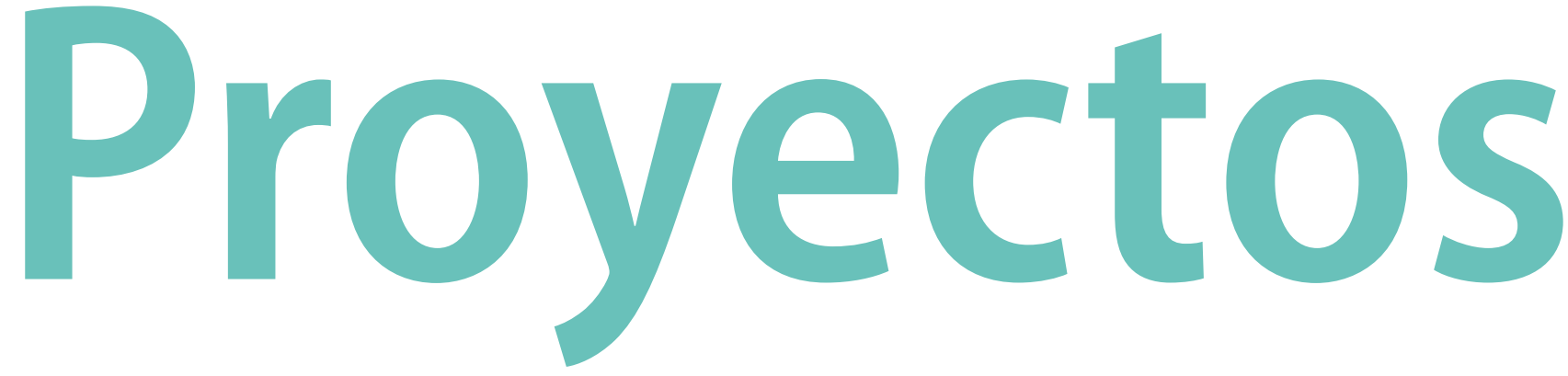

educativos

Qartuppi 
Libro colectivo financiado por PROFEXCE.

Obra arbitrada bajo el sistema doble ciego.

Proyectos educativos

Propuesta de gestión y procesos formativos

1era. edición, octubre 2021

ISBN 978-607-8694-15-0

DOI 10.29410/QTP.21.13

D.R. @ 2021. Qartuppi, S. de R.L. de C.V.

Villa Turca 17, Villas del Mediterráneo

Hermosillo, Son. 83220 México

http://www.qartuppi.com

Edición y Diseño: Qartuppi, S. de R.L. de C.V. 


\section{Tabla de contenido}

7 Presentación

Emilia Cristina González Machado y Jesús Adolfo Soto Curiel

11 Capítulo 1

Sistematización del diseño de un instrumento para explorar prácticas docentes y convivencia escolar participativa

Claudia Rosalinda Juárez Fernández, Emilia Cristina González Machado

y Alma Arcelia Ramírez Iñiguez

29 Capítulo 2

La relación entre autorregulación de los aprendizajes y reprobación escolar desde la perspectiva del estudiante y de los académicos

Betsy Berenice Arvayo Moncada, Erika Paola Reyes Piñuelas

y Emilia Cristina González Machado 


\section{Capítulo 3}

Propuesta de mediación didáctica para operar la Licenciatura

en Ciencias de la Educación en modalidad semipresencial

Brenda Iliana Núñez Pérez, Karla Lariza Parra Encinas

y Shamaly Alhelí Niño Carrasco

78 Capítulo 4

La tutoría en educación superior: una guía para la movilidad estudiantil

Mariel Alejandra Mariscal Mendoza y Fausto Medina Esparza

95 Capítulo 5

La consulta de empleadores en los procesos de acreditación

de programas de estudio de nivel superior

Alonso Vega Zamorano, Evangelina López Ramírez

y Jorge Eduardo Martínez Iñiguez

118 Capítulo 6

La educación en el marco legal hacia la reinserción social de las personas

privadas de la libertad: un análisis documental

Eva Carolina Contreras Sánchez, Joaquín Vázquez García

y Jesús Adolfo Soto Curiel

135 Acerca de los coordinadores 


\section{Presentación}

Emilia Cristina González Machado y Jesús Adolfo Soto Curiel

La educación como bien público y social tiene pretensiones que trascienden los espacios escolares, desde este marco, la presente obra colectiva tiene como propósito reportar un conjunto de experiencias educativas con el fin de articular, por un lado, el proceso de un programa de posgrado y, por otro, los diseños de diagnósticos que sustentan las propuestas, las cuales delimitan necesidades concretas, enmarcadas en distintos escenarios educativos. Cada uno de los textos que componen este libro, emanan de un programa de posgrado en Educación, cuyas líneas de investigación y generación de conocimiento se centran en los procesos formativos y la gestión educativa.

En el primer capítulo, se reporta el proceso de construcción de un instrumento que tiene como objetivo identificar las actitudes de la planta docente de educación primaria hacia la convivencia escolar participativa. El estudio describe el proceso para definir los referentes teóricos, los cuales se delimitaron a partir de la revisión de literatura especializada. Desde una aproximación cuantitativa se diseñó una muestra del tipo no probabilística, constituida por 58 docentes de educación primaria pública en Mexicali, Baja California. La validación de contenido se realizó con tres jueces especialistas, quienes evaluaron la relevancia de cada ítem; además, se realizó la prueba de alfa de Cronbach para identificar la consistencia interna de la escala. Entre los resultados, el instrumento quedó integrado por siete subescalas y 36 ítems, relacionadas con las dimensiones reportadas en otras investigaciones empíricas. Se discute que, aun cuando los ítems muestran buen ajuste y fiabilidad, se sugiere contar con un diseño robusto de la muestra, lo que permitirá hacer análisis factorial exploratorio y un análisis confirmatorio de las dimensiones de la escala. 
En el segundo capítulo, las autoras presentan un trabajo que se centra en conocer, desde la perspectiva del estudiante y académicos, la autorregulación de los aprendizajes y la reprobación académica en estudiantes universitarios. Se reporta una investigación de enfoque cualitativo, a través de la técnica de entrevista a profundidad, realizada a dos académicos y un estudiante. La guía de entrevista se diseñó a partir del análisis teórico-conceptual de la autorregulación de los aprendizajes y la reprobación académica. Los resultados reflejan que los estudiantes cuentan con escasas estrategias de aprendizaje, ausencia de establecimiento de metas y objetivos académicos, así como dificultades de adaptación por la transición del bachillerato. Se concluye que es importante la promoción del desarrollo de la autorregulación de los aprendizajes en los estudiantes, para mejorar su rendimiento académico, alcanzar el éxito escolar de culminar sus estudios y aportar en la reducción de los porcentajes de reprobación escolar.

En el tercer capítulo, las autoras parten de la siguiente premisa: consideran que la influencia de las nuevas tecnologías de la información y la comunicación en los ambientes educativos han propiciado la necesidad de innovar los procesos de enseñanza y aprendizaje; en este sentido, el capítulo desarrolla una revisión teórica que gira en torno a la modalidad semipresencial y los procesos de retroalimentación en esta. El objetivo del estudio es implementar una propuesta de mediación didáctica que se opere bajo una modalidad de aprendizaje semipresencial y que mejore los procesos del programa educativo de Ciencias de la Educación. El estudio muestra el proceso de recogida de datos a manera de diagnóstico, desde un diseño mixto, que incluye una entrevista a profundidad con el propósito de conocer la percepción del docente sobre la problemática; además, se aplicó una escala Likert para conocer la percepción del estudiante. A partir de los hallazgos, se infiere que las experiencias de los estudiantes en los cursos semipresenciales no han sido favorables en los procesos de retroalimentación entre docente y estudiante, por lo que se considera necesario diseñar una intervención para atender dicha problemática.

En el capítulo cuatro, se muestra la relación entre la movilidad estudiantil y la tutoría en la Facultad de Ciencias Humanas (FCH) de la Universidad Autónoma de Baja California a partir de los siguientes objetivos: (a) obtener el reporte de los alumnos partícipes en movilidad estudiantil en los periodos 2016-1 a 2019-2 para conocer el flujo de estudiantes que maneja la FCH en movilidad nacional e internacional; (b) encontrar los posibles factores que puedan generar problemáticas en la experiencia de los alumnos de movilidad; y (c) conocer la participación del tutor en el proceso de movilidad estudiantil de sus tutorados. 
Además, se presenta un método mixto, en el cual se utiliza una encuesta para obtener datos cuantitativos y una guía semiestructurada para realizar entrevistas. Los resultados de la fase cuantitativa muestran que los estudiantes consideran a la movilidad estudiantil como una gran experiencia en general, sin embargo, la fase cualitativa evidencia la falta de apoyo por parte de los tutores en algún momento del proceso de movilidad. Como conclusión, se necesita contar con una propuesta educativa que atienda la necesidad de los estudiantes acerca de la falta de acompañamiento educativo en movilidad estudiantil a través de la tutoría.

En el capítulo cinco, se abordan los elementos contemplados para el desarrollo de una exploración metodológica en el contexto educativo, enfocada en el análisis de los procedimientos institucionales para la consulta de empleadores en el proceso de acreditación del plan de estudios de la Licenciatura en Ciencias de la Educación, en la Facultad de Ciencias Humanas de la Universidad Autónoma de Baja California. El diseño metodológico implementado fue con enfoque cualitativo; para la exploración del fenómeno se utilizó la técnica de entrevista y se diseñó una cédula de entrevista para cada uno de los informantes clave. Los resultados obtenidos arrojaron la necesidad de fortalecer los instrumentos institucionales implementados para la consulta de empleadores permitiendo mejorar la apreciación de la expectativa del campo ocupacional, así como el fortalecimiento de los mecanismos para el seguimiento de egresados, esto con la finalidad de tener un acercamiento real a las necesidades presentes y futuras del campo ocupacional concerniente al plan de estudios.

En el capítulo seis, se analiza el papel que reviste la educación desde el marco legal en el tratamiento de las personas privadas de la libertad para lograr la reinserción social, así como su relevancia y naturaleza como derecho humano; a través de un análisis documental se abordan las siguientes categorías: (a) la educación en el derecho, (b) la reinserción social y (c) la educación penitenciaria. A partir de los referentes teóricos analizados metódicamente, se llega a la reflexión sobre la relevancia de crear espacios penitenciarios donde se respete y promueva una cultura de los derechos humanos, teniendo como eje vertebrador a la educación, que ha de ser un derecho sustancial en todas las formas que involucran a los espacios penitenciarios: derecho constitucional, derecho penal y derecho penitenciario. Asimismo, se reconoce la educación penitenciaria y la reinserción social como un derecho fundamental de las personas privadas de la libertad y una obligación del Estado. 
Sin duda, la formación profesional en el nivel de posgrado es uno de los retos y desafíos permanentes para las instituciones de educación superior en general y para las del sector público en particular. La tarea de formar profesionales requiere de un trabajo articulado con los distintos sectores de la sociedad. En México, los posgrados de calidad son espacios que dirigen sus esfuerzos en formar a profesionales que transformen y promuevan el bienestar social, la sustentabilidad y el desarrollo económico y cultural del país. En ese sentido, los capítulos tratan de dar cuenta de las necesidades educativas a modo de recortes específicos en colaboración con las comunidades de dicho sector; de esta manera, la obra integra seis propuestas educativas que emergen de los análisis y construcción del trabajo terminal, como medio de bisagra entre la teoría y el contexto, con la intención genuina de atender problemas específicos circunscritos en el campo de la educación. 


\section{Capítulo 1}

Sistematización del diseño de un instrumento para explorar prácticas docentes y convivencia escolar participativa

Claudia Rosalinda Juárez Fernández, Emilia Cristina González Machado

y Alma Arcelia Ramírez Iñiguez

A partir del enfoque de la convivencia, se establece que el ser humano forma vínculos para interiorizar aprendizajes axiológicos que le propicie un sentido a su vida y que a través de esto se establezca un contacto con la otredad para establecer propósitos de vida en común (Giménez, 2005). En los contextos escolares, la convivencia es un elemento dentro de las prácticas educativas para la transformación personal de los sujetos escolares, sobre todo un catalizador para el conocimiento de los diferentes modos de vida, pensamientos, actitudes e ideas (Vignolo \& Maturana, 2001). En este sentido, los docentes cumplen un papel estratégico para que los vínculos que se forman dentro de la escuela — poniendo en primer plano la relación que tiene con los niños- estén fundados bajo valores que propicien que sus estudiantes se resuelvan en sociedad con inclusividad y democracia (Oldak, 2017).

La escuela, como un espacio democrático con fines de formación ciudadana, requiere de la convivencia para que la comunidad participe a través del diálogo, la disertación y la construcción crítica de soluciones (Fierro \& Carbajal, 2019). Por lo que la participación es una condición constante para la convivencia de una comunidad escolar con propósitos de adquirir aprendizajes culturales, sociales y políticos, tanto de los agentes educativos como de los docentes y los alumnos (Fierro, Tapia et al., 2013). De manera que, la escuela - como un lugar de reconocimiento democrático donde es posible valorar la capacidad de los niños para resolver sus propios conflictos, tomar acuerdos y construir conocimiento 
a través de su propia experiencia- demanda de docentes que establezcan dentro de su práctica metas y estrategias aplicadas a los mecanismos de convivencia para el alcance de habilidades sociales y democráticas, como el diálogo y la resolución de conflictos (Carvajal \& Valencia, 2016; Torres, 2006).

Los niños aprenden que, a través del ejercicio de la participación, se convive con el propósito de hacer valer su opinión y expresar su voz como un derecho (Landeros \& Chávez, 2015). Es decir, la convivencia no es solo una forma de socializar para establecer vínculos hacia una meta indefinida, sino que, la participación ofrece a la infancia escolarizada desarrollar capacidades basadas en la ejecución de sus derechos. En este sentido, promover prácticas en el aula que habiliten estos derechos logra ubicar a los niños como sujetos sociales con el poder de expresar ideas y decidir sobre los asuntos que le conciernen (United Nations Children's Fund \& Save the Children, 2003).

Lo anterior, es sostenido por la Comisión Nacional de los Derechos Humanos (2018) que manifiesta que, en todos los contextos, incluyendo el escolar, los niños tienen derecho a ser escuchados en asuntos de su interés, acorde a su edad, etapa y madurez; además, se debe garantizar que la infancia posea todos de medios de búsqueda, recepción y difusión de información. Dicho de otra manera, lo que se busca a través de la participación infantil es que el alumnado aprenda a opinar y expresarse desde el conocimiento informado. De esta manera, el docente debe motivar y diseñar los medios de información adecuada que cumplan las necesidades para solventar problemáticas y desarrollar un mayor interés por aprender.

Desde otro punto de vista, la participación como objeto de aprendizaje es un catalizador que ofrece capacidades para resolver los conflictos que se presentan al convivir dentro de la cotidianeidad, ya que se desarrolla la consciencia de la libertad para tomar decisiones y el interés de involucrarse en la organización para la solución de problemáticas (Giménez, 2005; Landeros \& Chávez, 2015). Por lo tanto, la participación constituye una serie de aprendizajes específicos para que los niños desarrollen la autonomía de resolver implicaciones de su contexto y comprendan los valores alusivos al compromiso social, como lo es la libertad de decidir.

Para Trilla y Novella (2001), el protagonismo de la infancia sobre su contexto requiere de proyectos que destaquen una participación verídica, donde el alumnado sea libre de reconocer el mundo público, criticarlo y construirlo a través de su propia mirada, con metas que en esencia contengan ideas, opiniones y acciones propias. Esto implicaría, por un lado, reconocer el papel del infante en su propia vida social y, por el otro lado, 
reconocer su capacidad para poder crear y dirigir proyectos, de manera que se revalorice el rol del docente y su perspectiva de la infancia.

La capacidad que tienen los niños para reconocer sus necesidades, parte de la naturaleza de su desarrollo, que les impulsa a expresar y exigir desde su vulnerabilidad, las condiciones necesarias para desenvolverse, las cuales son base de una comunidad que incluye a todo tipo de integrante social (Tonucci, 2009). Por lo tanto, es la infancia en la escuela quien determina oportunidades de transformación escolar, ya que valorar sus necesidades a través de la voz de sus necesidades alimenta constantemente la labor pedagógica que se propone, no desde el adulto escolar sino desde el impulso de la infancia.

Por lo anterior, para que los docentes logren que los niños se impliquen, convivan y participen en las problemáticas de su contexto, es necesario que su práctica pedagógica incorpore habilidades reflexivas que le permitan reconocer la trascendencia social de su labor (Ferry, 1997). Asimismo, los docentes deben ser los adultos que controlen y direccionen las metas de aprendizaje social, admitir un rol que motive la autonomía infantil y adquirir un rol de mediación reflexiva que mantenga la figura de influencia que los infantes necesitan para comprometerse con sus procesos de crecimiento (Manen, 1998). Por lo tanto, es necesario que la reflexión docente sobre la convivencia escolar y la participación infantil conlleve a reflexionar sobre las habilidades democráticas en el alumnado, basadas en la autonomía, la expresión, el diálogo, la crítica y el conocimiento de los derechos de la infancia.

En México, la Ley General de los Derechos de los Niños, Niñas y Adolescentes (Comisión Nacional de los Derechos Humanos [CNDH], 2018), así como la Ley General de Educación (2019), hacen énfasis sobre la importancia de la capacitación docente para la convivencia escolar en el nivel básico. Sin embargo, en un estudio nacional realizado por Chaparro et al. (2019) se hizo evidente la deficiente preparación, sensibilización y práctica del docente para intervenir en los conflictos de convivencia en el aula, demostrando poco conocimiento para desarrollar competencias socioemocionales en el alumnado.

Por otro lado, una investigación centrada en analizar la relación entre la participación infantil y la convivencia escolar reportó que las barreras para la construcción de una vida escolar participativa son consecuencia de prácticas docentes centradas en la obediencia y en la subordinación del alumno, cuya lógica se centra en perspectivas adultocéntricas que desvalorizan los alcances de las capacidades los niños (Serrano et al., 2019). Además, existen pruebas acerca de prácticas de violencia física y simbólica de los docentes, inmersas en los vínculos cotidianos con el alumnado de educación primaria, las cuales 
se justifican en la normalización de la violencia, formas de disciplina o estilo de comunicación (Fondo de las Naciones Unidas para la Infancia, 2017).

Asimismo, se han probado proyectos de investigación con base empírica (Baquedano \& Echeverría, 2013; Cárdenas, 2017; Ochoa \& Pérez, 2017) que demuestran que es posible afrontar las actitudes adultocéntricas de los docentes hacia su alumnado para el desarrollo de la convivencia participativa. A partir de las categorías que forman este trabajo, se descubren estudios e intervenciones desde el contexto internacional hasta el local, con el propósito de analizar e intervenir las distintas problemáticas en la práctica docente y las limitaciones para establecer vínculos que promuevan la participación infantil desde la educación primaria.

Las investigaciones realizadas en el contexto europeo determinaron la presencia de prácticas docentes donde el modelo pedagógico en el que basan su acción se caracteriza por la lógica adultocéntrica, lo cual es percibido desde la infancia como un alejamiento a las necesidades de los niños y las posibilidades democráticas que se pudiesen habilitar desde esa etapa (Castro \& Caldeiro, 2018; Ochoa \& Salinas, 2015).

En Latinoamérica, estudios empíricos demuestran que las concepciones que presenta el docente acerca de la participación de la infancia están reguladas bajo sus propias condiciones, por lo que el alumnado carece de libertad de expresión y vínculos afectivos, demostrando que la diversidad cultural en el aula puede no ser aprovechada para el logro de aprendizajes (Guzmán et al., 2014; Ochoa, 2015). En este sentido, Chang y Henríquez (2013) hallaron que el dominio adultocéntrico en las prácticas escolares limita la participación y el desarrollo de competencias para la ciudadanía y, además, que las expectativas que se tienen sobre la infancia determinan su desempeño y comportamiento en el aula. Según Hecht (2013), la cultura adultocéntrica es un factor que limita la percepción sobre los aportes de la infancia al desarrollo de los individuos de su comunidad, puesto que la imposición del concepto de adulto se establece como parámetro y meta, desvalorizando, por ejemplo, los aportes a la enseñanza informal lingüística de sus pares o familiares.

Muñoz et al. (2014), en su investigación sobre la percepción de la convivencia y clima escolar en un colegio inclusivo, descubrieron que algunos temas que generan conflicto son el respeto de las normas del colegio, el apoyo de los profesores a los alumnos y el respeto de los alumnos a los profesores.

Con relación a los trabajos de intervención, las experiencias lúdicas fueron determinantes para resolver las problemáticas de convivencia en las instituciones escolares de primaria. Según los estudios, el juego como objeto de aprendizaje y parte de las estrate- 
gias de intervención lograron cambiar la perspectiva y mejorar las relaciones interpersonales entre los alumnos, afectando de forma significativa su manera de convivir (Gómez, 2016).

En el contexto nacional, Serrano et al. (2019) analizaron las conceptualizaciones sobre la participación que refieren tanto a niños, docentes y familiares, en tres escuelas ubicadas en zonas urbanas de rasgos de marginación. Los resultados indicaron que la escolarización de la infancia limita el concepto que se tiene sobre participación, remitiéndose a entenderla como la emisión de opiniones cuando es solicitud del docente. Los investigadores sostienen que el adultocentrismo y la obediencia son impedimento para la construcción de una escuela inclusiva.

De acuerdo con Ochoa y Pérez (2019), la experiencia de intervención basada en el aprendizaje servicio (AS) mejora el clima escolar a través de la transformación de "algunas prácticas pedagógicas, así como el posicionamiento del alumnado como protagonista del proceso de implementación del proyecto" (p.1). Sin embargo, este tipo de metodologías de participación no son frecuentes en el contexto de la educación básica, a pesar de que legitiman el reconocimiento del alumnado al ser escuchados y permitirles actuar sobre su propio contexto.

Cárdenas (2017) desarrolló un proyecto de intervención basado en una metodología participativa, mediante el cual, a través del fortalecimiento de las capacidades pedagógicas de los docentes, se busca desarrollar competencias en los alumnos de educación básica de escuelas públicas. Como resultado se logró ampliar las oportunidades de enseñanza y aprendizaje tanto para los docentes como para los estudiantes. En el caso particular de los docentes, se concluyó que estos se comprometen en la transformación de su práctica pedagógica y motivan la participación de los estudiantes en la construcción de su comunidad escolar con una perspectiva cívica.

Finalmente, se reporta un trabajo de investigación-acción del tipo participativa realizado por los investigadores Baquedano y Echeverría (2013), en el que se concluye que las propuestas basadas en la metodología participativa, cuando son aplicados en los centros escolares, disminuyen las resistencias, ya que este tipo de recurso promueve el compromiso de los participantes, provoca un cambio en el ambiente y posibilita asumir que cualquier conflicto es una oportunidad de aprendizaje.

A pesar de que existen diversas investigaciones sobre convivencia escolar, la mayoría se ha enfocado en describir el tipo de prácticas escolares que favorecen la convivencia, pero sin proponer un proyecto de intervención con intenciones de cambio (Díaz \& Sime, 
2016). Además, se tiene la intención de abordar dicho campo desde una visión analítica a partir de la cultura escolar. Al respecto, Fierro, Lizardi et al. (2013) señalan la pertinencia de realizar investigación educativa en el tema, descifrando el potencial de las relaciones humanas dentro de la escuela para ofrecer la posibilidad de mejorar las experiencias de intervención y generar nueva información para los distintos actores educativos.

Por lo tanto, con el objetivo de realizar un proyecto de intervención para dar continuación a la labor investigativa sobre este tema con una base científica sustentable, se creó una escala para medir las actitudes docentes sobre la convivencia escolar participativa. La construcción de la escala es el resultado de un proceso de una sistematización rigurosa de los objetivos del proyecto origen, investigación documental, un trabajo de validación a través de especialistas en materia de investigación, pedagogía y psicología. Además, se realizó una prueba piloto con docentes de la ciudad de Mexicali, Baja California, y se aplicó una prueba de confiabilidad con el alfa de Cronbach para hacer un ajuste en las dimensiones e ítems de la escala.

\section{Método}

El presente trabajo es resultado de una investigación con un diseño metodológico cuantitativo (Hernández et al., 2014), en la cual se somete a validez y confiabilidad un instrumento que evalúa prácticas de gestión de la convivencia escolar. El instrumento construido para la recolección de datos cuantitativos es un cuestionario basado en la escala Likert. Para Ospina et al. (2005), la escala Likert es una escala de tipo ordinal que mide actitudes a través de intervalos aparentemente iguales, para la cual se definen una serie de afirmaciones para obtener una respuesta por parte de los participantes. Este tipo de escala en el diseño del cuestionario ofrece la capacidad de identificar las percepciones, actitudes, representaciones y opiniones de los sujetos (Fabila et al., 2012).

En relación con lo anterior, para observar las actitudes y concepciones de los docentes, se siguió la premisa de Blanco y Alvarado (2005), que plantea un ejercicio de operacionalización de la variable a partir de la descomposición teórica de los conceptos que se manejan en la investigación. El ejercicio mencionado se realizó a partir de los objetivos de diagnóstico del proyecto de investigación denominado: "Prácticas docentes para la convivencia escolar participativa en escuela primaria". El proceso de sistematización del trabajo investigativo del que se origina esta escala se asocia con la problematización, los antecedentes y el marco conceptual del tema que se aborda. Los objetivos que persigue el trabajo son: 
1. Analizar las acciones de intervención docente para incentivar la toma de decisiones del alumnado, así como las estrategias que le ofrece para la solución de conflictos de manera autónoma.

2. Identificar los tipos de relación comunicativa que existen en las interacciones entre el docente y el alumnado, y el tipo de interacciones que fomenta entre el alumnado.

3. Detectar características de las interacciones que limitan o incentiven la convivencia escolar participativa.

4. Analizar las relaciones entre el docente con otros agentes educativos que conllevan a la reflexión y cambio de la práctica pedagógica.

Aunado a lo anterior, los autores también especifican que para que las variables sean observables, estas deben de bajarse a un nivel que sea factible observar desde la realidad, por lo tanto, para la elaboración precisa y clara de ítems se adaptaron y utilizaron cuatro instrumentos dirigidos a docentes de nivel básico, cuyas teorías, objetivos y dimensiones estuviesen relacionados con: (a) la práctica docente, (b) la convivencia escolar y (c) la participación en la educación básica.

Uno de los instrumentos seleccionados para la recolección de datos fue una guía de autodiagnóstico (Fierro, Tapia et al., 2013). Esta guía se basa en dos enfoques contemporáneos de la teoría de la convivencia, el enfoque analítico y el de calidad. El objetivo del instrumento es producir para quien lo usa, un proceso de observación, análisis y diagnóstico desde la experiencia compartida de los docentes y directivos de un centro educativo con referencia a la gestión de la convivencia escolar. Se presentan cuatro dimensiones: (1) reconocimiento y atención de la diversidad, (2) el trato en la escuela y espacios de reflexión, (3) toma de decisiones y acuerdos, y (4) participación y corresponsabilidad en el fortalecimiento de la enseñanza. La guía está integrada por 24 reactivos con una escala de respuesta de cinco opciones: (a) Esto nunca sucede en la escuela; (b) esto sucede muy rara vez en la escuela; (c) esto sucede con bastante frecuencia en la escuela; (d) esto sucede de forma habitual en la escuela: y (e) no se tiene suficiente información para emitir un juicio. Los autores únicamente reportan el procedimiento al cual fue sometido el instrumento para validar y ajustarlo en condiciones de lenguaje y relevancia, para garantizar que el instrumento pudiese aplicarse de forma autoadministrada. Por lo que el procedimiento de prueba se dio en dos momentos; la primera prueba fue aplicada en seis estados del país con el fin de registrar, analizar y adecuar el instrumento, tomando en cuenta los diferentes contextos y regímenes de escuela, es decir, si fuese rural o urbana, privada o públi- 
ca, en la cual se obtuvieron 14 observaciones con relación a dificultad en comprender el lenguaje y el contenido de las afirmaciones; la segunda prueba se realizó en seis escuelas, de las que se obtuvieron nueve observaciones respecto al contenido. Después de ese procedimiento se llegó a la muestra final. Con relación a la consistencia interna, los autores no realizaron el reporte.

El segundo instrumento que se utilizó como referencia para la construcción de la escala pertenece a Arancibia (2014): "Cuestionario de diagnóstico para un proyecto de convivencia escolar, aplicación docente". Este instrumento, basado en la convivencia escolar desde el enfoque de Derechos Humanos, bajo el sustento de la Convención de los Derechos del Niño, tiene el objetivo de determinar la situación referida a la convivencia escolar en las escuelas mediante la comparación de resultados entre la planta docente y la población estudiantil del centro escolar. El cuestionario presenta cuatro dimensiones que son: (a) abordaje de conflictos, (b) comprensión empática, (c) comunicación y (d) espacios de convivencia. El instrumento contiene 36 reactivos con una escala de respuesta numerada del uno al siete, donde uno es la respuesta en el extremo más bajo y siete el más alto. Para la medición de la respuesta, la autora recomienda hacerlo a través de la descripción de frecuencia. De acuerdo con los reportes de confiabilidad y validación, únicamente se reporta la validez, de la cual se explica brevemente que fue pasada por una revisión de equipo de expertos que realizaron la validez y la adaptación.

El tercer instrumento fue diseñado por López y Valdés (2018), quienes tomaron como referencia teórica y conceptual las prácticas de convivencia escolar orientadas a "crear culturas escolares inclusivas (Booth \& Ainscow, 2015) y la disposición organizacional al cambio (Helfrich et al., 2009; Stevens, 2013)" (p.8). El objetivo del instrumento es evaluar las prácticas de la gestión de la convivencia a través del descubrimiento de acciones concretas que realizan los profesionales de la escuela. El instrumento cuenta con doce dimensiones que se presentan a continuación: (1) Cultura inclusiva, (2) prácticas inclusivas, (3) formación continua, (4) orientación al trabajo en equipo, (5) normas compartidas, (6) participación democrática, (7) prácticas punitivas, (8) actitudes de disposición al cambio, (9) disposición organizacional, (10) cultura del mejoramiento de la convivencia, (11) prevención de los problemas de la convivencia y (12) promoción de la buena convivencia. De manera adicional, se consideró como criterio de validez la dimensión que alude a las denuncias por maltrato escolar y discriminación. El cuestionario consta de 78 ítems con cinco opciones de respuesta donde 1 representa nunca, 2 es equivalente a algunas veces, 3 significa regularmente, 4 es casi siempre y 5 es siempre. El instrumento fue validado 
con una muestra de 741 profesionales correspondientes a 129 escuelas. Con relación a la prueba de confiabilidad, el instrumento presenta indicadores de ajuste y consistencia aceptables, presentando ítems con estimación estandarizada sobre .50 y coeficientes de alfa de Cronbach sobre .7.

Un cuarto instrumento que se analizó es la escala de autoadscripción inclusiva en docentes secundarios en Chile, diseñado por Castro-Rubilar et al. (2017). Dicha escala se fundamenta en el Índice de Inclusión de Booth y Ainscow, cuyo objetivo consiste en medir la aceptación y disposición de la inclusión escolar. Este comprende seis dimensiones: (1) enseñanza para el aprendizaje de todos, (2) construyendo comunidad inclusiva, (3) diseño curricular para la diversidad, (4) políticas escolares para la diversidad, (5) prácticas de inclusión en la escuela y (6) desarrollo de cultura para la inclusión. El instrumento está constituido por 55 ítems con una escala de respuesta tipo Likert de cuatro opciones, donde nunca es igual a 0 , algunas veces es 1 , muchas veces es 2 y casi siempre es 3. La escala fue sometida a una validación de contenido y redacción por parte de profesionales expertos en psicología y pedagogía. Después, se realizó una prueba piloto con 122 docentes y se analizó el nivel de confiabilidad con la prueba de alfa de Cronbach, del cual resultó una eliminación de ítems que presentaban baja confiabilidad. Finalmente, en la siguiente aplicación se realizó un nuevo análisis de confiabilidad alcanzando un alfa de Cronbach de 0.954 , estableciéndose en un alto nivel.

\section{Muestra}

Para realizar la prueba piloto se diseñó una muestra no probabilística, conformada por 56 docentes de educación básica, provenientes de primarias públicas. La edad media de los participantes es de 34.5 años; 46 son mujeres (82.1\%) y 10 son hombres (17.9\%). La mayor proporción de formación académica corresponde a estudios de licenciatura (73.1\%) en contraste con el grado de maestría (7.1\%). En relación con la experiencia docente, 20 expresaron tener de 3 a 6 años, 10 indicaron tener de 7 a 10 años, nueve señalaron de 11 a 14 años, nueve indicaron tener 19 o más años y cinco participantes mencionaron contar con un rango de 15 a 18 años de experiencia.

\section{Resultados}

\section{Dimensiones y conceptos de la escala}

A partir de la articulación rigurosa de los objetivos, los antecedentes de investigación y los distintos referentes teóricos del presente proyecto, se construyó la “Escala de Prácticas 
Docentes para la Convivencia Escolar Participativa", cuyo objetivo es conocer las actitudes docentes de educación primaria en relación con la convivencia escolar participativa. Los ítems corresponden a siete dimensiones o subescalas basadas en la sistematización de objetivos con los referentes teóricos, las cuales son: (1) intervención docente para la toma de decisiones; (2) solución de conflictos de manera autónoma; (3) relación comunicativa entre el docente y el alumnado; (4) estrategias para el aprendizaje mutuo; (5) estrategias de interacción participativa; (6) relaciones reflexivas del docente con otros agentes educativos; y (7) relaciones con otros agentes educativos que transforman la práctica pedagógica. En la tabla 1 se describen cada una de las dimensiones.

\section{Tabla 1}

Dimensiones y conceptos de la escala de prácticas docentes para la convivencia escolar participativa

\begin{tabular}{ll}
\hline \multicolumn{1}{c}{ Dimensión } & \multicolumn{1}{c}{ Concepto } \\
\hline $\begin{array}{l}\text { 1. Intervención docente para } \\
\text { la toma de decisiones }\end{array}$ & $\begin{array}{l}\text { Acciones que el docente de primaria realiza para impulsar al } \\
\text { alumnado a crear y dirigir proyectos sobre temas de interés o } \\
\text { problemas de su contexto que incluyan el trabajo colaborativo, } \\
\text { la expresión de ideas, el acceso a la información y la toma de } \\
\text { decisiones. }\end{array}$ \\
\hline $\begin{array}{l}\text { 2. Solución de conflictos de } \\
\text { manera autónoma }\end{array}$ & $\begin{array}{l}\text { Acciones y medios que el docente utiliza, basado en la creativi- } \\
\text { dad, el fomento a la reflexión, la autonomía y el trabajo colabora- } \\
\text { tivo del alumnado, para que estos den solución a sus conflictos. }\end{array}$ \\
\hline $\begin{array}{l}\text { 3. Relación comunicativa entre } \\
\text { el docente y el alumnado }\end{array}$ & $\begin{array}{l}\text { Tipo de interacción que propicia el docente, donde existe } \\
\text { apertura al diálogo con el alumnado sobre los temas de su } \\
\text { interés, incorporando dichos temas en su planeación didáctica. }\end{array}$ \\
\hline $\begin{array}{l}\text { 4. Estrategias para el aprendiza- } \\
\text { je mutuo }\end{array}$ & $\begin{array}{l}\text { Estrategias de enseñanza utilizadas por el docente, que generan } \\
\text { un ambiente escolar que estimula el aprendizaje mutuo y el } \\
\text { liderazgo del alumnado en el proceso educativo. }\end{array}$ \\
\hline $\begin{array}{l}\text { 5. Estrategias de interacción } \\
\text { participativa }\end{array}$ & $\begin{array}{l}\text { Estrategias utilizadas por el docente para promover la participa- } \\
\text { ción, a partir del establecimiento de relaciones de confianza, del } \\
\text { diálogo y de la creación de espacios de reconocimiento. }\end{array}$ \\
\hline $\begin{array}{l}\text { 6. Relaciones reflexivas del } \\
\text { docente con otros agentes } \\
\text { educativos }\end{array}$ & $\begin{array}{l}\text { Relaciones reflexivas entre docentes y otros agentes educativos, } \\
\text { que se centran en discutir y tomar decisiones para conocer al } \\
\text { alumnado y sus problemáticas. }\end{array}$ \\
\hline práctica pedagógica & $\begin{array}{l}\text { Relaciones entre docentes y otros agentes educativos, basadas en } \\
\text { el trabajo colaborativo, el aprendizaje permanente y la búsqueda } \\
\text { de soluciones alternativas para las problemáticas escolares. }\end{array}$ \\
\hline
\end{tabular}




\section{Evidencias de validación}

En la etapa de validación de contenido del instrumento participaron un grupo de tres especialistas en el campo de la evaluación educativa, con estudios de doctorado y experiencia en la investigación. Para la asignación de calificación de cada reactivo $(k=65)$ se utilizó un recorrido de 1 a 3 puntos, con base en los siguientes criterios: (a) suficiencia del ítem, (b) claridad de redacción, (c) coherencia del ítem, (d) relevancia del ítem para el constructo y (e) espacio de observaciones (tabla 2).

\section{Tabla 2}

Criterios para la validación de contenido

1. Ítems

2. Definición de la dimensión

3. Suficiencia (pertenece a esta dimensión)

4. Claridad (se comprende fácilmente)

5. Coherencia (tiene relación lógica con la dimensión)

6. Relevancia (es esencial para medir el constructo)

7. Observaciones (espacio para comentar el ítem)

Para establecer el índice de relevancia del ítem (IRI) se sumaron las puntuaciones totales y se determinó la calificación proporcional por cada criterio; para estimar la confiabilidad entre jueces, se realizó un análisis de varianza por medio del coeficiente de correlación intraclase (CCI); se consideraron resultados con valores de 0.51 a 0.60 como moderada correlación y de 0.61 a 0.83 como sustanciales, según el criterio propuesto por Landis y Koch (1977). Los análisis se procesaron en el software libre llamado Vassarstats.

Una vez atendidas las observaciones vertidas por las especialistas en el apartado de comentarios al ítem, así como el IRI, se ajustó la escala; quedando integrada con 41 ítems, manteniendo el mismo número de dimensiones, con una escala de respuesta del 0 al 6 , donde 0 es igual a nada cierto y 6 es igual a totalmente cierto. Estas afirmaciones fueron trasladadas a un formulario de la plataforma de Google para iniciar el pilotaje que tuvo una duración de tres semanas. 


\section{Prueba de confiabilidad}

Se realizó un análisis de fiabilidad a través de la prueba Alfa de Cronbach para analizar la consistencia de cada dimensión y el total de la escala y así revisar la permanencia de los ítems en la escala. Los resultados de la primera muestra se observan en la tabla 3.

\section{Tabla 3}

Primera prueba de consistencia interna

\begin{tabular}{lcccc}
\hline \multicolumn{1}{c}{ Variable } & $N$ & $M$ & $D E$ & $a$ \\
\hline Intervención docente para la toma de decisiones & 56 & 42.41 & 4.45 & .61 \\
\hline Solución de conflictos de manera autónoma & 56 & 27.19 & 3.88 & .84 \\
\hline Relación comunicativa entre el docente y el alumnado & 56 & 10.80 & 1.60 & .50 \\
\hline Estrategias docentes para el aprendizaje mutuo & 56 & 28.78 & 1.64 & .31 \\
\hline Estrategias de interacción participativa & 56 & 43.71 & 4.53 & .72 \\
\hline Relaciones reflexivas con otros agentes educativos & 56 & 43.14 & 10.30 & .91 \\
\hline $\begin{array}{l}\text { Relaciones con otros agentes educativos que } \\
\text { transforman la práctica pedagógica }\end{array}$ & 56 & 24.55 & 5.16 & .77 \\
\hline Total & 56 & 214.80 & 23.76 & .92 \\
\hline
\end{tabular}

A partir de los resultados, se realizó una eliminación de ítems en las dimensiones donde existía una consistencia interna baja. En la subescala Intervención docente para la toma de decisiones se eliminaron tres ítems (ítems 2, 7 y 8). En la subescala Relación comunicativa entre el docente y el alumnado, que refleja una consistencia interna baja, se tomó la decisión de no eliminar ítems, ya que los dos ítems que integran la escala presentan una correlación del ítem con el total no menor de 0.3. En el mismo sentido, en la subescala Estrategias Docentes para el Aprendizaje Mutuo se eliminaron dos ítems (ítems 17 y 18). Después de realizar una prueba de correlación, se obtuvieron los siguientes resultados en los análisis de confiabilidad (tabla 4).

Con los resultados del segundo análisis de confiabilidad se obtuvo un Alfa de Cronbach de .92, a partir de este dato se estableció la versión final de la escala, integrada por 36 ítems. Se mantuvieron las siete dimensiones de origen, así como su concepto, es decir, no se realizó ninguna modificación. En relación con la sensibilidad de la medida de la escala, fue necesario asignar categorías para detectar los cambios a través del tiempo y se asignó una denominación a cada categoría para interpretar las distintas reacciones de los participantes a las afirmaciones de la escala (Bisquerra \& Pérez, 2015). 
Tabla 4

Segunda prueba de consistencia interna

\begin{tabular}{lcccc}
\hline \multicolumn{1}{c}{ Variable } & $N$ & $M$ & $D E$ & $a$ \\
\hline Intervención docente para la toma de decisiones & 56 & 25 & 4.13 & .63 \\
\hline Solución de conflictos de manera autónoma & 56 & 27.19 & 3.88 & .84 \\
\hline Relación comunicativa entre el docente y el alumnado & 56 & 10.80 & 1.60 & .50 \\
\hline Estrategias docentes para el aprendizaje mutuo & 56 & 17.41 & 1.17 & .51 \\
\hline Estrategias de interacción participativa & 56 & 43.71 & 4.53 & .72 \\
\hline Relaciones reflexivas con otros agentes educativos & 56 & 43.14 & 10.30 & .91 \\
\hline $\begin{array}{l}\text { Relaciones con otros agentes educativos que } \\
\text { transforman la práctica pedagógica }\end{array}$ & 56 & 24.55 & 5.16 & .77 \\
\hline Total & 56 & 186.01 & 23 & .92 \\
\hline
\end{tabular}

\section{Discusiones y conclusiones}

La participación en la convivencia escolar se detecta como un factor que permite desarrollar capacidades cívicas, convirtiendo la escuela como un espacio para la formación de la ciudadanía y la democracia. La participación se practica en la convivencia a través del reconocimiento de la diversidad de capacidades e identidades, la valoración de la pluralidad de ideas, el encuentro en espacios de disertación, diálogo y construcción crítica (Fierro \& Carbajal, 2019). Establecer un tipo de convivencia escolar permite atender específicamente el universo de conceptos, perspectivas y problemáticas que se presentan al estudiar la convivencia escolar, la cual se ha fijado como un campo de estudio relevante, pero que requiere mayor definición en el método de estudio (Díaz \& Sime, 2016).

Dar continuidad a la investigación educativa en el tema de convivencia escolar ofrece la posibilidad de ofrecer nueva información que permita retroalimentar y mejorar las experiencias escolares, a partir del estudio sobre los vínculos escolares (Fierro, Lizardi et al., 2013). En este sentido, ya existen algunos instrumentos con el objetivo de evaluar la calidad de la convivencia en los centros escolares, pero son escasas las creaciones de instrumentos que buscan conocer prácticas específicas de la convivencia escolar (López \& Valdés, 2018). Por lo que construir una escala con el propósito de abordar los diferentes aspectos que devienen de la convivencia escolar desde la perspectiva participativa, permite conocer las actitudes y experiencias del profesorado respecto a la necesidad de dar protagonismo al alumnado desde la infancia como agentes de cambio, a partir del desarrollo de competencias democráticas como la capacidad de decidir y solucionar problemáticas 
de su contexto, trabajar colaborativamente con sus pares para el logro de aprendizajes y relacionarse asertivamente con metas en común; además, que en este proceso, el docente se permita aprender de la infancia, convocar y compartir de manera colaborativa con el profesorado, participar en las soluciones y proyectos para el desarrollo de la convivencia escolar; asimismo, que en este proceso exista un aprendizaje permanente.

Se recomienda dar seguimiento a investigaciones con enfoque cuantitativo relativas a la convivencia escolar con relación a la experiencia de la participación infantil. Ya que, desde el enfoque participativo de la convivencia escolar, se detectan elementos que pueden ser estudiados con mayor profundidad tales como las habilidades de expresión y el acceso a la información de la infancia, así como profundizar los distintos niveles en los que el docente interviene para desarrollar la autonomía.

Construir escalas de medición con alta sensibilidad de respuesta ofrece la posibilidad de analizar y hacer inferencias de temas de relevancia social desde el contexto escolar, como la convivencia participativa; esto permitirá describir y explicar las necesidades educativas que nos acontecen. Finalmente, el trabajo reportado brinda las pautas para continuar con estudios de elaboración de escalas que muestren evidencias de calidad técnica, es decir, instrumentos confiables y válidos para obtener datos, cuantificar y comparar realidades educativas; no obstante, se sugiere ampliar la muestra y considerar análisis factorial para confirmar el constructo. 


\section{Referencias}

Arancibia, M. (2014). Diagnóstico e intervención en escuelas desde la política de convivencia escolar y enfoque de derechos humanos. Actualidades Investigativas en Educación, 14. https://doi.org/10.15517/aie.v14i3.16092

Baquedano, C., \& Echeverría, R. (2013). Competencias Psicosociales Para la Convivencia Escolar Libre de Violencia: Experiencia en una Primaria Pública de Mérida, Yucatán, México. Psicoperspectivas. Individuo y Sociedad, 12(1), 139-160. https://doi. org/10.5027/psicoperspectivas-Vol12-Issue1-fulltext-210

Bisquerra, R., \& Escoda, N. (2015). ¿Pueden las escalas Likert aumentar en sensibilidad? REIRE, Revista d'Innovació i Recerca en Educació, 2, 129-147. https://doi.org/10.1344/ reire2015.8.2.828

Blanco, N., \& Alvarado, M. E. (2005). Escala de actitud hacia el proceso de investigación científico social. Revista de Ciencias Sociales, 11(3), 537-546.

Cárdenas, M. (2017). Desarrollo de capacidades pedagógicas en la educación democrática: Experiencias del programa Aprender a participar, participando. XIV Congreso Nacional de Investigación Educativa (COMIE). http://www.comie.org.mx/congreso/ memoriaelectronica/v14/doc/simposios/1727.pdf

Carvajal, G. I., \& Valencia, G. C. (2016). Toma de decisiones en el aula escolar. Plumilla Educativa, 17(1), 69-89. https://revistasum.umanizales.edu.co/ojs/index.php/ plumillaeducativa/article/view/1750

Castro, A., \& Caldeiro, M. C. (2018). Empoderando a la infancia en la investigación educativa: Retos, posibilidades y marcos para la acción. En G. de la Cruz (Coord.), Experiencias educativas en el aula de infantil, primaria y secundaria (pp. 12-21). Adaya Press. https://dialnet.unirioja.es/servlet/articulo?codigo=6893895

Castro-Rubilar, F., Castañeda-Díaz, M. T., Ossa-Cornejo, C., Blanco-Hadi, E., \& CastilloValenzuela, N. (2017). Validación de la escala de autoadscripción inclusiva en docentes secundarios de Chile. Psicología Educativa, 23(2), 105-113. https://journals. copmadrid.org/psed/art/j.pse.2017.05.003

Cervantes, A., \& Salinas, J. (2015). Percepción acerca de la interacción entre maestros y alumnos: su impacto en el bienestar de los estudiantes. Interacçoes. 11(38), 153-174. http://revistas.rcaap.pt/interaccoes/article/download/8496/6070

Chang, S., \& Henríquez, K. (2013). Adultocentrismo y ciudadanía infantil: Dos discursos en conflicto para la convivencia. CLACSO. http://biblioteca.clacso.edu.ar/clacso/ posgrados/20140120034301/ChangSpino.pdf 
Chaparro, A. A., Mora, N., \& Medrano, V. (s/f). Estudio de la implementación del Programa Nacional de Convivencia Escolar (PNCE) en una entidad federativa mexicana. Psicoperspectivas, 18(1), 1-15. https://www.psicoperspectivas.cl/index.php/ psicoperspectivas/article/view/1489

Comisión Nacional de los Derechos Humanos. (2018). Ley General de los Derechos de Niñas, Niños y Adolescentes (4a ed.). CNDH. https://www.cndh.org.mx/sites/default/files/ doc/Programas/Ninez_familia/Material/ley-guarderias-ninos.pdf

Díaz, S. P., \& Sime, L. E. (2004). Convivencia escolar: Una revisión de estudios de la educación básica en Latinoamérica. Revista Virtual Universidad Católica del Norte, 49, 125 145. https://revistavirtual.ucn.edu.co/index.php/RevistaUCN/article/view/801

Fabila, A., Minami, H., \& Izquierdo, J. (2013). La escala de Likert en la evaluación docente: Acercamiento a sus características y principios metodológicos. Perspectivas docentes, 52, 31-40. https://revistas.ujat.mx/index.php/perspectivas/article/view/589

Ferry, G. (1997). Pedagogía de la formación. Novedades Educativas.

Fierro, C., \& Carbajal, P. (2019). Convivencia Escolar: Una revisión del concepto. Psicoperspectivas, 18(1), 9-27. https://www.psicoperspectivas.cl/index.php/ psicoperspectivas/article/view/1486

Fierro, M. C., Tapia, G., Fortoul, B., Martínez-Parente, R., Macouzet, M., \& Muñoz-Ledo, M. J. (2013). Conversando sobre la convivencia en la escuela: Una Guía para el autodiagnóstico de la convivencia escolar desde las perspectivas docentes. Revista Iberoamericana de Evaluación Educativa, 6(2), 103-124. https://revistas.uam.es/riee/ article/view/3407

Fierro, M., Lizardi, A., Tapia, G., \& Juárez, M. (2013). Convivencia Escolar. Un tema emergente de investigación educativa en México. En Violencia en las escuelas. Problemas de Convivencia y Disciplina (pp. 73-131). https://www.researchgate. net/publication/309787486_Convivencia_Escolar_Un_tema_emergente_de_ investigacion_educativa_en_Mexico

Fondo de las Naciones para la Infancia Unidas. (2017). Informe anual: México 2017. UNICEF. https://www.unicef.org.mx/Informe2017/Informe-Anual-2017.pdf

Giménez, C. (2005). Conceptualización y sugerencias para la praxis. Cuadernos Puntos de Vista, (1), 7-32. https://www.conapred.org.mx/documentos_cedoc/CARLOS_ GIMENEZ_convivencia[1][1].pdf

Gómez, C. N. (2016). La lúdica como estrategia pedagógica para mejorar la convivencia escolar en los niños y niñas del grado transición jornada mañana, de la institución 
educativa Santa Rosa. Sede 2 JoséCardona Hoyos (Trabajo de especialidad), Fundación Universitaria Los Fundadores, Santiago de Cali, Colombia. https://repository. libertadores.edu.co/bitstream/handle/11371/541/G\%C3\%B3mezV\%C3\%A1squezC laraNayibe.pdf? sequence $=2 \&$ is Allowed $=y$

Guzmán, E. J., Muñoz, J., Preciado, E. A., \& Menjura, M. I. (2014). La convivencia escolar. Una mirada desde la diversidad cultural. Plumilla Educativa, 13(1), 153-175. https:// revistasum.umanizales.edu.co/ojs/index.php/plumillaeducativa/article/view/404

Hecht, A. C. (2013). Del adultocentrismo a la agencia infantil: Perspectivas sobre la socialización lingüística. Infancias Imágenes, 12(1), 7-17. https://dialnet.unirioja.es/ ejemplar/375912

Hernández, R., Fernández, C., \& Baptista, M. P. (2014). Metodología de la investigación (6a ed.). McGraw-Hill.

Landeros, L., \& Chávez, C. (2015). Convivencia y disciplina en la Escuela: Análisis de Reglamentos Escolares de México. Instituto Nacional para la Evaluación de la Educación. https://www.inee.edu.mx/wp-content/uploads/2019/01/Sesion_5_Concepcion_ Chavez.pdf

Landis, J. R., \& Koch G. G. (1977). The measurement of observer agreement for categorical data. Biometrics, 33, 159-174.

Ley General de Educación (2019). Nueva Ley publicada. Diario Oficial de la Federación, DOF 30-09-2019. http://www.diputados.gob.mx/LeyesBiblio/pdf/LGE_300919.pdf

López, V., \& Valdés, R. V. (2018). Construcción y validación de instrumentos para evaluar prácticas de convivencia escolar en profesionales y padres. Actualidades Investigativas en Educación, 18(3), 1-29. https://revistas.ucr.ac.cr/index.php/aie/ article/view/34328

Manen, M. V. (1998). El tacto en la enseñanza. Paidós Educador.

Muñoz, M. T., Lucero, B. A., Cornejo, C. A., Muñoz, P. A., \& Araya, N. E. (2014). Convivencia y clima escolar en una comunidad educativa inclusiva de la Provincia de Talca, Chile. Revista Electrónica de Investigación Educativa, 16(1), 16-32. http://www.scielo.org. $\mathrm{mx} / \mathrm{pdf} / \mathrm{redie} / \mathrm{v} 16 \mathrm{n} 2 / \mathrm{v} 16 \mathrm{n} 2 \mathrm{a} 2 . \mathrm{pdf}$

Ochoa, A. (2015). Concepciones sobre participación de niñas, niños y adolescentes: Su importancia en la construcción de la convivencia escolar. Revista cultura, educación y sociedad, 6(2), 9-28. http://oce.uaq.mx/index.php/10-investigacion/186concepciones-sobre-participacion-de-ninas-ninos-y-adolescentes-su-importanciaen-la-construccion-de-la-convivencia-escolar 
Ochoa, A., \& Pérez, L. (2019). El aprendizaje servicio, una estrategia para impulsar la participación y mejorar la convivencia escolar. Psicoperspectivas, 18(1), 1-13. https:// www.scielo.cl/pdf/psicop/v18n1/0718-6924-psicop-18-01-00089.pdf

Ochoa, A., \& Salinas, J. J. (2015). Percepción acerca de la interacción entre maestros y alumnos: Su impacto en el bienestar de los estudiantes. Revista Interacçoes, 11(38), 153-174. http://oce.uaq.mx/index.php/10-investigacion/185-percepcion-acercade-la-interaccion-entre-maestros-y-alumnos-su-impacto-en-el-bienestar-de-losestudiantes

Oldak, E. (2017). Guía para el docente. Educación primaria (2a ed.). Secretaría de Educación Pública. http://convivenciaescolar.seph.gob.mx/material_didactico/PRIMARIA/ GUIA_PARA_EL_DOCENTE_2DO_GRADO.pdf

Ospina, B. E., Sandoval, J. de J., Aristizábal, C. A., \& Ramírez, M. C. (2005). La escala de Likert en la valoración de los conocimientos y las actitudes de los profesionales de enfermería en el cuidado de la salud. Antioquia, 2003. Investigación y Educación en Enfermería, 23(1), 14-29. https://www.redalyc.org/articulo.oa?id=105215401002

Serrano-Arenas, D., Ochoa-Cervantes, A., \& Arcos-Miranda, E. (2019). Conceptualizaciones, perspectivas y referentes de la participación en la educación primaria, México. Revista Latinoamericana de Ciencias Sociales, Niñez y Juventud, 17(2), 1-22. https:// doi.org/10.11600/1692715x.17202

Tonucci, F. (2009). Ciudades a escala humana: La ciudad de los niños. Revista de educación, 1, 147-168.

Torres, M. B. (2006). La libertad de expresión en la filosofía de John Stuart Mill. Anuario de filosofía del derecho, (23), 13-36. https://dialnet.unirioja.es/servlet/ articulo?codigo $=2476026$

Trilla, J., \& Novella, A. (2001). Educación y participación social de la infancia. Revista Iberoamericana De Educación, 26, 137-164. https://doi.org/10.35362/rie260982

United Nations Children's Fund \& Save the children (2003). Participar también es cosa de niños. Guía didáctica para el profesorado. Generalitat Valenciana.

Vignolo, C., \& Maturana, H. (2001). Conversando sobre educación. Perspectivas, 4(2), 249266. https://www.researchgate.net/publication/318107503_Conversando_sobre_ educacion 


\section{Capítulo 2}

La relación entre autorregulación de los aprendizajes y reprobación escolar desde la perspectiva del estudiante y de los académicos

Betsy Berenice Arvayo Moncada, Erika Paola Reyes Piñuelas

y Emilia Cristina González Machado

En México, la educación superior cuenta con la proporción más baja de eficiencia terminal (17\%), ubicándose muy por debajo del promedio (37\%), según la Organización para la Cooperación y el Desarrollo Económico (OCDE, 2019); en comparación con la información del Instituto Nacional para la Evaluación de la Educación (INEE, 2017) que indica que, en la educación primaria se presenta un $98.3 \%$, en secundaria $87.7 \%$ y en bachillerato $65 \%$. Con los datos expuestos, es imprescindible abatir el abandono escolar para la mejora de la eficiencia terminal de los programas educativos.

La Universidad Autónoma de Baja California (UABC) no está exenta de estas problemáticas, cuenta con $71 \%$ de eficiencia terminal y un $44 \%$ en reprobación (UABC, 2019); por ello, la necesidad de desarrollar programas institucionales que atiendan el problema de rezago escolar, enfocado en la atención a los estudiantes que cuentan con bajo rendimiento académico, que se encuentran en situación de vulnerabilidad o requieren de atención especial.

En este sentido, Nava et al. (2007) y Rodríguez y Hernández (2008) expresaron que la reprobación es uno de los factores que suele manifestarse como antesala al abandono de los estudios, por lo cual se recomienda su estudio como complemento de la deserción escolar y la eficiencia terminal de las instituciones.

La UABC (2021), en los últimos análisis sobre la reprobación en el periodo 2018-2, reporta un porcentaje de reprobación del 54\% en el campus Mexicali, 51\% en Ensenada y 
49\% en Tijuana, lo cual indica que, en promedio, más de la mitad de los estudiantes ha reprobado al menos una materia durante su trayectoria escolar, lo cual representa un riesgo y puede traer como consecuencia el abandono de estudios por reprobación.

Específicamente el tronco común — conjunto de asignaturas que se cursan en la etapa básica e inicial de los programas educativos - de la Facultad de Ciencias Humanas (FCH) se ubica en la posición 14 de los 15 programas educativos en la categoría de mayor deserción por baja académica — de los 63 programas educativos que oferta la UABC - y presenta un bajo rendimiento académico del 65\% (UABC, 2017). El porcentaje de reprobación académica por programa educativo se refleja en la tabla 1.

\section{Tabla 1}

Porcentaje de reprobación por programa educativo en la Facultad de Ciencias Humanas 2018-2

\begin{tabular}{lcc}
\hline \multicolumn{1}{c}{ Programa educativo } & Pscolarizado* & Semiescolarizado ${ }^{*}$ \\
\hline Tronco común & $43 \%$ & $44 \%$ \\
\hline Ciencias de la Educación & $56 \%$ & $47 \%$ \\
\hline Psicología & $51 \%$ & $38 \%$ \\
\hline Comunicación & $44 \%$ & $51 \%$ \\
\hline Sociología & $56 \%$ & $46 \%$ \\
\hline Historia & $58 \%$ & - \\
\hline
\end{tabular}

Nota. ${ }^{*}$ Estudiante que asiste toda la semana a clases; ${ }^{* *}$ Estudiante que asiste dos veces a la semana a clases. Elaboración propia con base en UABC, 2021.

En suma, la reprobación en la FCH fluctúa entre un $40 \%$ y un $58 \%$, aun con la implementación y establecimiento de políticas y acciones que buscan disminuir los índices de reprobación y deserción des de la tutoría académica, la orientación educativa y la psicopedagógica (UABC, 2019).

En un estudio que involucró a estudiantes de los 77 programas educativos, analizando las variables asociadas al rendimiento académico, personales, contexto de los estudiantes, institucionales y la práctica docente, Murillo (2020) encontró que en rendimiento académico el aspecto que mayormente influye en la reprobación de los alumnos son los valores bajos, que presentaron en autorregulación de los aprendizajes, específicamente 
en las variantes metacognitivas, afectivas y manejo de la ansiedad. Lo cual hace que aumente la probabilidad de que reprueben.

En este sentido, Schober et al. (2015) manifestaron que la autorregulación de los aprendizajes es una estrategia que puede atender directamente la problemática de la reprobación ya que, a través de esta se puede determinar el éxito académico, así como prevenir el fracaso escolar.

Por lo anterior, esta investigación tiene como objetivo conocer la relación entre los procesos autorregulatorios de los estudiantes y la reprobación escolar, desde la perspectiva del estudiante y de académicos.

El interés por este estudio resulta por diversos motivos; por una parte, la reprobación escolar es un tema incipiente de analizar a nivel universitario en México. El desarrollo de estudios en el ámbito nacional e internacional se ha desarrollado desde aproximaciones de tipo cuantitativo y se requiere de trabajos de investigación que consideren aquellos aspectos particulares inmersos en la vida del estudiante y que se dificulta ser explicados de manera cuantitativa (Hernández et al., 2018; Ramírez \& Gallur, 2016). Por otra parte, desde la autorregulación de los aprendizajes, se busca aminorar los problemas de ausencia escolar, incumplimiento de tareas y reprobación de exámenes, los cuales son factores que pueden traer en consecuencia el cambio o, inclusive, el abandono definitivo del programa educativo o institución (Quintana, 2014).

La vinculación de la autorregulación y la reprobación escolar parte de la intención de mejorar el rendimiento académico, ayudando a los alumnos a ser eficaces y proactivos, incitándolos a buscar ayuda y regular su propio esfuerzo para el cumplimiento de metas (Daura, 2015).

La autorregulación de los aprendizajes y su implicación en el rendimiento académico La autorregulación de los aprendizajes es una estrategia de mejora del rendimiento académico para los universitarios, debido a que la falta de estrategias y procesos autorregulatorios son el principal factor de fracaso académico, en consecuencia, formar a los estudiantes en el desarrollo de habilidades autorregulatorias puede traer como beneficio el logro académico (Ramírez-Dueñas \& Ramírez-Dueñas, 2017). Además, con la autorregulación de los aprendizajes se pueden ajustar los pensamientos positivos y negativos, estimular la motivación, suscitar la atención y la conducta en los alumnos, a partir de una autonomía en la cual el estudiante siente la necesidad e interés por tomar decisiones de su proceso de aprendizaje, logrando enfocar su atención en el cumplimiento de sus ta- 
reas, mejorar su aprovechamiento escolar, aminorar errores e incrementar la calidad de los aprendizajes (Alvarado et al., 2014).

En este mismo sentido, según Rosário et al. (2012), utilizar estrategias autorregulatorias en el proceso de aprendizaje aumenta el rendimiento académico; es necesario que los docentes implementen estas estrategias dentro del currículo de sus clases en situaciones determinantes del aprendizaje; además, que estas sean útiles para ser aplicadas en distintos contextos y, de esta manera, tener mayores posibilidades de lograr el éxito escolar. La propuesta de estos autores considera que los estudiantes desarrollen autoeficacia y motivación académica, con la intención de lograr reconocer la utilidad que tiene el aprendizaje para su futuro.

La autorregulación de los aprendizajes se define como el proceso autodirectivo en el cual los estudiantes logran transformar sus habilidades mentales en habilidades académicas, enfocando sus pensamientos, sentimientos y comportamientos en el desarrollo de estrategias de aprendizajes, que los lleven al cumplimiento de metas y objetivos académicos que han sido fijados para sí mismos (Panadero \& Alonso-Tapia, 2014; Schunk, 2012; Zimmerman, 2001, 2002).

En este contexto, sobre la autorregulación de los aprendizajes, Zimmerman (2002) propuso que los alumnos desarrollen el establecimiento de objetivos, gestión del tiempo, estrategias de aprendizaje, autoevaluación, autoatribuciones, y que sean capaces de buscar ayuda o información, tengan automotivación, autoeficacia e interés por sus propias tareas; lo anterior, con la intención de lograr alcanzar el éxito académico.

Teorías explicativas de la autorregulación de los aprendizajes

Las teorías que mayor influencia tienen en la autorregulación de los aprendizajes son las siguientes: (a) operante, (b) fenomenológica, (c) del procesamiento de la información, (d) volitiva y (e) sociocognitiva.

A partir de la teoría operante se contempla la influencia que tiene el contexto social constantemente cambiante, el cual se ve reflejado en el mismo comportamiento de las personas; el comportamiento autocontrolado de los individuos está dirigido por el entorno en el que se encuentran situadas las personas; asimismo, desde la autorregulación de los aprendizajes, los estudiantes pueden emitir un comportamiento autocontrolado como subprocesos de autocontrol, autoinstrucción y autoesfuerzo. Dichos comportamientos surgen a partir del esfuerzo positivo, estímulos y elogios que pueden influir en el buen desempeño futuro de los estudiantes (Mace et al., 1989; Rosenbaum \& Drabman, 1979). 
Entre las limitaciones de esta teoría, se encuentra la imposibilidad de explicar de manera explícita cuáles son aquellos incentivos conductuales, que hacen que incrementen las expectativas de los estudiantes para mejorar su esfuerzo autorregulado (Panadero \& Alonso-Tapia, 2014).

Respecto a la teoría fenomenológica, McCombs (1989) contempló la experiencia de los individuos en cuanto a su autoconcepción, considerando percepciones cognitivas y emocionales, estas se pueden relacionar tanto con el yo real de la persona o con el contexto, los cuales influyen en aquello que la persona procesa, interpreta y actúa. Con la autorregulación de los aprendizajes se pretende que los estudiantes desarrollen autoconceptos positivos, autoestima, competencia, responsabilidad, autodeterminación, autodesarrollo y autorregulación, con el propósito de favorecer sus procesos para la mejora de rendimiento académico y cumplimiento de actividades escolares. Desde este enfoque, los estudiantes son capaces de definir y monitorear sus aprendizajes, objetivos, expectativas, motivación y comportamiento.

Sin embargo, esta teoría se ve influenciada por el éxito o fracaso académico que puede obtener como resultado el alumno e influye directamente en sus emociones, provocando emociones negativas que traen en consecuencia el no sentirse competente, ansiedad y desmotivación (Panadero \& Alonso-Tapia, 2014).

En la teoría del procesamiento de la información, se observa el aprendizaje como una codificación de la información en la memoria a largo plazo, donde el estudiante es capaz de activar y relacionar su memoria con los conocimientos nuevos para que estos sean significativos, debido a que el conocimiento llega a ser más sencillo de integrar y recordar. Asimismo, a partir de la autorregulación se pretende que los estudiantes relacionen sus conocimientos previos en la realización de actividades académicas, a partir de estrategias y cualidades personales, por lo que influyen aspectos metacognitivos y motivacionales (Schunk, 2012).

En efecto, esta teoría pretende que los alumnos elijan, organicen, repasen, relacionen y aumenten la información y sus significados, para lograr crear y mantener ambientes positivos de aprendizaje y, en consecuencia, disminuir la ansiedad a las pruebas, mejorar la autoeficacia, el valor del aprendizaje, las expectativas y las actitudes positivas en sus resultados (Schunk, 2012; Weinstein \& Mayer, 1986).

En el caso de la teoría volitiva, Corno (1989) y Schunk (2012) coincidieron en que la autorregulación de los aprendizajes depende de factores personales, contextuales, de la capacidad cognoscitiva de los individuos y el acondicionamiento ambiental, además, con- 
sideran la inteligencia como un condicionamiento instrumental o motivacional interno. En particular, se aspira a alcanzar una adaptación de estrategias de aprendizaje y realización de tareas académicas, acompañada de la capacidad de los alumnos por trasladarlas y mantenerlas cuando estas sean necesarias, es decir, esta teoría contempla la comprensión de la cognición, de los sentimientos y la motivación.

Según Schunk (2012), la teoría mayormente aplicada en la autorregulación de los aprendizajes es la teoría sociocognitiva; la cual considera los procesos personales del aprendizaje y el efecto que tiene el contexto en este, debido a que los estudiantes solucionan los problemas desde percepciones personales, los cuales se ven efectuados por los estímulos ambientales. Es decir, existe una acción recíproca entre aspectos intrapersonales, conductuales, contextuales, motivacionales y cognitivos (Chaves \& Rodríguez, 2017; Zimmerman, 1989).

Además, la teoría sociocognitiva llega a cambiar la percepción tradicionalista, donde el estudiante es un ser receptivo y pasivo de información, para involucrarse activamente en sus propios objetivos de aprendizaje, logrando ser capaz de controlar y cumplir sus metas académicas a través de la autoeficacia.

Lo anterior con la finalidad de implementar acciones necesarias para la mejora de su propio rendimiento (Schunk, 1989). Asimismo, se enfoca en tres subprocesos: autoobservación, auto-juicio y auto-reacción, con la intención de que los estudiantes sean capaces de reconocer su propio progreso hacia las metas que lo motivan, si es necesario esforzarse más para mejorar el aprendizaje y lograr tener éxito sin importar cuánto se esfuercen (Schunk, 2012).

\section{Factores explicativos de la reprobación académica}

Se entiende como reprobación académica al estado en el cual el estudiante no logra compilar los requisitos mínimos para aprobar un curso de un plan estudios en el cual se encuentra (Hernández et al., 2018).

La reprobación académica se considera un tema incipiente de tratar en el desarrollo de investigación, ya que existe una pobre definición teórica que sustente de manera integral sus causas o motivos, además de existir un predominio de estudios que analizan variables cuantitativas, sin contemplar aspectos cualitativos o mixtos que permitan generar un análisis más completo a partir de conocer el proceso y el porqué de la reprobación (Ramírez \& Gallur, 2017). 
Con el propósito de ubicar elementos que se consideran relacionados con la presencia de reprobación escolar, en la tabla 2, se muestra una síntesis de estudios sobre reprobación académica en educación superior, respecto a las causas, factores o motivos principales. El elemento que más predomina en causas o motivos de reprobación en educación superior es el académico, debido tal vez a la carencia de estrategias de aprendizaje, bajo aprovechamiento escolar, escasez de hábitos de estudio, así como problemas de enseñanza y evaluación.

Tabla 2

Factores más comunes que influyen en la reprobación escolar

\begin{tabular}{|c|c|c|c|c|c|c|c|}
\hline Autor & Personal & Emocional & Familiar & Social & Académico & $\begin{array}{l}\text { Sistema } \\
\text { educativo }\end{array}$ & Económico \\
\hline \multicolumn{8}{|l|}{ Nava et al. (2007) } \\
\hline \multicolumn{8}{|l|}{$\begin{array}{l}\text { Ramírez y Gallur } \\
\text { (2017) }\end{array}$} \\
\hline \multicolumn{8}{|l|}{$\begin{array}{l}\text { Hernández et al. } \\
\text { (2018) }\end{array}$} \\
\hline \multicolumn{8}{|l|}{$\begin{array}{l}\text { Viramontes et al. } \\
\text { (2015) }\end{array}$} \\
\hline Ruíz et al. (2006) & & & & & & & \\
\hline
\end{tabular}

En la revisión de los estudios, señalan además que influyen factores estructurales de sociedad, familia, personal, institucionales, problemas con la obtención de hábitos de estudio, antecedentes escolares, aspectos cognitivos, desinterés por parte del estudiante, falta de orientación vocacional, falta de motivación, bajos conocimientos adquiridos, falta de gusto por aprender, entre otros. Lo anterior demuestra que en los estudios analizados existe un énfasis en reprobación retribuidas a causas personales. Por lo tanto, se recomienda que, desde la autorregulación, los estudiantes logren mejorar en aspectos de organización, logro de objetivos y establecer su actividad académica; desde una postura autónoma y motivada, siendo capaz de transformar su capacidad mental en competencias académicas (Hernández \& Camargo, 2017; Núñez et al., 2006). 


\section{Método}

La presente investigación parte de un diagnóstico cualitativo con la finalidad de entender, describir y explicar los fenómenos sociales desde el análisis de las experiencias, interacciones, comunicaciones y documentos de los participantes (Gibbs, 2014). Por lo que, para fines de estudio se realizó un análisis de experiencias de manera individual a través del conocimiento cotidiano por parte de los participantes, los cuales se describen a profundidad en los siguientes apartados.

\section{Participantes}

La muestra seleccionada fue intencionada debido a la heterogeneidad para elegir el contexto. Para Abero et al. (2015), el número de casos o entrevistas se define durante el proceso de recolección de datos, hasta haber saturado la información necesaria.

Se seleccionó a los participantes clave con base en el caso típico-ideal, con la finalidad de que los sujetos cumplieran con los atributos esenciales para el estudio, por lo que se diseñó un perfil para poder considerar la interrelación que tienen los participantes con un gran número de rasgos o variables (Rodríguez et al., 1996).

En este sentido, los participantes tenían que cumplir con las características de: (1) ser estudiantes universitarios, específicamente de la FCH; (2) que se encontraran en situación de rezago en nivel 2 (dos asignaturas reprobadas) y nivel 3 (tres asignaturas reprobadas o más), según la UABC (2017). Lo anterior, porque son estudiantes que al mantenerse en la situación actual o de no atenderse la problemática se consideran en mayor riesgo de abandono escolar.

El participante estudiante pertenece al género femenino con la edad de 28 años, que se identificó en el nivel de rezago 2, el cual cursa el cuarto semestre de la licenciatura en Psicología en la modalidad semiescolarizada, además de ser madre, por lo que se dedica al hogar y a estudiar de manera simultánea.

Respecto a las características de los académicos tenían que cumplir con las siguientes características: (1) tener más de tres años de experiencia con atención a alumnos; (2) que su atención a estudiantes estuviera mayormente enfocada en alumnos de primeros semestres; y (3) tener trato directo con docentes.

En un segundo momento, se contó con la colaboración de dos trabajadores institucionales de la UABC. La primera entrevista se realizó a una académica con estudios de doctorado en educación y con más de 24 años de experiencia. En la segunda entrevista participó un académico con estudios de maestría en educación y con 12 años de expe- 
riencia. Los dos participantes se encuentran en áreas de cercanía directa a estudiantes y docentes, principalmente en los primeros semestres de la universidad y en atención con alumnos con dificultades escolares.

Para el cumplimiento de los objetivos cualitativos se utilizó la técnica de entrevista a profundidad, que consiste en obtener información sobre determinados problemas, a través del establecimiento de una lista de temas que cubrir, según la problemática y en función de la problemática de interés, dejando abierta la información que va surgiendo durante la entrevista, para tener el conocimiento desde el punto de vista de los participantes (Abero et al., 2015; Rodríguez et al., 1996).

Se realizó una entrevista semiestructurada; según Sandoval (2002), implementar esta técnica ayuda a enriquecer y reorientar la entrevista conforme avanza el proceso de investigación, convirtiéndose en un medio para profundizar en el análisis de los datos.

Para la preparación de la entrevista, como instrumento se elaboró una guía, en la cual se hicieron preguntas abiertas con la finalidad de obtener mayor información por parte de los sujetos. La guía se realizó conforme a la revisión previa de la literatura de las dos categorías principales del trabajo, la autorregulación de los aprendizajes, donde se analizaron las subcategorías estrategias de aprendizaje, motivación, objetivos académicos y metacognición (Flórez, 2000; Fuentes \& Rosário, 2013; Schunk, 2012; Zimmerman, $2001,2002)$ y la reprobación académica, con la finalidad de conocer las causas y factores que lo provocaron (Hernández et al., 2018; Nava et al., 2007).

Una vez diseñada la guía de entrevista, se realizó el consentimiento informado bajo el Informe Belmont (1978), considerando los principios de respeto, beneficencia y justicia, con la finalidad de proporcionar a los participantes la información necesaria sobre su participación en la investigación. En el consentimiento informado, se explicó el objetivo y propósito de la divulgación del estudio, así como los riesgos y beneficios de participar, además de explicar que la participación era voluntaria y con fines académicos, asegurando la confidencialidad de los datos y otorgando el derecho a negarse a participar.

En la fase de desarrollo, se invitó vía correo electrónico a estudiantes que se identificaron en nivel de rezago 2 y 3; a quienes respondieron con interés de participar, se les dio seguimiento de manera directa y personalizada con la intención de acordar día y hora de la entrevista. En un segundo momento, a los académicos se les contactó vía correo electrónico y, una vez aceptada su participación, se acordó día y fecha para la entrevista.

Las tres entrevistas se implementaron desde plataformas digitales como Zoom (estudiante) y vía Google Meet (académicos), según el medio óptimo para los participantes. 
Se llevó a cabo de forma virtual debido a la presencia de la pandemia por Coronavirus (COVID-19) declarada por la Organización Mundial de la Salud (OMS, 2020). Al respecto, Rodera y González (2014) sustentaron que realizar trabajos de campo desde la web, brinda la oportunidad de obtener herramientas que se pueden utilizar cuando no es posible realizarse de manera presencial, además permite grabar directamente desde aplicaciones o distintos medios de grabación de pantalla.

Para el análisis de las entrevistas con estudiantes y académicos se obtuvieron subcategorías y códigos (tabla 3) que se obtuvieron a partir del análisis del marco teórico y de la revisión documental sobre las dos grandes categorías: (1) autorregulación de los aprendizajes y (2) reprobación escolar.

\section{Tabla 3}

Códigos de entrevista

\begin{tabular}{|c|c|c|}
\hline Categoría & Subcategoría & Código \\
\hline \multirow{20}{*}{$\begin{array}{l}\text { Autorregulación } \\
\text { de los aprendizajes }\end{array}$} & \multirow{7}{*}{$\begin{array}{l}\text { Estrategias de } \\
\text { aprendizaje }\end{array}$} & Acompañamiento académico \\
\hline & & Falta de actitudes positivas \\
\hline & & Autoeficacia \\
\hline & & Hábitos de estudio / Técnicas de estudio \\
\hline & & Ansiedad ante exámenes \\
\hline & & Problemas de aprendizaje \\
\hline & & Procesamiento de la información \\
\hline & \multirow{6}{*}{ Motivación } & Búsqueda de ayuda \\
\hline & & Motivación intrínseca \\
\hline & & Falta de motivación \\
\hline & & Expectativas \\
\hline & & Motivación extrínseca \\
\hline & & Cumplimiento de metas \\
\hline & \multirow{3}{*}{$\begin{array}{l}\text { Objetivos } \\
\text { académicos }\end{array}$} & Problemas de transición \\
\hline & & Planteamiento de objetivos \\
\hline & & $\begin{array}{l}\text { Monitoreo y control de cogniciones, motivaciones y } \\
\text { comportamientos }\end{array}$ \\
\hline & \multirow{4}{*}{ Metacognición } & Creencias de control \\
\hline & & Valor de la tarea / aprendizaje / compromiso escola \\
\hline & & Rendimiento académico \\
\hline & & Resolución de problemas \\
\hline
\end{tabular}




\begin{tabular}{lll}
\hline Categoría & \multicolumn{1}{c}{ Subcategoría } & \multicolumn{1}{c}{ Código } \\
\hline \multirow{2}{*}{ Académicos } & Dedicación \\
\cline { 2 - 3 } Reprobación & Personales & Faltas \\
\cline { 2 - 3 } & Institucionales & Palta de interés o compromiso \\
\cline { 2 - 3 } & Droblemas familiares \\
\cline { 2 - 2 } & Docentes/Tutor & Programas \\
\cline { 2 - 2 } & & Práctica docente \\
\hline
\end{tabular}

\section{Resultados y discusión}

Los resultados obtenidos del análisis de las entrevistas muestran cómo se presenta la autorregulación de los aprendizajes y la reprobación académica, así como la relación o influencia que tiene una sobre la otra. A continuación se describen los hallazgos más relevantes.

\section{Autorregulación de los aprendizajes}

Los resultados relacionados a la autorregulación de los aprendizajes se analizaron de acuerdo con cuatro subcategorías: (1) estrategias de aprendizaje, (2) motivación, (3) objetivos académicos y (4) metacognición.

En cuanto a las estrategias de aprendizaje, tanto académicos como la alumna coinciden en las dificultades que presentan los estudiantes en desarrollar y aplicar estrategias que los ayuden a alcanzar el aprendizaje esperado.

La académica 1 comenta lo siguiente respecto a estrategias de aprendizaje:

en cuanto a las estrategias yo lo que veo es que de entrada sobre todo el primer semestre, los alumnos, lo que he observado son más bien estrategias tradicionales, a lo mejor el desarrollo de notas o la memorización, esquemas mapas mentales... creo que las estrategias son las básicas, para aprender o sea desde la escucha, la toma de notas. (Académica 1, comunicación personal)

Lo cual se confirma con lo expresado por la estudiante:

tengo una retención tan mala, tengo pésima retención. Apenas anoche estaba estudiando para mi examen...y me puse a leer porque nos dejaron estudiar 
cinco capítulos para el examen. Entonces he estado leyendo calmado y dije pues leyendo. (Estudiante, comunicación personal)

Lo cual atrae problemas en su capacidad de procesar la información (memoria), el control de la ansiedad, así como en la búsqueda de ayuda tanto con docente como con sus pares. En este sentido, Schunk (2012) y Weinstein y Mayer (1986) coincidieron en que los estudiantes al desarrollar y utilizar las estrategias de aprendizaje como elegir, organizar, repasar y seleccionar información relevante trae resultados positivos en su proceso de aprendizaje, aportando así en el control de la ansiedad ante exámenes, en la mejora del sentido de autoeficacia y valor de la tarea, así como una mejora en las expectativas y actitudes sobre los resultados académicos. Logrado lo anterior, el alumno sentirá necesidad, deseo y tendrá motivos para aprender (García, 2012).

Con relación a la motivación, esta se entiende como la forma en que el estudiante afronta sus actividades educativas de manera intrínseca y extrínseca. Se entiende por motivación intrínseca cuando el estudiante realiza sus actividades por interés, curiosidad, placer y desafío personal, mientras que la motivación extrínseca es cuando realizan las actividades por una recompensa, para evitar un castigo, por presión o por obligación desde una forma externa, por lo que suelen elegir realizar tareas más sencillas que asegure tal remuneración (Bzuneck \& Boruchovitch, 2016; Rianudo et al., 2003).

En este sentido, los académicos expresan que la motivación intrínseca es la que mayor efecto tiene en el aprendizaje de los estudiantes, la cual influye en el interés que tienen por aprender y por quedar en la licenciatura que desean ingresar (esto respecto a los estudiantes de los primeros semestres que, después de segundo semestre, realizan una subasta para seleccionar la carrera de interés). Además, consideran que los estudiantes de primer semestre ingresan con altos porcentajes de motivación, sin embargo, después del primer semestre se empieza a debilitar, por cumplir parcialmente con sus propias expectativas.

Los académicos expresan que los estudiantes "traen una inclinación vocacional, una expectativa vocacional que es estudiar tal carrera y algunos traen en el imaginario un posible campo laboral entonces cuando entran a veces cambian por la naturaleza de nuestros programas" (Académico 1, comunicación personal).

Por lo que no suele haber "una motivación real porque resulta que ellos traen una idea o un plan de un futuro diferente. Entonces es ahí donde nos damos cuenta... porque no tienen ganas, ese también es un factor determinante, las ganas que tengan por aprender" (Académico 2, comunicación personal). 
Es decir, presentan problemas de adaptación por el incumplimiento de sus metas académicas. Por lo que, los académicos declaran la importancia de que el estudiante reconozca por qué y para qué estudia, debido a que un estudiante con falta de motivación intrínseca trae como consecuencias bajas calificaciones, incumplimiento de tareas y faltas.

En este sentido uno de los académicos informó lo siguiente:

Entran bien motivados, pero cuando terminan el primer semestre eso era lo primero que empezaba a decrementar. La motivación se entiende como el inicio del cumplimiento de un proyecto o una meta académica que ellos tienen, pero cuando se enfrentan al nuevo ámbito, nuevos retos, ven nuevas circunstancias que les pueden generar hasta ciertas problemáticas eso se puede ver comprometida... porque empiezan a sentir más presión, sienten que no se adaptan, porque a lo mejor no hay cierta empatía con los compañeros, no hay cierta empatía con los profesores. (Académico 1, comunicación personal)

Los anterior está presente aun con la existencia de programas de apoyo a los estudiantes en su integración a la universidad como, por ejemplo, el curso de inducción, la asignación de un tutor que los acompañe en los dos primeros semestres (tronco común) y la existencia del departamento psicopedagógico; los cuales, entre otros propósitos, buscan a poyar a los alumnos en planear estrategias académicas que les ayuden a realizar y cumplir sus compromisos de aprendizaje, así como brindar orientación educativa y psicológica.

En este sentido, Lamas (2008) expresó que un estudiante, al encontrarse motivado intrínsecamente, logra ser capaz de seleccionar y realizar — por su propio interés, curiosidad y desafío - las actividades académicas, incitándolo a generar un trabajo mental representativo y comprometido a generar pensamientos más abundantes y elaborados al momento de aplicar estrategias de aprendizaje complejas y efectivas.

Respecto a la motivación extrínseca, la estudiante y los académicos lo asocian al apoyo que reciben los alumnos por parte de sus padres o parejas, así como el ejemplo que puedan ser para sus hijos. Sin embargo, también consideran que el escaso apoyo emocional y económico por parte de sus familiares puede provocar una baja motivación. De esta forma, los académicos manifestaron necesario que el alumno reconozca para qué y por qué está estudiando, así como cuáles son sus metas a corto y largo plazo.

Según Lamas (2008), aquellos estudiantes cuya motivación se inclina hacia las metas extrínsecas suelen realizar tareas fáciles para obtener recompensas externas. No obs- 
tante, es importante que los estudiantes establezcan metas y expectativas desde sus propias acciones y autoeficacia para lograr los resultados académicos esperados, ya que se relaciona de manera importante con el uso de estrategias cognitivas y autorreguladoras en el aprendizaje (Pintrich \& García, 1991; Schunk, 2012).

Por otro lado, los objetivos académicos se entienden como el fin al que los alumnos desean llegar en su formación académica, orientando a los estudiantes a monitorear, regular y controlar sus cogniciones, motivaciones y comportamientos ante el aprendizaje (Fuentes \& Rosário, 2013). Respecto a esta subcategoría, los académicos manifestaron que los alumnos, en ocasiones, no son capaces de esclarecer lo que quieren, no tienen definida su orientación vocacional y sus objetivos académicos suelen estar planteados a un nivel intermedio y no logran cumplirlos por falta de monitoreo y control.

Además, los estudiantes de los primeros semestres se enfrentan a una realidad que no cumple con sus expectativas respecto a su orientación vocacional y de lo que esperan encontrar en la universidad, continuando con problemas de adaptación, lo cual se confirma con la información proporcionada por el estudiante, ya que acepta no establecer objetivos a corto o mediano plazo, sino a largo plazo.

primerito, graduarme y como nos han dicho en la universidad uno no se gradúa y da terapia, es graduarme y seguir tomando cursos y seguir aprendiendo, practicando, y en un futuro poder tener un consultorio en casa para ahí aprender. (Estudiante, comunicación personal)

En este sentido, es importante instruir a los estudiantes en el establecimiento de metas a corto, mediano y largo plazo debido a que, como mencionaron Núñez et al. (2006), los estudiantes al establecer objetivos orientados en su aprendizaje logran ser más enfocados en su avance académico, por lo que propende a aprender de forma eficaz.

Respecto a la subcategoría de metacognición, se refiere al conocimiento que tienen los estudiantes sobre su propio proceso de aprendizaje; tanto los académicos como el estudiante entrevistados indicaron la relevancia de que los estudiantes se interesen por su rendimiento académico, que sean comprometidos y responsables sobre su aprendizaje, a través del cumplimiento de tareas, la participación en clases, la organización de sus tiempos de estudio, la asistencia a clases, el aprovechamiento de sus ratos libres para estudiar, el interés por su carrera y por aprender cosas nuevas. 
Por su parte, los académicos expresaron que su rendimiento académico no logra ser el adecuado, porque los estudiantes muestran problemas de adaptación a la universidad y baja motivación, cuentan con escasos hábitos de estudio, tienen una limitada capacidad para resolver problemas y carecen de un compromiso escolar.

Los chamacos que tienen al final un rendimiento con problemáticas que pasó en extra o reprobó pues Ilama la atención porque significa que hay gente no termina de adaptarse o le va mal, o no estudia, o no tiene una estructura de hábitos de estudio o no está motivado, etcétera. (Académica 1, comunicación personal)

Al respecto, se indicó que, en ocasiones, son los alumnos quienes no se acercan a solicitar apoyo por miedo a preguntar o por no saber a quién acudir: "el estudiante lo que tiene que hacer es acercarse a las personas que debería acercarse en los momentos que no logre comprender, entender, aprender el tema que sea, o sea, quitarnos el miedo de preguntar" (Académico 2, comunicación personal).

En contra respuesta con la estudiante que admite que su rendimiento se ve influenciado "por desinterés, si no te genera interés esas clases que dice ay de qué me sirve, pero creo que es eso, que no le ponemos ganas como otras materias y el docente también tiene mucho que ver" (Estudiante, comunicación personal).

Por tanto, existe una discrepancia entre académicos y alumna, en cuanto a la postura sobre qué provoca su rendimiento académico; es decir, los académicos atribuyen la responsabilidad a los estudiantes, mientras que el alumno, además de reconocer cierto desinterés, atribuye la responsabilidad de su rendimiento al docente.

Según Flórez (2000), un estudiante que desarrolla metacognición es capaz de implementar acciones para buscar ayuda con la finalidad de mejorar su rendimiento académico, logrando ser capaz de resolver problemas de mejor manera. Además, aquellos estudiantes con metacognición conocen su potencial y limitaciones cognitivas; conocen los objetivos y características de sus tareas académicas, además, tienen conocimiento sobre la diversidad de estrategias que pueden implementar para realizar de manera efectiva las tareas escolares (Osses \& Jaramillo, 2008).

En suma, los estudiantes, al presentar problemas en autorregulación de los aprendizajes, pueden percibir el aprendizaje como una amenaza, debido a que a partir de este se evalúa su desempeño académico y su capacidad cognitiva; lo que trae, en consecuencia, la negación a oportunidades de aprendizaje y a que se limiten a lo que imparte el docente (Valle et al., 2008). 
Todo lo contrario con lo que sucede con los alumnos que logran ser autorregulados y, por lo tanto, elevan su rendimiento y éxito escolar; lo anterior, a través de la selección pertinente de estrategias de aprendizaje que los ayudan a controlar y regular su cognición, motivación y conducta para el logro de objetivos y metas académicas, siendo capaces de seleccionar y organizar su ambiente de aprendizaje por medio de personas o desde el contexto (Núñez et al., 2006).

\section{Reprobación académica}

A partir de la categoría de reprobación se obtuvieron las siguientes subcategorías: (1) factores académicos, (2) factores personales y (3) problemas institucionales.

La reprobación por factores académicos se enfoca en la complejidad de los contenidos, así como en la relación docente-alumno, por lo que tanto estudiante como académicos coinciden y atribuyen que la reprobación es causada por la falta de sensibilidad docente ante ciertas situaciones, así como la exigencia y autoritarismo, inclusive por una falta de organización y planificación de clases por parte de los docentes; sumado a la dificultad de los contenidos que tienen ciertas materias.

Lo que pasa es que en cuanto entré al semestre, avisé a los que iba faltar esos fines de semana, y todos me dieron oportunidad... Yo también creo que me pude haber aplicado para el ordinario o pudo haber sido que la profe fuera más flexible como los otros profesores y creo que también por el tipo de materia, era neuroanatomía, entonces si estaba muy complicada... una maestra muy desorganizada, no seguía el plan, al final nos quiso reprobar a todo el grupo casi. (Estudiante, comunicación personal)

Lo anterior coincide con Cortés (2017), quien indicó que los factores académicos de reprobación se atribuyen a las dificultades de las pruebas, la relación docente-alumno y las estrategias de enseñanza que estos implementan. Además, como consecuencia la motivación, la ansiedad ante los exámenes y la baja autoestima de los estudiantes, se puede ver influenciada por la actitud docente y la relación que mantienen con los estudiantes.

En cuanto a la categoría reprobación por factores personales, esta se relaciona con aspectos que fueron identificados en los estudiantes de la $\mathrm{FCH}$, tales como escasa dedicación, interés y compromiso ante el estudio, dificultades en adaptación al entorno universitario, baja motivación, insuficiente uso de estrategias de aprendizaje que los ayude 
en su proceso de aprendizaje, inasistencias a clases; en el caso de los académicos, estos consideran que los alumnos presentan dificultades para regular sus emociones ante los problemas familiares; en conjunto, estos aspectos interfieren directamente en su rendimiento académico.

Un alumno que no está motivado o su motivación decrementa, eso se traduce también en que empieza a reprobar, a tener bajas calificaciones, empieza a no hacer tareas, a faltar... como te das cuenta que puede haber un problema de motivación simplemente con la reprobación... Puede ser uno el tema de motivación, el tema de adaptación al entorno escolar y ahí va incluido el tema a lo mejor de los maestros, puede ser algún elemento, otra la dificultad de los contenidos. (Académica 1, comunicación personal)

Empezamos a indagar qué es lo que sucede, es académico, no entiendes la asignatura, no logras acceder al conocimiento con base a qué o qué problemas hay en tu entorno, qué problemas están causando que no logres acceder... Por qué reprueban, desde maestros muy exigentes, los cuales, yo creo que deberían evaluar sus formas y manejos de grupos... si hay alumnos que no les interesa el aprender y les interesa más el divertirnos, el momento de la universidad... tiene que ver por edades, o sea que están joven o no tan joven soy para enfocarme en mi estudio, mi trabajo, mis necesidades o pasármela padre... les cuesta mucho trabajo porque no saben ellos mismos distribuir su tiempo, hacer las preguntas adecuadas y directamente, al alumno le da tanto miedo preguntar al maestro qué prefiere quedarse con la duda. (Académico 2, comunicación personal)

Lo anterior, coincide con Murillo (2020), quien al analizar las variables personales reportó la ausencia de compromiso escolar, dificultades con el control y el manejo del tiempo, pobre monitoreo de estrategias de aprendizaje, problemas de autoestima y un escaso manejo de la ansiedad académica; en conjunto, aumentan el riesgo de reprobación, lo que limita alcanzar el éxito escolar.

De acuerdo con Garbanzo (2007), los determinantes personales de los estudiantes, asociados al rendimiento académico son las competencias cognitivas, la motivación, las condiciones cognitivas, el autoconcepto académico, la autoeficacia percibida, el bienestar psicológico, entre otros. Por su parte, Cortés (2017) indicó que las habilidades persona- 
les que poseen los estudiantes de primer año radican en lo que también los académicos mencionaron en la subcategoría de estrategias de aprendizaje, es decir, que los estudiantes muestran una participación pasiva y de repaso en el aula; además, que la estrategia que con mayor frecuencia emplean es la toma de apuntes y uso de la memoria. Asimismo, según Vera et al. (2012), los estudiantes suelen estudiar para acreditar las materias y no para lograr un aprendizaje.

En la subcategoría de reprobación por factores institucionales se consideran los programas de acompañamiento estudiantil. Los académicos lo asocian con la falta de acercamiento por parte de los estudiantes a los programas de acompañamiento escolar, como es la orientación educativa por parte del departamento psicopedagógico y la tutoría; además, expresan que la universidad ya implementa acciones de apoyo como la creación de materias que ayudan al estudiante a conocerse, identificarse y lograr resolver problemas.

Desde la visión de los académicos, los estudiantes son responsables de la falta de acercamiento y, por lo tanto, el seguimiento por parte del psicopedagógico y la tutoría no se puede llevar a cabo de forma puntual. En este sentido, expresan que los programas de apoyo a los estudiantes "están, pero no las utilizan, entonces todo programa adecuado o institucionalizado dentro de la universidad está para el apoyo, la cosa es de que los alumnos se acerquen a él" (Académico 2, comunicación personal).

Además, consideran que a nivel institucional no se ha encontrado la forma efectiva de dar seguimiento a los estudiantes desde la tutoría, esto en función de detectar las deficiencias académicas de los estudiantes y, de esta forma, evitar que se retrasen, reprueben e inclusive deserten.

De acuerdo con García (2013), los factores institucionales en la reprobación son aquellos que tienen que ver con"la elección de los estudios según interés del estudiante, complejidad en los estudios, condiciones institucionales, servicios institucionales de apoyo, ambiente estudiantil" (p. 48), entre otros.

En este sentido, Vera et al. (2012) señalaron que los factores institucionales que interfieren en el rezago educativo son el currículo, el comportamiento que tienen los estudiantes para seleccionar materias, la orientación que reciben los alumnos y la captación de apoyo que reciben por parte de la universidad.

\section{Conclusiones}

Respecto a los resultados obtenidos, se concluye que los estudiantes presentan mayores problemas en el desarrollo y aplicación de estrategias de estudio adecuadas para lograr 
un buen rendimiento académico y éxito escolar. Influyendo en los aspectos motivacionales mayormente intrínsecos, ya que existe una falta de definición clara de objetivos y metas escolares que los impulsen a lograr el aprendizaje esperado.

Lo anterior se relaciona con la reprobación académica, pues el estudiante al no contar con las estrategias de aprendizaje, hábitos de estudio, motivación y esclarecimiento de objetivos, obtiene un bajo aprovechamiento escolar, el cual se ve reflejado en su reprobación. Si bien, tanto para los académicos como el estudiante, el docente influye en gran medida en la reprobación, los factores personales o académicos son los que resaltan más -el bajo compromiso del estudiante ante el estudio, el escaso uso de técnicas de estudio y la pobre preocupación por aprender-.

En el análisis de las dos categorías (autorregulación y reprobación escolar), ambas coinciden en que los estudiantes presentan dificultades de adaptación en la transición de bachillerato a universidad. Por ello, es importante que futuros estudios aborden el proceso de adaptación de los alumnos a través de distintos programas que existen en las instituciones de educación superior como, por ejemplo, los cursos de inducción y las tutorías. Una de las limitantes presentadas en la investigación fue la presencia de la pandemia por COVID-19 y, en consecuencia, poco interés y participación por parte de los estudiantes en situación de rezago (reprobación), aún con la ayuda de autoridades directivas de la FCH. En este sentido, se recomienda para estudios futuros la implementación de técnicas que ayuden a captar mayor número de participación y, con ello, una recopilación de información más enriquecedora. La cual puede ser a través de la técnica de grupo focal, con la intención de promover una discusión activa que ayude a conocer los motivos y causas de reprobación en los estudiantes de la FCH, así como explicar la influencia que tiene la autorregulación de los aprendizajes en los estudiantes.

A partir de los resultados obtenidos, se propone que, desde la autorregulación de los aprendizajes, los alumnos logren adoptar estrategias de aprendizajes óptimas para su rendimiento académico, motivación, metacognición, establecimiento de objetivos y metas académicas; de esta manera, evitar sentimientos negativos como ansiedad, desinterés o desmotivación, que puedan provocar un bajo rendimiento académico y, posteriormente, la reprobación escolar. 


\section{Referencias}

Abero, L., Berari, L., Capocasale, A., García, S., \& Rojas, R. (2015). Investigación educativa. Abirnedo puertas al conocimiento. CLACSO.

Alvarado, Z., Cepeda, M., \& Del Bosque, A. (2014). Comparación de estrategias de estudio y autorregulación en universitarios. Revista electrónica de investigación educativa, 16(1). https://redie.uabc.mx/redie/article/view/730/897

Bzuneck, J., \& Boruchovitch, E. (2016). Motivation and Self-regulation of Motivation in the Educational Context. Psicologia Ensino \& Formação, 7(2), 73-84. https://doi. org/10.21826/2179-58002016727584

Chaves, E., \& Rodríguez, L. (2017). Aprendizaje autorregulado en la teoría sociocognitiva: Marco conceptual y posibles líneas de investigación. Revista Ensayos Pedagógicos, 12(2), 47-71. https://doi.org/10.15359/rep.12-2.3

Corno, L. (1989). Self-regulated lerning: A volitional analysis. En B. Zimmerman, \& D. Schunk (Eds.), Self-regulated learning and academic achievement theory, research, and practice (pp. 111-141). Springer-Verlag.

Cortés, G. (2017). Factores que intervienen en la reprobación de asignaturas de los estudiantes de primer año de la Facultad de Ingeniería y Arquitectura de la Universidad Centroamericana José Simeón Cañas (Tesis de maestría). Universidad Rafael Landívar, Guatemala. http://recursosbiblio.url.edu.gt/tesiseortiz/2017/05/83/Cortes-Guillermo.pdf

Daura, F. (2015). Aprendizaje autorregulado y rendimiento académico en estudiantes del ciclo clínico de la carrera de Medicina. Revista electrónica de investigación educativa, 17(3), 28-45. http://www.scielo.org.mx/scielo.php?script=sci_arttext\&pid=S160740412015000300003\&lng=es\&tlng=es

Flórez, R. (2000). Autorregulación, metacognición y evaluación. Acción pedagógica, 9(1), 4-11. http://bibliotecadigital.udea.edu.co/bitstream/10495/6913/1/ OchoaRafael_2000_atorregulacionmetacognicionevaluacion.pdf

Fuentes, S., \& Rosário, P. (2013). Mediar para la autorregulación del aprendizaje: Un desafío educativo para el siglo XXI. Instituto Internacional para el Desarrollo Cognitivo, INDESCO.

Garbanzo, G. M. (2007). Factores asociados al rendimiento académico en estudiantes universitarios, una reflexión desde la calidad de la educación superior pública. Educación, 31(1), 2007, 43-63. https://www.redalyc.org/pdf/440/44031103.pdf

García, D. (2013). Estrategia didáctica para mejorar el rendimiento académico de los estudiantes en la asignatura Cálculo I de la Facultad Experimental de Ciencias y 
Tecnología de la Universidad de Carabobo (Tesis de maestría). Universidad de Carabobo, Venezuela. http://mriuc.bc.uc.edu.ve/bitstream/handle/123456789/852/ dgarcia.pdf?sequence $=1$

García, M. (2012). La autorregulación académica como variable explicativa de los procesos de aprendizaje universitario. Profesorado: Revista de currículum y formación del profesorado, 16(1), 19. http://www.ugr.es/ recfpro/rev161ART12.pdf

Gibbs, G. (2014). El análisis de datos cualitativos en investigación cualitativa. Morata.

Hernández, A., \& Camargo A. (2017). Autorregulación del aprendizaje en la educación superior en Iberoamérica: una revisión sistemática. Revista Latinoamericana de Psicología, 49(2), 146-160.

Hernández, E., Hernández, G., \& Flores, A. (2018). La reprobación en una universidad del sureste de México: El caso de la Licenciatura en Humanidades. Revista electrónica de investigación de la Universidad de Xalapa, 6(18), 15. https://ux.edu.mx/wp-content/ uploads/Art.-5.pdf

Instituto Nacional para la Evaluación de la Educación. (2017). Tasa de eficiencia terminal. https://historico.mejoredu.gob.mx/evaluaciones/panorama-educativo-de-mexicoisen/at02e-eficiencia-terminal/

Informe Belmont. (1978). Principios éticos y directrices para la protección de sujetos humanos de investigación. Comisión Nacional para la Protección de Sujetos Humanos de Investigación Biomédica y de Comportamiento.

Lamas, H. (2008). Aprendizaje autorregulado, motivación y rendimiento académico. Liberabit. Revista de Psicología, 18, 15-20. http://www.scielo.org.pe/pdf/liber/ v14n14/a03v14n14.pdf

Mace, F., Belfiore, P., \& Shea, M. (1989). Operant theory and research on self-regulation. En B. Zimmerman, \& D. Schunk (Eds.), Self-regulated learning and academic achievement theory, research, and practice (pp. 27-50). Springer-Verlag.

McCombs, B. (1989). Self-regulated learning and academic achievement: A phenomenological view. En B. Zimmerman \& D. Schunk (Eds.), Self-regulated learning and academic achievement theory, research, and practice (pp. 51-82). Springer-Verlag.

Murillo, O. (2020). Factores asociados al rezago por reprobación en estudiantes universitarios (Tesis doctoral). Instituto de investigación y desarrollo educativo, Universidad Autónoma de Baja California, México.

Nava, G., Rodríguez, P., \& Zamorano, R. (2007). Factores de reprobación en los alumnos del Centro Universitario de Ciencias de la Salud de la Universidad de Guadalajara. 
Revista de educación y desarrollo, 7(9), 17-26. https://www.cucs.udg.mx/revistas/ edu_desarrollo/anteriores/7/007_Nava.pdf

Núñez, J., Solano, P., González-Pienda, J., \& Rosário, P. (2006). El aprendizaje autorregulado como medio y meta de la educación. Papeles del Psicólogo, 27(3), 139-146. https:// www.redalyc.org/articulo.oa?id=77827303

Organización para la Cooperación y el Desarrollo Económico. (2019). Higher education in Mexico: Labour market relevance and outcomes. OECD.

Organización Mundial de la Salud. (2020). Brote de enfermedad por coronavirus (Covid-19). https://www.who.int/es/emergencies/diseases/novel-coronavirus-2019?gclid=EAl alQobChMlt8fmoZCD6gIVicDACh1ahwHzEAAYASAAEgLkNPD_BwE

Osses, S., \& Jaramillo, S. (2008). Metacognición: Un camino para aprender a aprender. Estudios pedagógicos (Valdivia), 34(1), 187-197. https://doi.org/10.4067/S071807052008000100011

Panadero, E., \& Alonso-Tapia, J. (2014). Teorías de autorregulación educativa: Una comparación y reflexión teórica. Psicología Educativa, 20(1), 11-22. https://doi. org/10.1016/j.pse.2014.05.002

Pintrich, P., \& García, T. (1991). Student goal orientation and self-regulation in the collage classroom. En M. Maehr, \& P. Pintrich (Eds.), Advances in motivation and achievement: Goals and self-regulation processes (pp. 371-402). JAI Press.

Quintana, M. (2014). El aprendizaje autorregulado en estudiantes de educación superior. (Tesis doctoral). Universidad Iberoamericana, Puebla, México. https://rei.iteso.mx/ bitstream/handle/11117/1488/UIAP_Celia_Quintana.pdf?sequence=2

Ramírez, L., \& Gallur, S. (2016). La reprobación académica en educación superior: ¿inclusión o calidad? Análisis desde la perspectiva socio-cultural. Primer congreso ONLINE sobre desigualdad social y educativa en el siglo XXI. https://www.eumed.net/libros-gratis/ actas/2016/desigualdad/41.pdf

Ramírez, L., \& Gallur, S. (2017). La perspectiva socio-cultural como modelo teórico de análisis de la reprobación académica en Educación Superior. Atenas, 2(38), 1-17. https://www.redalyc.org/articulo.oa?id=478055148001

Ramírez-Dueñas, L., \& Ramírez-Dueñas, M. (2017). Estrategia educativa para la autorregulación y el aprendizaje profundo en médicos residentes. Revista de educación y desarrollo., 44, 39-48. https://www.cucs.udg.mx/revistas/edu_ desarrollo/anteriores/44/44_Ramirez.pdf

Rianudo, M., Chiecher, A., \& Donolo, D. (2003). Motivación y estrategias en estudiantes universitarios. Su evaluación a partir del Motivated Strategies Learning Questionnaire. 
Anales de Psicología, 19, 107-119. https://www.um.es/analesps/v19/v19_1/11-19_1. pdf

Rodera, A., \& González, A. (2014). Tesis 2.0: Herramientas para su diseño, desarrollo, lectura y difusión. En E. Romero \& M. Sánchez (Eds.), Ciencias sociales y humanidades digitales. Técnicas, herramientas y experiencias de e-Research e investigación en colaboración. CAC, Cuadernos Artesanos de Comunicación.

Rodríguez, G., Gil, J., \& García, E. (1996). Metodología de la investigación cualitativa. Ediciones Aljibe.

Rodríguez, J., \& Hernández, J. (2008). La deserción escolar universitaria en México. La experiencia de la Universidad Autónoma Metropolitana Campus Iztapalapa. Actualidades investigativas en educación, 8(1), 1-30. https://revistas.ucr.ac.cr/index. php/aie/article/view/9308

Rosário, P., Lourenço, A., Paiva, M. O., Núñez, J. C., \& González-Pienda, J. A. (2012). Autoeficacia y utilidad percibida como condiciones necesarias para un aprendizaje académico autorregulado. Anales de Psicología, 28, 37-44. https://www.redalyc.org/ articulo.oa?id=16723161005

Rosenbaum, M., \& Drabman, R. (1979). Self-control training in the classroom: A review and critique. Journal of applied behavior analysis, 12(3), 467-485. https://www.ncbi.nlm. nih.gov/pmc/articles/PMC1311431/pdf/jaba00106-0155.pdf

Ruíz, N., Romano, C., \& Valenzuela, G. (2006). Causas de reprobación vinculadas a las características de los estudiantes de la Licenciatura de Filosofía de la BUAP. Revista de la Facultad de Filosofía y Letras, 6, 150-155.

Sandoval, C. (2002). Investigación cualitativa. Instituto Colombiano para el Fomento de la Educación Superior.

Schober, B., Klug, J., Jöstl, G., Spiel, C., Dresel, M., Steuer, G., Schmitz, B., \& Ziegler, A. (2015). Gaining substantial new insights into university students' self-regulated learning competencies: How can we succeed? Zeitschrift für Psychologie, 223, 64-65. https:// doi.org/10.1027/2151-2604/a000201

Schunk, D. (1989). Social cognitive theory and self-regulated learning. En B. Zimmerman, \& D. Schunk (Eds.), Self-regulated learning and academic achievement theory, research, and practice (pp. 83-111). Springer-Verlag.

Schunk, D. (2012). Teorías del aprendizaje: Una perspectiva educativa (6a ed.). Pearson Educación. 
Universidad Autónoma de Baja California. (2017). Factores asociados al rezago por reprobación y deserción de estudiantes de licenciatura de la UABC. UABC.

Universidad Autónoma de Baja California. (2019). Plan de Desarrollo Institucional (PDI) 20192023. UABC. http://pedagogia.mxl.uabc.mx/transparencia/PDI/PDI_UABC_20192023.pdf

Universidad Autónoma de Baja California. (2021). Sistema Institucional de Indicadores. UABC.

Valle, A., Núñez, J., Cabanach, R., González-Pienda, J., Rodríguez, S., Rosário, P., Cerezo, R., \& Muñoz-Cadavid, M. A. (2008). Self-regulated profiles and academic achievement. Psicothema, 20(4), 724-731. http://www.psicothema.com/pdf/3547.pdf

Vera, J., Ramos, D., Sotelo, M., Echeverría, S., Serrano, D., \& Vales, J. (2012). Factores asociados al rezago en estudiantes de una institución de educación superior en México. Revista iberoamericana de educación superior, 3(7), 41-56. https://www. redalyc.org/pdf/2991/299129031003.pdf

Viramontes-Olivas, O., Martínez-Murillo, E., \& Ordoñez, A. (2015). Análisis de factores de reprobación en alumnos de la carrera de contador público en la FCA-UACH. Ponencia. XVII Congreso Internacional sobre Innovaciones en Docencia e Investigación en Ciencias Económico Administrativas, APCAM. http://www.fca.uach.mx/apcam/xvi_ congreso/2015/02/24/P113_UACH.pdf

Weinstein, C., \& Mayer, R. (1986). The teaching of learning strategies. En Handbook of research on teaching (pp. 315-327). Macmillan.

Zimmerman, B. (1989). A social cognitive view of self-regulated academic learning. Journal of Educational Psychology, 81(3), 329-339. https://doi.org/10.1037/00220663.81.3.329

Zimmerman, B. (2001). Theories of self-regulated learning and academic achievement: An overview and analysis. En B. Zimmerman, \& D. Schunk (Eds.), Self-regulated learning and academic achievement: Theoretical perspectives. Lawrece Erlbaum.

Zimmerman, B. (2002). Becoming a self-regulated learner: An overview. Theory Into Practice, 41(2), 64-70. https://doi.org/10.1207/s15430421tip4102_2 


\title{
Capítulo 3
}

\author{
Propuesta de mediación didáctica para operar la Licenciatura \\ en Ciencias de la Educación en modalidad semipresencial
}

Brenda lliana Núñez Pérez, Karla Lariza Parra Encinas

y Shamaly Alhelí Niño Carrasco

Con la incorporación de las tecnologías de la información y la comunicación (TIC) en la educación, se han transformado los espacios tradicionales educativos, diversificándolos hacia nuevas modalidades educativas mediadas por la tecnología, las cuales han generado un impacto en el proceso de enseñanza y aprendizaje (PEA) de las instituciones de educación superior (IES).

El ritmo acelerado con el que las TIC han incursionado en la vida de las personas ha transformado la manera en que estas se desempeñan e interactúan en todos los contextos, desde lo cotidiano hasta lo profesional. En efecto, el uso de recursos tecnológicos como las computadoras, el internet y los dispositivos móviles, no solo posibilita el acceso a la información, sino que además facilita que las personas se comuniquen con otras a través de distintos medios y de formas distintas, por lo que, incluso, han desaparecido las barreras geográficas (Fandiño, 2011).

Ante este panorama, en las últimas décadas se ha discutido sobre el impacto, posibilidades, limitaciones y retos que ha traído consigo la incursión de las TIC en los contextos sociales y educativos, y sobre el papel que desempeña la escuela en la actualidad y su necesidad de renovarse para atender a las demandas de las generaciones actuales (Hernández, 2017).

Lo anterior plantea importantes retos para la enseñanza de la educación superior, puesto que la formación del individuo debe asegurar su integración efectiva en la socie- 
dad actual, así como su actuar competente en un campo laboral cada vez más globalizado y competitivo supone inevitablemente la actualización de las IES en todas sus funciones y dimensiones, incluyendo la curricular y la docente (Portilla, 2002).

Ante la creciente demanda de la educación y el uso de las TIC en los ambientes universitarios, se han propiciado nuevas metodologías que implican que el alumno realice sus estudios en diferentes modalidades, surgiendo diversas ofertas educativas, basadas en modelos distintos al tradicional sistema presencial, que buscan atender las necesidades educativas de la sociedad moderna, por lo que se presentan diversas opciones educativas no convencionales como son: abierta, no escolarizada, no presencial, a distancia, en línea o virtual; "los modelos híbridos como 'semiescolarizada', 'semipresencial' y 'multimodal', además del uso de anglicismos como online, e-learning, b-learning y m-learning" (Zubieta \& Rama, 2015, p.17). Por lo que se insiste en la necesidad de adaptar el currículum universitario a esta nueva sociedad del conocimiento, como una apuesta al futuro en la educación superior. Lo que implica reflexionar sobre la pertinencia de los modelos de enseñanza-aprendizaje semipresenciales.

En este apartado se retoman los conceptos y teorías de las categorías que sustentan el presente proyecto, siendo estas la modalidad semipresencial, la mediación didáctica y el diseño instruccional (DI).

De acuerdo con Torres y López (2015), la modalidad semipresencial se caracteriza por ser un modelo flexible que combina las características de la educación presencial con la educación a distancia. En lo presencial, se solicita que el alumno trabaje bajo un tiempo y lugar determinado, mientras que en la educación a distancia se requiere del uso de recursos apoyados por tecnología, de manera que ambas modalidades generen una experiencia de aprendizaje mixto.

La educación semipresencial enmarca dentro de la educación a distancia, se desarrolla como una propuesta innovadora que busca combinar las características de la educación presencial con la educación a distancia, enriqueciéndose una de la otra. Asimismo, según Domínguez et al. (2008), la semipresencialidad surge a partir de la asociación de ambos tipos de educación, mezclando encuentros presenciales con aquellos que se llevan a cabo mediante medios tecnológicos, en donde la autonomía y la independencia académica cobran un alto nivel de relevancia.

De acuerdo con Bartolomé (2004), el término de educación semipresencial no es considerado nuevo, sino que ha recibido varias denominaciones, destacando conceptos como el "aprendizaje mixto o híbrido", "formación mixta" utilizado por Pascual (2003), en 
inglés el término "Blended Learning/B-learning" que se traduce como"formación combinada" o "aprendizaje mixto" (Parra, 2008), para referirse a un modelo que combina técnicas de aprendizaje, bajo la metodología presencial con técnicas llevadas a cabo por medios tecnológicos.

Según Morán (2018), la innovación en la modalidad se encuentra en el reconocimiento del potencial con el que cuenta, ya que ofrece rediseñar la experiencia de aprendizaje y surge para solucionar los problemas de la enseñanza tradicional en cuanto a problemas de costos, además de ofrecer flexibilidad en el proceso y nuevos modos de interacción entre los actores involucrados, así como propiciar la autonomía y la responsabilidad, de manera que el alumno se involucre más en su propio proceso y así garantizar mejores resultados.

Para la implementación de esta modalidad, de acuerdo con Yong et al. (2017), es necesario contar con un lugar físico, un acompañamiento de tutorías, aprendizaje colaborativo, contenidos en línea, trabajos y retroalimentación en clase, medios impresos y electrónicos e internet; siendo estos elementos los que establecen el tiempo dedicado a la acción presencial y en línea que se necesita, para seleccionar el modelo semipresencial adecuado. Otro aspecto importante es el grado de competencias digitales con las que se cuenta y el lugar geográfico donde el estudiante toma el curso.

Tucker (2012) indicó que esta modalidad presenta como uno de sus principales beneficios la flexibilidad entre los participantes, logrando una mayor receptividad por parte de los estudiantes, esto se debe a que posee la ventaja de que las clases se pueden llevar a cabo en espacios comunes y de interés para los estudiantes y, a su vez, controlado para su evaluación. De esta manera, los docentes pueden diseñar lecciones uniendo lo mejor de ambas modalidades para lograr un mejor aprendizaje en sus alumnos. Por lo anterior, según Parra (2008), hacer uso de esta modalidad propicia la mejora en la calidad de la educación, ya que proporciona una nueva forma de aprendizaje para los estudiantes y una nueva estrategia de enseñanza para los docentes, logrando potenciar sus habilidades.

Para fines de este proyecto, se define que la modalidad semipresencial es la mezcla de educación presencial con educación a distancia, siendo dependiente una de la otra para el logro de los objetivos de aprendizaje, ya que ambas deben ofrecer lo mejor de sí. Considerando que el tiempo dedicado a la educación a distancia se centra en proporcionar contenidos, desarrollar actividades en equipo, generar el proceso de retroalimentación de estas y trabajar la interacción docente-alumno, alumno-alumno, mientras que el tiempo dedicado a lo presencial será de utilidad para la discusión de lo anteriormente mencionado. 


\section{Evaluación y retroalimentación en la educación semipresencial}

En la actualidad, la evaluación se define como un proceso continuo y constante que mejora el proceso de enseñanza y aprendizaje en los espacios educativos; tiene el objetivo de evaluar la pertinencia y calidad con la que los estudiantes reciben y retienen las enseñanzas, se pretende emitir un juicio de valor y ofrecer alternativas para mejorar la trayectoria escolar del alumno.

Dicho proceso, tradicionalmente se encontraba dirigido a la aplicación en estudiantes, con base en la recopilación de datos sobre el rendimiento de los conocimientos que obtuvo durante el desarrollo de una clase, inclinado más hacia una evaluación que emitía un juicio de valor numérico, el cual define el avance del estudiante. Este tipo de evaluación ha evolucionado; ahora, la forma de obtener mejores resultados en el proceso de enseñanza y aprendizaje es evaluando — además de los conocimientos - la calidad de los contenidos, el plan de estudios e incluso los espacios donde se llevan a cabo las clases (Ponce, 2016).

Castillo y Cabrerizo (2009) afirmaron que evaluar todo el proceso educativo conlleva identificar acciones en clase, actitud, trabajo realizado en el día a día, actividades dirigidas para realizar en casa, entre otras; a diferencia de la forma tradicional de evaluar mediante el examen, como instrumento definitivo para emitir una calificación final, por lo tanto, contempla los procesos de enseñanza y aprendizaje, la práctica docente, aspectos curriculares y demás elementos del sistema educativo. Por lo tanto, la evaluación ayudará a comprobar si han sido logrados los objetivos académicos planteados, teniendo en cuenta que no solo los aprendizajes pueden ser evaluados, sino también la participación del alumno, el currículum, el material didáctico y digital, la comunicación y la misma institución (García, 2015).

La evaluación es un proceso comunicativo y analítico sobre los resultados de los aprendizajes de los estudiantes, tiene el objetivo de recoger y analizar la información necesaria de forma sistemática, continua y planificada, tomando en cuenta los diversos factores que influyen en el estudiante que se encuentra bajo un proceso formativo, con el fin de identificar el avance, las problemáticas y los logros de los alumnos y así brindar el apoyo necesario.

La evaluación formativa se centra en el alumno; el docente realiza un seguimiento de su progreso y brinda información sobre las dificultades que presenta, esto con el objetivo de favorecer su aprendizaje durante su trayecto escolar (Orozco, 2006). Lo anterior se lleva a cabo a través de una efectiva retroalimentación basada en la detección oportuna 
de errores y aciertos de los estudiantes (Alvarado, 2014). De acuerdo con Luna y Reyes (2015), el principal objetivo de este tipo de evaluación es hacer que el docente dé prioridad al desarrollo personal del estudiante, logrando que exista más allá de los aspectos académicos una superación personal, emocional y personal del estudiante; en este sentido, a diferencia de la evaluación sumativa, este tipo de evaluación es de carácter holístico y no inmediato. La retroalimentación se convierte, entonces, en un elemento fundamental de la evaluación formativa, por lo que debe ser constante, clara, oportuna, suficiente y pertinente (Quesada, 2006). Consiste en el medio a través del cual el estudiante podrá identificar sus carencias, trabajar en ellas y lograr el éxito.

Como lo afirma Sánchez (2015), “La evaluación formativa cumple su propósito siempre y cuando esté acompañada de un proceso de retroalimentación efectivo" (p.12), lo cual implica desarrollar cuatro categorías:

el tiempo, el método, los elementos y el formato (Brookhart, 2008). El tiempo en el que se recibe la retroalimentación es crucial para el proceso de enseñanza aprendizaje, como lo afirma Gibbs y Simpson (2004), si la retroalimentación no se da suficientemente rápido, los estudiantes ya han pasado a otros contenidos y por tanto la información es irrelevante y es poco probable que se produzcan apropiados aprendizajes de la actividad. (Sánchez, 2015, p.12)

Por lo tanto, se deberá entregar al estudiante un conjunto de comentarios y criterios a corregir, acompañada de su trabajo original o, en su caso, hacer notar al estudiante el alcance de realizar esta actividad, alentar sus logros y motivarlo para mantenerse.

La retroalimentación consistirá en regresar al alumno la información que describa sus logros y avances, tomando en cuenta los criterios de evaluación establecidos; lo anterior tiene como objeto ayudar al alumno a comprender las maneras en que aprende, a valorar y adueñarse de su propio proceso, permitiendo la autorregulación de los aprendizajes. La retroalimentación propicia la construcción de la autonomía mediante procesos de reflexión que motiven en el estudiante resolver sus problemas, identificar sus estrategias de aprendizaje, sus aciertos y necesidades.

Para definir el concepto de retroalimentación y la importancia de su implementación en la educación en línea, se deben mencionar cuáles serán los pasos para obtener resultados satisfactorios de retroalimentación, por lo que es necesario que el docente cuen- 
te con habilidades pedagógicas, que los alumnos mantengan un alto nivel de actividad y que exista disposición de ambas partes para lograrlo (Jackson \& Graesser, 2006).

El papel del docente implica compromiso y disciplina, ya que deberá ser constante en su actuar, entregando a los estudiantes retroalimentaciones diarias de acuerdo con las políticas de tiempo expuestas por la institución (Alvarado, 2014). En este sentido, el profesor (tutor) deberá poseer habilidades de comunicación, dominar el contenido de temas a tratar, informar al estudiante de los lineamientos del curso, asegurar la claridad en las actividades y temas, poseer conocimientos básicos referentes a las tecnologías y el uso de la plataforma institucional, generar el pensamiento crítico y motivar al estudiante a desarrollar su autonomía. Por lo anterior, según Jackson y Graesser (2006), la retroalimentación se considera una especie de andamiaje, por lo que es un proceso que se da desde el inicio.

Considerar estas habilidades permitirá al profesor un correcto seguimiento durante el proceso de enseñanza y aprendizaje, es por ello que, el docente que trabaja bajo esta modalidad juega un papel de guía para los estudiantes — que varía según el tiempo del proceso educativo-, se convierte en un mediador entre los saberes, planea actividades cooperativas entre los estudiantes, conoce los aspectos cognoscitivos de sus alumnos y se le considera un experto en la materia que imparte (Hernández, 2007).

Uno de los objetivos principales de la educación a distancia es lograr que el estudiante adquiera la capacidad de autorregular su aprendizaje, se mantenga motivado y tenga gusto por el estudio; por lo tanto, se vuelve importante evaluar y retroalimentar el desempeño del estudiante en cada actividad o tarea realizada, entendiendo que la retroalimentación es un elemento que coadyuva para el logro de los objetivos del proceso de enseñanza y aprendizaje (Lozano \& Tamez, 2014). De acuerdo con Lima (2017), para lograr una amplia adquisición de los conocimientos es necesario que el docente desarrolle una retroalimentación completa hacia el estudiante, lo cual consiste en implementar tres pasos: (1) feed back, que permite al estudiante identificar cómo ha sido su desempeño en relación con el objetivo principal de una actividad; (2) feed up, que consiste en lograr que el estudiante asocie los conocimientos previos con la actividad actual; y (3) feed forward, que consiste en realizar una reflexión o comentario que le permite al alumno conocer de qué manera puede mejorar en próximas actividades.

En este sentido, se plantea el Modelo de Hattie y Timperley (2007), el cual tiene el objetivo de reducir las discrepancias entre lo que se ha entendido y cómo se ha desempeñado el estudiante con respecto al objetivo deseado (figura 1). 
Figura 1

Modelo de retroalimentación de Hattie y Timperley

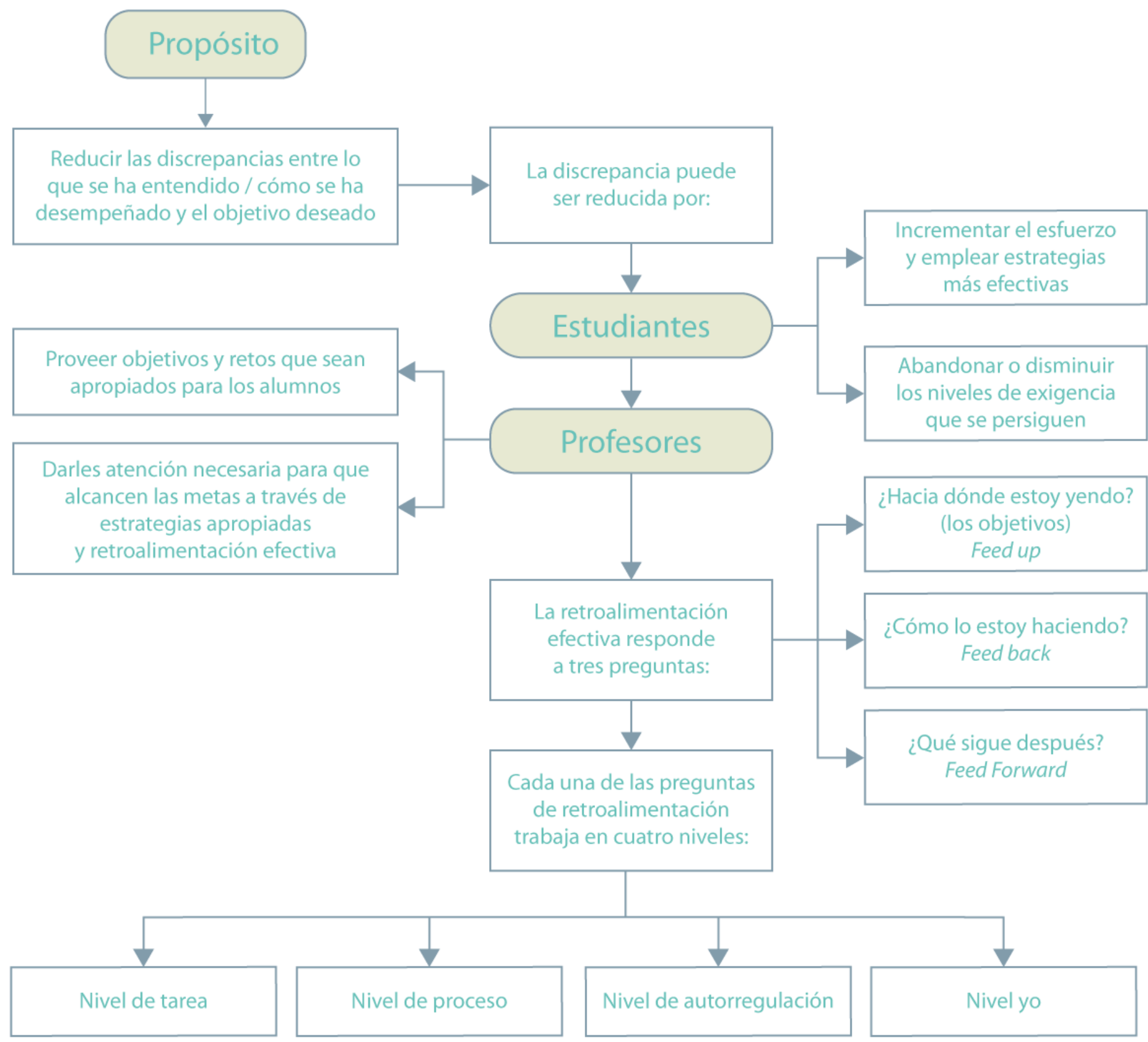

Nota. Tomado de Hattie y Timperley, 2007.

De acuerdo con este modelo, el feed up hace referencia a la pregunta ¿hacia dónde voy?, la cual consiste en dar a conocer al estudiante si ha cumplido con los objetivos del curso y de la actividad en específico que se esté realizando. El feed back responde a la pregunta ¿cómo lo estoy haciendo?, esto consiste en informar al estudiante cómo está realizando las actividades de aprendizaje, explicar cómo va su proceso y, de esta manera, realizar los ajustes pertinentes a la actividad. Por último, el feed forward consiste en informar al estudiante de qué manera relacionar los aprendizajes previos con los próximos. 
Este modelo contempla cuatro niveles de retroalimentación: (1) nivel tarea, que consiste en identificar qué tanto quedó comprendido de la actividad a realizar y cómo se hizo; (2) nivel del proceso, que consiste en revisar cómo fue el desempeño del alumno con respecto a la actividad realizada; (3) nivel de autorregulación, que está relacionado con la capacidad del alumno para autodirigirse; y (4) nivel del yo, que consiste en realizar una evaluación personal que motive al alumno para su mejora.

Dichos elementos ayudan a complementar la acción de la retroalimentación que, si bien no son elementos propios de un tipo de evaluación bajo educación a distancia, cabe la posibilidad de realizar modificaciones pertinentes que apoyen el proceso de evaluación mediado por las TIC.

\section{Mediación didáctica}

En los contextos educativos, el concepto de mediación didáctica surge desde las aportaciones propuestas por Vigotsky, quien considera que los procesos mentales se ven mediados por el lenguaje, los símbolos y los códigos (González \& Hernández, 2016). Por su parte, Escobar (2011) coincidió en que el proceso de aprendizaje es de carácter social, por lo tanto, el proceso de enseñanza será el medio por el que se ve el avance de ese aprendizaje. En este sentido, la mediación se considera como una interacción educativa que provee de experiencias positivas a quienes se encuentran en un proceso de aprendizaje. Por lo anterior, la mediación es percibida como una acción que tiene como propósito el ser intermediario entre personas en una situación determinada (Oliveira, 1993).

Asimismo, según Tébar (2009), la mediación engloba distintos aspectos cotidianos de los estudiantes como cuestiones afectivas, cognitivas y sociales, así como las problemáticas que se presentan en los entornos académicos y que impactan de manera negativa en el PEA. La mediación propicia valores como la confianza y la paciencia, es un factor determinante de motivación para el logro de los objetivos, propicia el cuestionamiento del proceso con el fin de desafiar y lograr un cambio entre los docentes y estudiantes, además guía, orienta y planifica actividades, se autoevalúa y critica la estructura con el fin de identificar necesidades educativas que deberán atenderse.

En resumen, la mediación didáctica es la interacción entre el docente-alumno y los saberes que poseen y comparten para lograr el éxito escolar; además, se considera un acto humanista, de carácter positivo y potenciador de las habilidades de los actores principales (docentes y estudiantes). En este sentido, el objetivo de la mediación es la construcción y desarrollo de habilidades en la persona que es mediada (estudiante). Desde un 
punto de vista antropológico, busca la perfección y alta potencialidad del ser humano. Por lo tanto, desde el campo de la educación, la mediación debe involucrar al educador, docente o facilitador, quien será el intermediario entre el estudiante y el saber; de modo que, se entiende que el mediador en el contexto educativo es aquella persona que amplifica, organiza y diseña los procesos formativos del estudiante; deberá regular y favorecer el PEA a partir del acompañamiento, seguimiento y evaluación que permitan facilitar el proceso (Tébar, 2009).

El diseño instruccional en educación a distancia, como ya se ha mencionado, se considera un elemento importante en el proceso de aprendizaje, ya que su elaboración consiste en planificar las actividades académicas en cualquier modalidad y se basa en la búsqueda de la comprensión, el uso de diversas fuentes de información, a partir de estructuras sistemáticas, metodológicas y pedagógicas (Luzardo, 2004). Por su parte, Benítez (2010) complementó esta idea explicando que el DI permite identificar las necesidades y objetivos de la enseñanza y, a partir de ellos, se seleccionan y desarrollan las estrategias, actividades y recursos pertinentes para alcanzar las metas fijadas.

En los entornos educativos virtuales, el DI es un proceso de diseño tecnopedagógico que plantea de forma explícita y precisa, mediante un guion instruccional, los contenidos, objetivos, actividades de enseñanza y evaluación a realizar a través de una serie de pantallas de un recuso educativo digital para cumplir un proceso formativo (Pedroza, 2015). Por lo anterior, para elaborar un diseño instruccional es necesario conocer los usos de la tecnología, sus ventajas y limitaciones, entender las herramientas con las que cuenta y las características de lo esperado. También, se requieren conocimientos pedagógicos que permitan definir cuáles serán los contenidos, las actividades de enseñanza-aprendizaje y los elementos para desarrollarlas. Por ello, Luzardo (2004) resaltó la idea de que el DI se ha añadido en el vocabulario utilizado en el ámbito de la educación virtual como una expresión fundamental del PEA.

Al elaborar una propuesta de formación, es necesario conocer sobre la materia, las teorías de aprendizaje y las estrategias didácticas; respecto a la educación a distancia, es importante conocer cuál será el medio digital por el cual se establecerá un ambiente de aprendizaje mediado por tecnologías. Al respecto, el DI se considera como el proceso de planificación de las actividades que facilitan el aprendizaje de los alumnos, por lo que debe ser prioridad en el diseño e implementación de un programa educativo.

Es indudable que existen múltiples razones para realizar investigación, sin embargo, para un investigador, es una necesidad que surge a partir del interés por resolver una 
problemática acerca de una situación o fenómeno digno de ser estudiado (Manterola \& Otzen, 2013). Por lo tanto, el presente proyecto tiene el propósito de hacer una aportación sobre los modelos educativos mediados por tecnología en un contexto universitario. Lo anterior, bajo la premisa de que, en la actualidad, la sociedad se encuentra cada vez más orientada hacia la gestión de tecnologías que aporten en su desarrollo personal, académico y laboral, por ello, es necesario que los procesos educativos se renueven con mayor fluidez; en este sentido, la educación mediada por tecnología se ofrece como una alternativa que responda a las necesidades que manifiesta la sociedad (Morresi \& Donnini, 2007).

Por su parte, Hinojo y Fernández (2011) explicaron que la educación semipresencial se presenta como una oportunidad que favorece los procesos educativos ante la creciente demanda en los contextos universitarios. Por otro lado, los procesos de enseñanza y aprendizaje de la modalidad semipresencial se deben desarrollar con la intención de que el estudiante construya su propio conocimiento, lo que exige que el docente se forme en aspectos didácticos, pedagógicos, disciplinarios y prácticos, siendo estos elementos, la base sobre la que se garantiza la calidad en la modalidad (Espinosa, 2016). El docente juega un papel importante, ya que será mediador entre el estudiante y el saber. En relación con eso, el docente simplifica, organiza y diseña los procesos de formación del estudiante, regulando y favoreciendo su aprendizaje, a partir del acompañamiento, seguimiento y evaluación (Tébar, 2009).

En los últimos nueve meses, la pandemia por COVID-19 ha generado un cambio repentino, que no solo ha modificado la forma de interactuar de las personas, sino que propone un cambio en la forma de enseñar, en donde la educación a distancia ha sido la única opción para continuar con los procesos académicos (Pineda, 2020). En la Universidad Autónoma de Baja California (UABC), dicha situación ha sido un desafío para la comunidad estudiantil, docente y administrativa, dejando ver las fallas y limitaciones que se presentan en el desarrollo de una modalidad mediada por las tecnologías; sin embargo, para Gómez (2020), dicha problemática representa un área de oportunidad a tratar, a través de un análisis exhaustivo que permita establecer los cambios necesarios y aportar una solución para minimizar el déficit de aprendizaje por la transición a espacios no presenciales, reducir la brecha digital y establecer estrategias que propicien el interés del estudiante por nuevas modalidades.

Por esta razón, realizar una intervención que apoye a los procesos educativos de la modalidad semipresencial y la mediación didáctica, aporta a lo que a nivel institucional se plantea necesario atender en el Plan de Desarrollo Institucional (PDI) (UABC, 2019a), el 
cual, dentro del apartado de políticas, estrategias y acciones, establece como uno de sus objetivos el "asegurar la calidad de la oferta educativa de licenciatura, adecuándola a las demandas de los sectores público, privado y social y al proyecto universitario" (p.97). Lo anterior, a través de diversificar la oferta educativa en diferentes modalidades. Además, de manera interna, la Facultad de Ciencias Humanas (FCH) en su PDI (UABC, 2019b) plantea que la modalidad semipresencial debe ser evaluada con la finalidad de asegurar la calidad educativa de los estudiantes y la participación de estos en dicha modalidad.

Por lo anterior, dicho proyecto parte de la necesidad de preguntarse cuáles son las problemáticas persistentes asociadas con la educación superior de manera externa e interna en la FCH, específicamente en los diseños instruccionales de la modalidad semipresencial y cómo estos influyen en la mediación didáctica, es decir, la interacción entre docente y alumno.

La iniciativa de realizar este proyecto surge a partir de la reflexión y el interés de la forma como son llevados a cabo los procesos pedagógicos en esta modalidad educativa y cómo es percibida, desde el punto de vista del docente y del alumno, con la finalidad de transformar la manera como se desarrolla. A este respecto, el presente proyecto pretende la transformación de su estructura, haciendo partícipes a docentes y alumnos en un proceso de autorreflexión que permita generar cambios en los actores a nivel educativo (Alvarado \& García, 2008).

\section{Objetivos}

- Desarrollar una propuesta de mediación didáctica centrada en mejorar el diseño instruccional que opera en la modalidad semipresencial de la Licenciatura en Ciencias de la Educación (LCE) de la FCH.

- Analizar las problemáticas y necesidades de la comunidad estudiantil y docente de la FCH sobre la implementación del diseño instruccional utilizado en la modalidad semipresencial.

- Identificar una metodología que coadyuve en la mejora del diseño instruccional de la modalidad semipresencial de la LCE.

\section{Método de diagnóstico}

El método de diagnóstico utilizado en el presente proyecto de intervención corresponde a un diseño mixto, con la finalidad de identificar, desde la perspectiva del estudiante y del 
docente, las problemáticas encontradas en torno al diseño instruccional de las materias operadas bajo la modalidad semipresencial.

Desde la perspectiva del enfoque cualitativo, se recabaron las opiniones de los docentes que operan la modalidad semipresencial en la FCH; para ello, se utilizó la técnica de entrevista a profundidad y se diseñó ex profeso una guía para una entrevista no directiva en profundidad para tratar la información y desarrollar las dimensiones del problema, mientras que, desde la perspectiva del enfoque cuantitativo, se recabó la percepción de los estudiantes acerca de la implementación de la modalidad y su perspectiva sobre las habilidades y actitudes del docente que imparte en esta modalidad, a través de un instrumento en escala Likert con opciones de siempre, la mayoría de las veces, algunas veces, la mayoría de las veces no y nunca. La mencionada escala fue desarrollada por Del Hierro et al. (2014) y modificada para fines de este proyecto. El cuestionario está elaborado a partir de las variables del perfil idóneo del profesor, conformado por cuatro secciones: (1) las habilidades tecnológicas del profesor para impartir clases en la modalidad semipresencial; (2) las actitudes del profesor ante la modalidad; (3) la satisfacción general sobre las dos secciones previas; y (4) datos sociodemográficos del participante.

\section{Resultados}

\section{Aspectos cualitativos}

Considerando que la intención de las entrevistas fue conocer la opinión del profesorado acerca de la incorporación de la modalidad semipresencial a la institución, a partir del análisis de los resultados obtenidos, el profesorado señala los beneficios y retos a los que se ha enfrentado desde su implementación. Se lograron identificar cuatro dimensiones sobre las que se merece hacer un llamado de atención a los diseños instruccionales de la modalidad semipresencial.

Las dimensiones identificadas dan cuenta de los aspectos que se vislumbran en el uso y aplicación de las tecnologías en un ambiente de aprendizaje a distancia: (1) la incorporación de las TIC y la modalidad semipresencial en el proceso de enseñanza y aprendizaje, que describe la opinión y experiencia personal del profesorado al transitar de modalidad y cómo ha influenciado en el aprendizaje de los estudiantes y las prácticas pedagógicas del docente; (2) los beneficios y las ventajas identificados a partir del uso y la aplicación en los procesos de enseñanza y de aprendizaje; (3) los retos a los que se han enfrentado con dicha incorporación y tránsito de modalidad; y (4) el reconocimiento de necesidades de formación docente, según las fallas y limitaciones presentadas en el proceso para generar estrategias que apoyen en la mejora de la acción educativa a distancia. 
Las dimensiones anteriormente mencionadas explican los aspectos más recurrentes en las respuestas de los entrevistados, por lo tanto, se infiere que los participantes asumen una postura positiva en cuanto a la incorporación de las tecnologías y reconocen que la implementación de la modalidad semipresencial remite a los esfuerzos de la facultad por diversificar las formas de educación y cumplir con los objetivos que se han planteado. A su vez, su implementación ha dejado ver las adaptaciones de las prácticas pedagógicas que en la actualidad se necesitan, los beneficios y ventajas que representa para el proceso de enseñanza-aprendizaje, así como también, las fallas y las limitaciones en su desarrollo, entendiendo que son los retos a los que se enfrenta la acción educativa al propiciar ambientes de aprendizaje mediados por tecnologías.

\section{Aspectos cuantitativos}

La primera dimensión reporta la percepción que tiene el estudiante sobre las habilidades tecnológicas que posee el docente al impartir cursos bajo la modalidad semipresencial. En la tabla 1 se describen los ítems con mayor frecuencia obtenida.

\section{Tabla 1}

Dimensión 1. Habilidades tecnológicas del profesor para impartir cursos semipresenciales

\begin{tabular}{|c|c|c|c|}
\hline Ítems & Descripción & Valores & Frecuencia \\
\hline \multirow{3}{*}{$\mathrm{D}$} & \multirow{3}{*}{$\begin{array}{l}\text { ¿Con qué frecuencia el profesor utiliza } \\
\text { la herramienta foro de discusión? }\end{array}$} & Siempre & 18 \\
\hline & & La mayoría de las veces & 29 \\
\hline & & Algunas veces & 20 \\
\hline \multirow{3}{*}{ G } & \multirow{3}{*}{$\begin{array}{l}\text { ¿Con qué frecuencia el profesor utiliza la herra- } \\
\text { mienta publicación del programa de curso } \\
\text { (e. g., Programa, ¿diseño general del curso)? }\end{array}$} & Siempre & 47 \\
\hline & & La mayoría de las veces & 20 \\
\hline & & Algunas veces & 4 \\
\hline \multirow{3}{*}{$\mathrm{H}$} & \multirow{3}{*}{$\begin{array}{l}\text { ¿Con qué frecuencia el profesor utiliza la herra- } \\
\text { mienta publicación de plan de clase (e. g., plan de } \\
\text { sesiones, calendario de actividades y asignacio- } \\
\text { nes)? }\end{array}$} & Siempre & 49 \\
\hline & & La mayoría de las veces & 17 \\
\hline & & Algunas veces & 4 \\
\hline \multirow{3}{*}{ I } & \multirow{3}{*}{$\begin{array}{l}\text { ¿Con qué frecuencia el profesor utiliza la herra- } \\
\text { mienta publicación de materiales (e. g., presen- } \\
\text { taciones, guías de clase, asignaciones, guía de } \\
\text { observación de videos)? }\end{array}$} & Siempre & 33 \\
\hline & & La mayoría de las veces & 32 \\
\hline & & Algunas veces & 5 \\
\hline \multirow{4}{*}{ K } & \multirow{4}{*}{$\begin{array}{l}\text { ¿Con qué frecuencia el profesor utiliza la he- } \\
\text { rramienta presentación de foro de discusión con } \\
\text { bienvenida, desarrollo y evaluación? }\end{array}$} & Siempre & 32 \\
\hline & & La mayoría de las veces & 28 \\
\hline & & Algunas veces & 8 \\
\hline & & La mayoría de las veces no & 3 \\
\hline
\end{tabular}


De acuerdo con la perspectiva del estudiante, respecto a la dimensión de habilidades tecnológicas del profesor que opera cursos semipresenciales, se identificó que el docente de educación superior realiza un uso adecuado de las herramientas que ofrece la plataforma institucional para el desarrollo óptimo de la modalidad semipresencial, siendo Blackboard la plataforma utilizada para este proceso. Con respecto a los ítems sobre el uso del foro de discusión y el uso de videoconferencia (2.15 y 2.18 respectivamente), los estudiantes refieren que siempre o la mayoría de las veces hacen uso de ellas, entendiendo que estas herramientas son de uso común para llevar a cabo un curso semipresencial, ya que son espacios abiertos que permiten la discusión de un tema específico, con el propósito de intercambiar ideas, además de utilizarse para permitir reuniones cara a cara en ubicaciones separadas.

Por otro lado, en cuanto al uso de herramientas específicas correspondientes al diseño instruccional, los estudiantes refieren que el docente siempre (66.2\%) o la mayoría de las veces (28.2\%) publica el programa general del curso; en cuanto a la facilitación del plan de clase el profesor siempre (49\%) o la mayorías de las veces (23.9\%) lo hace llegar a los estudiantes a través de plataforma; así como siempre (46.5\%) o la mayoría de las veces (45.1\%) el docente publica el material pertinente para la elaboración de las actividades, como presentaciones, videos y material digital.

En este sentido, de acuerdo con la perspectiva de los participantes, se infiere que las habilidades tecnológicas del docente con respecto a la impartición de la modalidad son adecuadas. Considerando las opciones de respuesta del instrumento, de manera relativa, la mayoría de las veces el docente las utiliza, por lo tanto, el diseño instruccional considerado por Chiappe (2008) —como un desarrollo sistemático de los elementos instruccionales como la redacción de objetivos y competencias, descripción de tareas y el aseguramiento correcto del curso- se encuentra mayormente dominado.

La siguiente dimensión visualiza, desde la perspectiva del estudiante, las actitudes del profesor en la implementación de un curso semipresencial. En la tabla 2, se describen los ítems con el porcentaje obtenido.

Mientras que los resultados que se presentan en la tabla 3 enfatizan las opciones de respuesta a ítems con mayor y menor porcentaje en cuanto a las actitudes del profesor para impartir cursos semipresenciales. La media del ítem 2.1 (1.76) indica que el 42\% de los docentes atienden a las sugerencias y peticiones de sus estudiantes, mientras que solo un $15 \%$ de ellos algunas veces toman en cuenta estas sugerencias. En contraste con el ítem 2.2 (2.15), el 23\% de los docentes desarrolla actividades que promuevan en el 
Tabla 2

Dimensión 2. Actitudes del profesor para impartir cursos semipresenciales

\begin{tabular}{|c|c|c|c|}
\hline Ítems & Descripción & Valores & Frecuencia \\
\hline \multirow{3}{*}{2.1} & \multirow{3}{*}{$\begin{array}{l}\text { ¿Con qué frecuencia atiende las sugerencias y } \\
\text { peticiones de los alumnos? }\end{array}$} & Siempre & 30 \\
\hline & & La mayoría de las veces & 29 \\
\hline & & Algunas veces & 11 \\
\hline \multirow{4}{*}{2.2.} & \multirow{4}{*}{$\begin{array}{l}\text { ¿Con que frecuencia desarrolla actividades para } \\
\text { que puedas organizarte, establecer tus tiempos } \\
\text { de trabajo o que motiven una reflexión sobre tu } \\
\text { aprendizaje? }\end{array}$} & Siempre & 17 \\
\hline & & La mayoría de las veces & 3 \\
\hline & & Algunas veces & 18 \\
\hline & & La mayoría de las veces no & 5 \\
\hline \multirow{4}{*}{2.3.} & \multirow{4}{*}{$\begin{array}{l}\text { ¿Con que frecuencia se explican las retroalimenta- } \\
\text { ciones, cuando el alumno lo requiere para lograr } \\
\text { las metas a pesar de la distancia física? }\end{array}$} & Siempre & 20 \\
\hline & & La mayoría de las veces & 29 \\
\hline & & Algunas veces & 16 \\
\hline & & La mayoría de las veces no & 6 \\
\hline \multirow{4}{*}{2.4.} & \multirow{4}{*}{$\begin{array}{l}\text { ¿Con qué frecuencia mantiene al día la documen- } \\
\text { tación del curso y las noticias necesarias para la } \\
\text { buena comunicación en el curso? }\end{array}$} & Siempre & 27 \\
\hline & & La mayoría de las veces & 25 \\
\hline & & Algunas veces & 16 \\
\hline & & La mayoría de las veces no & 3 \\
\hline \multirow{4}{*}{2.5.} & \multirow{4}{*}{$\begin{array}{l}\text { ¿Con qué frecuencia la retroalimentación de una } \\
\text { tarea o trabajo se percibe previó al desarrollo de } \\
\text { una siguiente actividad? }\end{array}$} & Siempre & 22 \\
\hline & & La mayoría de las veces & 24 \\
\hline & & Algunas veces & 19 \\
\hline & & La mayoría de las veces no & 6 \\
\hline
\end{tabular}

alumno actitudes de organización que le permitan establecer sus tiempos de trabajo y lo motiven a reflexionar sobre su aprendizaje.

La media del ítem 2.3 (2.11) indica que el docente, la mayoría de las veces, explica las retroalimentaciones cuando el alumno se lo requiere a pesar de la distancia física (40\%); en contraste con el ítem 2.5, los resultados arrojan que el 31\% de los docentes siempre realizan la retroalimentación de una tarea o trabajo previo a una siguiente actividad, mientras que el $33 \%$ la mayoría de las veces y el $27 \%$ algunas veces hacen uso de los momento de retroalimentación a las tareas; al respecto, se percibe que no todos los docentes generan un momento de retroalimentación con sus estudiantes, considerando a la retroalimentación como un componente fundamental de la interacción entre docente-alumno que garantice un aprendizaje efectivo en la modalidad, lo que sugiere un área de oportunidad para pensar en un proceso de retroalimentación que favorezca los ambientes de aprendizaje virtuales. 
Por último, la siguiente dimensión visualiza la satisfacción general de los docentes y los estudiantes con respecto a su experiencia, a las habilidades y actitudes mostradas al desarrollar o llevar a cabo cursos semipresenciales. En la tabla 3, se describen los ítems con los porcentajes presentados en cada opción de respuesta por los participantes docentes y estudiantes.

Tabla 3

Satisfacción general de los estudiantes en cursos semipresenciales

\begin{tabular}{llc}
\hline \multicolumn{1}{c}{ Descripción del ítem } & \multicolumn{1}{c}{ Valores } & Porcentaje \\
\hline & Muy satisfecho & $16.9 \%$ \\
¿Qué tan satisfecho estás con tu experiencia respecto al & Algo satisfecho & $44.1 \%$ \\
desarrollo del curso semipresencial? & Neutral & $30.5 \%$ \\
& Algo insatisfecho & $5.1 \%$ \\
& Muy insatisfecho & $3.4 \%$ \\
\hline & Muy satisfecho & $33.9 \%$ \\
¿Qué tan satisfecho estás con las habilidades tecnológi- & Algo satisfecho & $44.1 \%$ \\
cas mostradas por el profesor para impartir cursos semi- & Neutral & $18.6 \%$ \\
presenciales? & Algo insatisfecho & $1.7 \%$ \\
& Muy insatisfecho & $1.7 \%$ \\
\hline & Muy satisfecho & $35 \%$ \\
¿Qué tan satisfecho estás con las actitudes del profesor & Algo satisfecho & $41.7 \%$ \\
para desarrollar o llevar a cabo la impartición de cursos & Neutral & $20 \%$ \\
semipresenciales? & Algo insatisfecho & $1.7 \%$ \\
& Muy insatisfecho & $1.7 \%$ \\
\hline
\end{tabular}

De acuerdo con los resultados obtenidos, el nivel de satisfacción presentada por los estudiantes no es alta con respecto a sus experiencias en un curso bajo la modalidad semipresencial. Los estudiantes manifiestan un grado de algo satisfecho (36\%) a neutral (25\%) en cuanto al desarrollo del curso. Lo anterior sugiere un área de oportunidad a tratar, ya que se propone profundizar sobre los aspectos donde los estudiantes manifiestan no estar satisfechos con su participación en un curso semipresencial.

Por otro lado, en cuanto a las habilidades tecnológicas mostradas por el profesor, el $26 \%$ de los estudiantes se sienten algo satisfechos con esto, mientras que un $15 \%$ se mantiene neutral. Este aspecto sugiere revisar cuáles son las habilidades tecnológicas ideales para que un docente imparta cursos en una modalidad a distancia y, en su caso, propiciar una estrategia de formación continua para docentes en habilidades tecnológicas. De la 
misma manera, en cuanto a las actitudes presentadas por el profesor, el 35\% se encuentra algo satisfecho, mientras que el $17 \%$ se mantiene neutral, por lo que se infiere que existe una problemática en cuanto a las actividades que se promuevan en la modalidad.

A partir de los resultados anteriores, de acuerdo con los aspectos que presentaron mayor frecuencia en la aplicación del instrumento cuantitativo y, según lo que se ha revisado, se debe poner mayor atención a lo que se remite en la Dimensión 2. Actitudes del profesor para impartir cursos semipresenciales, específicamente a los momentos de retroalimentación que se deberían generar en el PEA en esta modalidad, considerando este elemento como un componente esencial en la interacción entre el docente y el alumno.

\section{Síntesis de los resultados}

A partir de los diagnósticos realizados en las fases cualitativa y cuantitativa, los hallazgos conducen a deducir que existe una necesidad por parte de los estudiantes con respecto a sus experiencias en un curso semipresencial, destacando lo expuesto de acuerdo al análisis cuantitativo, el nivel de satisfacción ante esta temática no es alta, oscilando entre algo satisfecho y neutral, por lo tanto, se identificó una problemática inclinada específicamente en el desarrollo de las actividades que se promueven en la modalidad.

Asimismo, se identifica que por parte de los docentes no se generan momentos de retroalimentación efectiva — previos, durante y posterior a una actividad-, es decir, desde la planeación del curso no hay una evidencia de cómo se genera la retroalimentación hacia los estudiantes por parte del docente, que permita al estudiante conocer sus logros, áreas de oportunidad y errores en el desarrollo del curso.

Por lo anterior, es pertinente trabajar sobre el proceso de retroalimentación en los cursos semipresenciales como un producto que refleje las observaciones, correcciones y recomendaciones cualitativas y cuantitativas que serán esenciales en el proceso de construcción de conocimiento. Además, se debe reforzar la comunicación docente-alumno, alumno-docente, por lo que se sugiere realizar la intervención de este proyecto a partir de generar una propuesta de mediación didáctica que apoye los momentos de retroalimentación, considerando este proceso desde la elaboración del diseño instruccional.

\section{Proyecto de intervención}

La propuesta de intervención será implementada en la FCH de la Universidad Autónoma de Baja California, en específico para la Licenciatura en Ciencias de la Educación en modalidad semipresencial. Esta tiene el objetivo de fortalecer el diseño instruccional en dicha licenciatura en modalidad semipresencial, implementado una estrategia de mediación 
didáctica, través de la propuesta de una serie de pautas específicas para los momentos de retroalimentación, con la finalidad de coadyuvar en la mejora del proceso de evaluación y el rendimiento académico de los estudiantes.

Para realizar el proyecto de intervención se indican las actividades que se deben llevar a cabo para el funcionamiento del proyecto:

1. Describir la propuesta de criterios a llevar a cabo en un proceso de retroalimentación, tomando como referencia el modelo de Hattie y Timperley (2007).

2. Aplicar el cuestionario para alumnos, con la finalidad de obtener su opinión sobre las estrategias de retroalimentación que implementan los profesores durante el curso y la importancia de recibir dicha retroalimentación en sus actividades y tareas.

3. Entrevistar a profesores con el propósito de conocer su percepción acerca de la aplicación de una retroalimentación basada en el modelo de Hattie y Timperley (2007).

4. Conocer la percepción del alumno acerca de la aplicación de la propuesta de retroalimentación, haciendo la comparación de su rendimiento académico antes y después de aplicarlo.

Para fines de este proyecto, la literatura y los resultados del diagnóstico ayudan a construir una propuesta que cuente con una serie de pautas y recomendaciones que complementan el diseño instruccional implementado en la institución, específicamente en los procesos de retroalimentación; dichas pautas se sugieren tomando como referencia el modelo de Hattie y Timperley (2007). Se eligió este modelo considerando sus fortalezas teórico-prácticas y por ser un modelo poco aplicado en estudios de educación superior; cabe resaltar que no es un modelo de retroalimentación diseñado para la educación a distancia, sin embargo, sus elementos se adecuan a las características de la modalidad.

Como antecedente, se presenta la propuesta de diseño instruccional para el desarrollo de un curso bajo la modalidad semipresencial en la UABC desde la perspectiva del estudiante, a partir de tres preguntas centrales:

- ¿Qué voy a aprender? Hace referencia a la información, los conocimientos, habilidades, competencias, destrezas y actitudes que adquirirá el estudiante; generalmente, redactado en el objetivo general o competencia de la actividad.

- ¿Cómo lo voy a aprender? Remite a la selección de las estrategias de aprendizaje, las actividades a realizar bajo ciertos requisitos, tiempo y recursos.

- ¿Cómo sabré que logréla meta? Hace referencia a la evaluación de la actividad; por lo general, se visualiza en una calificación representada en número, esto se basará en si se ha cumplido con los criterios de evaluación descritos para cada actividad. 
Considerando lo anterior, las pautas y recomendaciones sugeridas a este diseño instruccional se remiten a la pregunta ¿Cómo sabré que logré la meta? En este apartado se pretenden implementar las preguntas: ¿Hacia dónde voy?, ¿Cómo lo estoy haciendo?, ¿Qué sigue después?

De acuerdo con Hattie y Timperley la retroalimentación busca que el alumno se dé cuenta de la discrepancia que hay entre lo que comprendió y lo que debió haber comprendido, o cómo se ha desempeñado para cumplir con el objetivo de aprendizaje de cada actividad. Dicho de otra manera, que vea la diferencia entre la actividad que entregó y la que debió haber sido entregada, o rectificar el proceso que llevó a cabo con el que debió haber realizado para cumplir con el objetivo o competencia de aprendizaje. (Lozano \& Tamez, 2014, p.201)

En este sentido, para que la retroalimentación sea efectiva debe enfocarse a la actividad que elaboró el alumno, debe permitir que adquiera hábitos de autorregulación que lo haga reflexionar acerca de sus logros, errores y fortalezas.

Las pautas y recomendaciones por implementar se describen en la tabla 4 y se sugiere que complementen el diseño instruccional actual. Con esta serie de recomendaciones se pretende alcanzar mejores resultados en el proceso de aprendizaje de los alumnos.

Tabla 4

Preguntas para retroalimentación

\begin{tabular}{|c|c|c|}
\hline $\begin{array}{c}\text { ¿Cómo voy? } \\
\text { ¿Hacia dónde voy? }\end{array}$ & ¿Cómo lo estoy haciendo? & ¿Qué sigue después de esto? \\
\hline $\begin{array}{l}\text { Informar al estudiante si ha } \\
\text { cumplido con los objetivos de la } \\
\text { actividad, recordarle el objetivo } \\
\text { del curso para que no realice las } \\
\text { actividades sin rumbo definido. }\end{array}$ & $\begin{array}{l}\text { Informar al estudiante el } \\
\text { desempeño y resultados del } \\
\text { producto entregado. } \\
\text { Proveer información sobre } \\
\text { cómo va realizando su actividad } \\
\text { con el fin de que pueda hacer } \\
\text { ajustes y logre el objetivo. }\end{array}$ & $\begin{array}{l}\text { Informar al estudiante cómo } \\
\text { esta actividad tendrá relación } \\
\text { con la siguiente; indicar que no } \\
\text { son productos aislados, sino } \\
\text { que cada actividad tiene un } \\
\text { objetivo claro encaminado a } \\
\text { cumplir con el objetivo general } \\
\text { del curso. }\end{array}$ \\
\hline
\end{tabular}




\section{Conclusiones}

La revisión de la literatura y los antecedentes teóricos vistos a lo largo de este documento permiten comprender la importancia de estudiar los componentes de la educación en línea. Particularmente, la diversificación de las modalidades está teniendo mayor aceptación por parte de las personas, ya que se ajusta a sus necesidades educativas; esto ha propiciado que cada vez sea más evidente la necesidad de mejorar los procesos de enseñanza y aprendizaje y que estos, a su vez, respondan a las sugerencias de organismos internacionales.

La educación a distancia surge como un cambio a los esquemas tradicionales, lo que implica que la metodología cuente con nuevas maneras de planificar, desarrollar, evaluar y retroalimentar el aprendizaje; por esta razón, es relevante elaborar un buen diseño instruccional como base de planificación en el quehacer educativo y así asegurar la calidad en el aprendizaje. Por otro lado, el proceso de la mediación didáctica consta en la interacción docente-alumno para la construcción de los aprendizajes, de modo que realizar un buen diseño instruccional supone organizar la acción mediadora, no solo como un conjunto de acciones desarticuladas, sino como la puesta en práctica de una planeación coherente, bien pensada y articulada.

Después de analizar el modelo instruccional de la Licenciatura en Ciencias de la Educación de la $U A B C$, se detectaron áreas de oportunidad a mejorar en los diseños instruccionales empleados para la modalidad semipresencial, así como la necesidad de establecer una serie de criterios que los complemente.

Por lo anterior, se plantea una propuesta que busca sumarse a lo implementado actualmente, con la finalidad de fortalecer y apoyar el proceso de evaluación y rendimiento académico de los estudiantes. Los criterios propuestos se retoman de un modelo diseñado para crear una retroalimentación efectiva en las actividades y tareas de un curso, considerando que por "cada actividad o tarea que el estudiante realice se necesita que su desempeño y/o producción académica sea evaluada y retroalimentada por un profesor [... quien será su guía en el proceso de aprendizaje" (Lozano \& Tamez, 2014, p.198).

La retroalimentación es fundamental en cualquier modalidad, pues esta permite que el estudiante se dé cuenta de sus fortalezas y debilidades; la retroalimentación hace constar no solamente los logros de los estudiantes, sino que se presenta como una oportunidad para que el docente interactúe con el conocimiento del alumno. 
Por último, como alcances y limitaciones del estudio se reconoce que existe una necesidad latente de brindar atención constante a las futuras propuestas para la modalidad semipresencial de la institución, considerando que en la actualidad su implementación ha sido de vital importancia; lo que sugiere dar seguimiento a la implementación de esta propuesta una vez que sea evaluada. 


\section{Referencias}

Alvarado, L., \& García, M. (2008). Características más relevantes del paradigma sociocrítico: su aplicación en investigaciones de educación ambiental y de enseñanza de las ciencias realizadas en el Doctorado de educación del instituto pedagógico de Caracas. Sapiens. Revista Universitaria de investigación, 9(2), 187-202. http://www. redalyc.org/articulo.oa?id=41011837011

Alvarado, M. (2014). Retroalimentación en educación en línea: una estrategia para la construcción del conocimiento. RIED Revista Iberoamericana de Educación a Distancia, 17(2). https://doi.org/10.5944/ried.17.2.12678

Bartolomé, A. (2004). Blended Learning Conceptos Básicos. Revista de Medios y Educación, 23, 7-20. http://www.redalyc.org/pdf/368/36802301.pdf

Benítez, M. G. (2010). El modelo de diseño instruccional Assure aplicado a la educación a distancia. Tlatemoani, Revista Académica de Investigación, (1), 1-15. http://www. eumed.net/rev/tlatemoani/01/pdf/63-77_mgbl.pdf

Castillo, S., \& Cabrerizo, J. (2009). Evaluación educativa de aprendizajes y competencias. Pearson.

Chiappe, A. (2008). Diseño instruccional: oficio, fase y proceso. Educación y Educadores, 11(2), 229-239. https://www.redalyc.org/articulo.oa?id=83411215\%2520

Del Hierro, E., García R., \& Mortis, S. (2014). Percepción de estudiantes universitarios sobre el perfil del profesor en la modalidad virtual presencial. Revista electrónica de tecnología educativa, 48, 1-18.

Domínguez, G., González, A., García, T., \& Rodríguez, T. (2008). Modalidad de curso semipresencial. Aplicación en la asignatura procesos tecnológicos. Revista de ingeniería mecánica, 11(3), 47-52. https://www.redalyc.org/pdf/2251/225115162007.pdf

Escobar, N. (2011). La mediación del Aprendizaje en la Escuela. Acción Pedagógica, 20(1), 58-73. http://dialnet.unirioja.es/servlet/articulo?codigo $=6222147$

Espinosa, E. (2016). La reflexión y la mediación didáctica como parte fundamental en la enseñanza de las ciencias: un caso particular en los procesos de formación docente. http://www.scielo.org.co/pdf/ted/n40/n40a07.pdf

Fandiño, Y. J. (2011). La educación universitaria en el siglo XXI: de la sociedad de la información a la sociedad del conocimiento. Revista Iberoamericana de Educación, 55(3). https://rieoei.org/historico/jano/3965Fandino_Jano.pdf

García, E. (2015). La evaluación del aprendizaje: de la retroalimentación a la autorregulación. El papel de las tecnologías. RELIEVE. Revista Electrónica de Investigación y Evaluación Educativa, 21(2), 1-24. https://www.redalyc.org/pdf/916/91643847005.pdf 
Gómez, N. (2020). Abordan las oportunidades para la educación superior ante la COVID-19. Gaceta UABC. http://gaceta.uabc.mx/notas/academia/abordan-las-oportunidadespara-la-educacion-superior-ante-la-covid-19

González, K., \& Hernández, L. (2016). La mediación didáctica y sus aportes a la formación docente (Tesis de licenciatura). Universidad del Valle, Santiago de Cali, Colombia. https://bibliotecadigital.univalle.edu.co/xmlui/bitstream/ handle/10893/10890/3467-0525568.pdf?sequence=1

Hattie, J., \& Timperley, H. (2007). The Power of Feed Back. Review of Educational Research, 77(1), 81-112. https://journals.sagepub.com/doi/10.3102/003465430298487

Hernández, R. M. (2017). Impacto de las TIC en la educación: Retos y Perspectivas. Propósitos y Representaciones, 5(1), 325-347 http://dx.doi.org/10.20511/pyr2017.v5n1.149

Hernández, S. (2007). El constructivismo social como apoyo en el aprendizaje en línea. Apertura, 7(7), 46-62. http://www.redalyc.org/articulo.oa?id=68800705

Hinojo, M., \& Fernández, A. (2011). El aprendizaje semipresencial o virtual: nueva metodología de aprendizaje en Educación Superior. Revista latinoamericana de Ciencias Sociales, Niñez y juventud, 10(1), 159-167. http://www.scielo.org.co/pdf/ rlcs/v10n1/v10n1a09.pdf

Jackson, G., \& Graesser, A. (2006). Aplicaciones del diálogo humano de tutoría al Auto Tutor: un sistema inteligente de tutoría. Revista Signos, 39(60), 31-48. http://www. redalyc.org/articulo. oa?id=157013768002

Lima, G. (2017). Enriquecer la realimentación para consolidar aprendizajes. Virtualidad, Educación y Ciencia, (14), 9-26.

Lozano, F. G., \& Tamez, L. A. (2014). Retroalimentación formativa para estudiantes de educación a distancia. RIED. Revista Iberoamericana de Educación a Distancia, 17(2), 197-221. https://www.redalyc.org/pdf/3314/331431248010.pdf

Luna, E., \& Reyes, P. (2015). Validación de constructo de un cuestionario de evaluación de la competencia docente. REDIE, 17(3). http://www.scielo.org.mx/scielo. php?pid=S1607-40412015000300002\&script=sci_arttext

Luzardo M. J. (2004). Herramientas Nuevas para los Ajustes Virtuales de la Educación: Análisis de los Modelos de Diseño Instruccional (Tesis doctoral). Tecana American University.

Manterola, C., \& Otzen, T. (2013). Por qué investigar y cómo conducir una investigación. International Journal of Morphology, 31(4), 1498-1504. https://scielo.conicyt.cl/ scielo.php?script=sci_arttext\&pid=S0717-95022013000400056 
Morán, F. (2018). La Modalidad de Educación Semipresencial en el sistema nacional de educación ecuatoriano (Tesis de doctorado). Universitat de Barcelona, España. http:// diposit.ub.edu/dspace/bitstream/2445/134322/1/FEMP_TESIS.pdf

Morresi, S., \& Donnini, N. (2007). Modalidad de educación semipresencial. Relato de una experiencia. VII Coloquio Internacional sobre gestión universitaria en América del Sur, Mar del Plata, Argentina. https://core.ac.uk/download/pdf/30363923.pdf

Oliveira, M. K. de. (1993). Vygotsky: aprendizado e desenvolvimento um processo sóciohistórico. Scipione.

Parra, L. (2008). Blended learning, la nueva formación en educación superior. Avances investigación en ingeniería, 1(9), 95-102. https://dialnet.unirioja.es/servlet/ articulo?codigo $=6684815$

Pascual, M. (2003). El Blended Learning reduce el ahorro de la formación online, pero gana en calidad. Educaweb. https://www.educaweb.com/esp/servicios/monografico/ formacionvirtual/1181108-a.html

Pedroza, K. (2015). Estrategias de diseño instruccional en objetos digitales de aprendizaje (Tesis de maestría). Universidad Pedagógica Nacional, México. http://200.23.113.51/ pdf/31211.pdf

Pineda, L. (2020). Educación semipresencial ¿Será este el futuro de la educación de nuestros hijos? Revista digital INESEM. https://revistadigital.inesem.es/educacionsociedad/educacion-semipresencial/

Ponce, M. (2016). La autogestión para el aprendizaje en estudiantes de ambientes mediados por tecnología. Diálogos sobre educación temas actuales en investigación educativa, 7(12). https://www.redalyc.org/jatsRepo/5534/553458153013/553458153013.pdf

Portilla, A. (2002). La formación docente del profesorado universitario: perfily líneas de acción (Tesis doctoral). Universidad Autónoma de Barcelona, España. https://www.tdx.cat/ bitstream/handle/10803/5017/abpr1de5.pdf

Quesada, R. (2006). Evaluación del aprendizaje en la educación a distancia "en línea". RED. Revista de Educación a Distancia, 5(6). 1-15. https://www.redalyc.org/articulo. oa?id=54709902

Sánchez, C. F. (2015). La retroalimentación: mecanismo para fortalecer la evaluación formativa en estudiantes y maestros de matemáticas en secundaria (Tesis de maestría). Tecnológico de Monterrey, Bogotá, Colombia. https://repositorio.tec.mx/bitstream/ handle/11285/633033/Tesis000000010.pdf?sequence=1

Tébar, L. (2009). El profesor mediador del aprendizaje. Editorial magisterio. 
Torres, M., \& López, C. (2015). Modalidades, sistemas y opciones educativas en México, ¿Es posible un acuerdo de bases conceptuales? En J. Zubieta, \& C. Rama (Coords.), La educación a distancia en México: una nueva realidad universitaria (pp. 17-25). Virtual educa. https://virtualeduca.org/documentos/observatorio/2015/la-educacion-adistancia-en-mexico.pdf

Tucker, C. R. (2012). Blended Learning in Grades 4-12: Leveraging the Power of Technology to Create Student-Centered Classrooms. SAGE.

Universidad Autónoma de Baja California. (2019a). Plan de desarrollo institucional 20192024. UABC.

Universidad Autónoma de Baja California. (2018b). Plan de desarrollo FCH 2018-2022. UABC.

Yong, E., Nagles, N., Mejía, C., \& Chaparro, C. (2017). Evolución de la educación superior a distancia: desafíos y oportunidades para su gestión. Revista Virtual Universidad Católica del Norte, (50), 80-105. https://revistavirtual.ucn.edu.co/index.php/ RevistaUCN/article/view/814/1332

Zubieta, J., \& Rama, C. (Coords.). (2015). La Educación a Distancia en México: Una nueva realidad universitaria. CUAED-Virtual. 


\section{Capítulo 4}

La tutoría en educación superior:

una guía para la movilidad estudiantil

Mariel Alejandra Mariscal Mendoza y Fausto Medina Esparza

La movilidad estudiantil puede considerarse como un conjunto de prácticas llevadas a cabo por estudiantes de licenciatura y posgrado en una universidad diferente a la de su origen (Asociación Nacional de Universidades e Instituciones de Educación Superior [ANUIES], 2012). También puede entenderse como una forma en la que se desplazan los alumnos de una institución a otra en un periodo escolar (Santiago et al., 2019) o puede interpretarse como un grupo de programas institucionales que facilita a los alumnos viajar y estudiar algunas materias en otras instituciones (Suárez, 2012). Por otra parte, se sabe de tres clasificaciones de movilidad estudiantil: grado académico, procedencia y modalidad distintiva (Maldonado et al., 2017). Además, es importante mencionar que la movilidad estudiantil solo incluye a estudiantes, mientras la movilidad académica brinda la oportunidad de movilidad a docentes e investigadores (García, 2013).

La movilidad estudiantil concentra seis modalidades: (1) periodos académicos, (2) prácticas profesionales, (3) investigaciones, (4) cursos cortos, (5) co-tutela y (6) educación continua (Universidad de San Buenaventura Medellín, 2017). Estas modalidades pueden llevarse a cabo en diversos programas de movilidad estudiantil como el ERASMUS, que es un ejemplo a nivel internacional para diversos programas en todo el mundo; el Asia Link, que vincula instituciones asiáticas con europeas; el Alban, que relaciona universidades europeas con latinoamericanas (Pérez, 2004); o el Alfa de 1992, que también relaciona instituciones educativas europeas con latinoamericanas (Universidad de Salamanca, 
2018); finalmente, existe el programa Alfa Tuning para América Latina del año 2004, que concentra 230 universidades de 18 países (Tuning América Latina, 2011).

La movilidad estudiantil es una actividad complementaria en la formación profesional de los alumnos que cursan alguna de las cinco licenciaturas (educación, psicología, comunicación, historia y sociología) que se ofertan en la Facultad de Ciencias Humanas (FCH) de la Universidad Autónoma de Baja California (UABC). La elección de la movilidad estudiantil es opcional y requiere del apoyo del tutor y del Coordinador del Departamento de Cooperación Internacional e Intercambio de la FCH. El apoyo del tutor reside en guiar al alumno en la elección de la universidad receptora, el contenido académico a cursar y sugerencias para adaptarse al nuevo escenario académico. Mientras que el apoyo del coordinador de dicho departamento consiste en asesorar la realización de trámites administrativos.

Sin embargo, hasta el 2020, no se tienen reportes que den cuenta del número de alumnos que han participado en la movilidad estudiantil, ni de los problemas o dificultades que han experimentado en dicha movilidad, ni de la participación de los tutores en la elección de dicha actividad complementaria. En este sentido, se plantearon tres objetivos: (1) Registrar el número de alumnos, universidades, ciudades y países que han sido objeto de movilidad estudiantil en cualquiera de las cinco licenciaturas que concentra la FCH desde el 2016-1 hasta el 2019-2; (2) Identificar los problemas que han experimentado los alumnos que optaron por la movilidad estudiantil entre los semestres 2016-1 y 2019-2; y (3) Conocer la participación del tutor en el proceso de la movilidad estudiantil.

A partir del ciclo 1993-2, en la UABC y en la FCH se incorporó el plan de estudios flexible, que incluía la movilidad estudiantil (UABC, 2012a). Con esta información, el 21 de junio de 2020, se revisó la página de Internet de la UABC y se examinaron los archivos del Departamento de Cooperación Internacional e Intercambio Académico de la FCH. El resultado de dicha exploración dio como resultado que no se cuenta con información básica que permita conocer el proceso de movilidad estudiantil en la FCH. Pero, se recuperaron diversos archivos en formato Excel donde se encuentran registros de los alumnos que han participado. Así, al no contar con evidencias de los problemas que hayan experimentado los alumnos durante su movilidad estudiantil, se buscó en la literatura evidencia de factores que dificulten dicha actividad complementaria. De esta manera, se identificaron cuatro factores que dificultan el proceso de movilidad estudiantil:

- Idioma diferente a la lengua materna. Suele ser la primera dificultad, debido a que se requiere cierto nivel de dominio que, al no tenerlo, propicia problemas de 
comunicación y de entendimiento en clases (Fernández et al., 2016; Rosas, 2014; Tsokaktsidu, 2010; Villafañe et al., 2011). En México, representa una limitante por la falta de impulso de parte del sistema educativo para aprender un segundo idioma como se oferta en países como Alemania, Holanda, entre otros (Ramírez et al., 2017). En este contexto, se afecta la capacidad de comunicación e incluso del estado de ánimo (Rivera, 2016; Zúñiga, 2010), que puede repercutir en el aprovechamiento académico del alumno (López, 2010).

- Administrativo. El problema reside en la escasa disposición del personal en las unidades académicas para brindar información acerca de los trámites que necesitan los alumnos para la movilidad estudiantil (Rojo, 2015). En este contexto, se enfatiza la falta de apoyo del personal de la universidad receptora hacia el alumnado (Tsokaktsidu, 2010), que deriva en el desconocimiento de los servicios que ofrecen (Villafañe et al., 2011). En México, también se presenta escasa atención por parte de las universidades receptoras, además de desorganización y falta de planeación en los trámites administrativos (Fresán, 2009; López, 2010).

- Contexto académico. Este factor se relaciona con el tiempo y la cantidad de clases que se van a cursar (Cueva et al., 2015), también tiene que ver con el proceso de adaptación de enseñanza, por ejemplo, pasar de aprender de forma teórica a aprender por proyectos (Rosas, 2014; Tsokaktsidu, 2010). En México, resulta difícil estudiar con un estilo de aprendizaje-enseñanza diferente al de la universidad de origen (Zúñiga, 2010).

- Contexto cultural. La dinámica social de la ciudad o país donde se encuentra la universidad receptora puede ser una dificultad durante la movilidad, por ejemplo, al utilizar el transporte público o saber conducir con el tráfico vehicular, entre otras actividades rutinarias (Fernández et al., 2016; Rosas, 2014). Por otra parte, están las relaciones sociales que, a falta de ellas, pueden afectar el estado de ánimo del estudiante de movilidad (Tsokaktsidu, 2010). En México, este factor resulta una barrera para el estudiante, ya que afecta la forma de socializar, desenvolverse y adaptarse a su nuevo entorno (Rivera, 2016).

Estos cuatro factores pueden ser considerados por el tutor cuando un alumno esté interesado en participar en la movilidad estudiantil y, en este tenor, asesorar a los alumnos antes y durante la movilidad (ANUIES, 2012) para brindar un seguimiento más puntual. Así, se enfatiza la función de la tutoría para guiar el proceso de movilidad estudiantil, 
ya que brinda acompañamiento individual y académico durante la trayectoria escolar de los estudiantes, facilitando información acorde sus necesidades (ANUIES, 2001).

La tutoría en educación superior es una estrategia de intervención educativa que, por una parte, tiene la intención de coadyuvar al logro de metas académicas y, por otra parte, contribuye al fortalecimiento de los profesores (De la Cruz, 2017; Narro \& Arredondo, 2013). En este sentido, resulta imprescindible que el tutor identifique las necesidades escolares de los tutorados, para intervenir antes de que cualquier obstáculo afecte su desempeño académico (Aguirre et al., 2017). Por último, las funciones del tutor requieren ser evaluadas para dar cuenta de su efectividad en el apoyo que brinda a los tutorados (Ponce et al., 2017).

En la UABC, la tutoría es un eje transversal (UABC, 2013) que acompaña la trayectoria académica de los alumnos de cualquiera de sus licenciaturas; es considerada un proceso de acompañamiento llevado a cabo a través del Sistema Institucional de Tutorías (UABC, 2012b).

En el caso de la FCH, la tutoría es una modalidad que contribuye a la calidad de la educación a través de la interacción entre tutores y tutorados que, entre otras actividades, ayuda a adecuar la oferta educativa con las necesidades académicas (UABC, 2012a). También los tutores de la UABC cuentan con diversos recursos para apoyar su función en la FCH, por ejemplo, pueden consultar los lineamientos para la operación de las tutorías (UABC, 2012c). Además, se cuenta con tres manuales que describen las funciones de los tres actores relacionados con la tutoría: responsable de tutores (UABC, 2014a), el tutor (UABC, 2014b) y el tutorado (UABC, 2014c). Finalmente, en la literatura especializada se destacan las dimensiones de la tutoría: académica, personal y profesional, que brinda una guía más completa al tutorado (Rodríguez, 2008).

\section{Método}

En este apartado se describe la forma en que se analizaron los archivos de Excel que contienen los datos de movilidad estudiantil desde el semestre 2016-1 hasta el 2019-2. Después, se describe la aproximación metodológica mixta que se utilizó: (a) cuantitativa, para identificar la presencia de los cuatro factores: idioma extranjero, trámites administrativos, contexto académico y contexto cultural, que pudieran afectar el proceso de movilidad estudiantil de los alumnos de la FCH entre los semestres 2016-1 hasta el 2019-2; (b) cualitativa, para conocer la participación de los tutores en el proceso de movilidad estudiantil de los alumnos en los semestres ya mencionados. 
Revisión de registros de movilidad estudiantil en formato Excel

Se consideró recuperar el número y género del alumno por universidad receptora nacional o internacional, por cada semestre o periodo entre el 2016-1 y 2019-2.

\section{Aproximación cuantitativa}

Participantes de aproximación cuantitativa

Se utilizó la técnica de muestreo no paramétrica deliberada. Se definieron dos criterios para seleccionar a los participantes: (1) Ser alumnos de alguna de las cinco licenciaturas de la FCH: Educación, Psicología, Comunicación, Sociología e Historia; (2) Haber participado en movilidad estudiantil entre el periodo 2016-1 y 2019-2.

Elaboración del instrumento de aproximación cuantitativa

Se buscaron conceptos sustentados en fuentes adecuadas para redactar cuatro categorías mediante un escalamiento riguroso y sistemático:

1. Movilidad estudiantil. Tiene tres subcategorías: (a) Desarrollo Personal, que contiene cinco ítems; (b) Desarrollo Educativo y Profesional, con seis ítems; y (c) Percepción de la Unidad Receptora, con siete ítems. En total son 18 ítems.

2. Idioma Extranjero. Tiene cuatro ítems.

3. Contexto Cultural y Académico. Tiene siete ítems.

4. Trámites Administrativos. Tiene seis ítems; la escala contiene 35 ítems. Además, se solicitan datos sociodemográficos, edad y género de los participantes.

\section{Procedimiento de aplicación aproximación cuantitativa}

Se realizó el pilotaje de la escala con un grupo de estudiantes para identificar errores en la redacción o poco entendimiento de los ítems. De la revisión previa, se decidió administrar la escala mediante un formulario de Google. Para aplicar la escala, se identificaron los correos institucionales de los participantes gracias a la información proporcionada por el área de Cooperación Internacional e Intercambio Académico de la FCH. El 17 de marzo de 2020 se envió la escala. El 3 de abril del 2020 se obtuvieron 21 escalas con respuestas de 99 enviadas. Cabe señalar que la administración de la escala se dio al inicio de la contingencia sanitaria relacionada con la COVID-19 que obligó a las personas a quedarse en casa.

Análisis de los datos aproximación cuantitativa

Los datos se capturaron en una plantilla previamente diseñada del programa Statistical Package for the Social Sciences (SPSS). Se agruparon los ítems de acuerdo con las cuatro 
categorías utilizadas en la escala y se ingresaron las respuestas. Después, se obtuvieron las frecuencias y porcentajes de cada grupo correspondientes a cada categoría.

\section{Aproximación cualitativa}

Participantes de aproximación cualitativa

Se seleccionaron a los 21 estudiantes que participaron en la aproximación cuantitativa, es decir, alumnos de la FCH entre los periodos 2016-1 y 2019-2 de cualquier licenciatura y de edad y sexo indistintos.

\section{Elaboración del instrumento de aproximación cualitativa}

Se elaboró una guía de entrevista semiestructurada, la cual se caracteriza por ser un tipo de entrevista en donde se designan preguntas dirigidas a todos los participantes y ciertas preguntas se realizan solamente a algunos de ellos; en este caso, diferenciando entre los entrevistados que participaron en movilidad internacional y nacional. La guía de entrevista consta de cuatro preguntas relacionadas con cuatro categorías de análisis sobre la participación del tutor en el proceso de movilidad estudiantil: (1) el tutor motiva a la participación, (2) el tutor ayuda a realizar trámites administrativos, (3) el tutor orienta en el contenido curricular a cursar y (4) el tutor brinda seguimiento antes y durante la movilidad estudiantil.

\section{Procedimiento de aplicación aproximación cualitativa}

El día 5 de febrero de 2021 se envió por correo la invitación para participar en la entrevista. En esta ocasión, de los 21 alumnos que participaron en la escala, solo contestaron cuatro. Las entrevistas se agendaron en sesiones individuales y se realizaron por medio de Google Meet.

\section{Análisis de los datos aproximación cualitativa}

Las entrevistas se ordenaron por participante, se transcribieron y se analizaron para conocer la contribución del tutor en el proceso de movilidad estudiantil.

\section{Resultados}

Movilidad estudiantil del periodo 2016-1 al 2019-2

A partir de la información obtenida del área de Cooperación Internacional e Intercambio Académico de la FCH, se analizó la información de los 99 alumnos que participaron en movilidad estudiantil entre los periodos 2016-1 al 2019-2. 
En movilidad nacional se contó con la participación de 40 alumnos, en donde todas las carreras participaron en al menos un periodo escolar, resaltando Psicología (52.5\%) y Comunicación (35\%), el resto de las carreras tuvieron mínima participación: Educación (7.5\%), Historia (2.5\%) y Sociología (2.5\%). Entre los participantes se encontró que la mayoría fueron mujeres (72.5\%). El semestre que tuvo mayor movilidad nacional fue el 20171, contando con 13 aplicaciones a convocatorias, de las cuales 10 fueron aceptadas y tres rechazadas. En el mismo sentido, el semestre que contó con menor participación fue el 2018-2, en el cual no se registró ningún alumno de movilidad nacional, además de los periodos 2019-1 y 2019-2 que contaron con un alumno respectivamente. En estos periodos de movilidad nacional fueron rechazados seis solicitudes a causa de reprobación (50\%), no aceptación (33.3\%) y cancelación de la solicitud por parte del estudiante (16.7\%).

Los destinos e instituciones educativas que se escogieron con mayor frecuencia en estancias nacionales fueron Ciudad de México (50\%) en la Universidad Nacional Autónoma de México (UNAM) y el Instituto Politécnico Nacional (IPN); Guadalajara (30\%) en su totalidad en la Universidad de Guadalajara; Nuevo León (7.5\%) en la Universidad Autónoma de Nuevo León, Campus Monterrey; Puebla (7.5\%) en la Benemérita Universidad Autónoma de Puebla; Hidalgo (2.5\%) en la Universidad Autónoma del Estado de Hidalgo; y Querétaro (2.5\%) en la Universidad Autónoma de Querétaro.

En movilidad internacional participaron 59 alumnos, la mayoría mujeres (80\%). Las carreras que se registraron durante el periodo de estudio fueron psicología (45\%), comunicación (36.7\%) y educación (16.7\%). Los semestres con mayor índice de participación fueron el 2016-1 contando con 12 estudiantes de movilidad internacional, el 2018-1 con 11 solicitudes aceptadas y una rechazada y el 2018-2 con 11 participaciones y dos rechazos. En cuanto a los periodos que registraron menor movimiento estudiantil se encuentran 2019-1 con dos participaciones y el 2019-2 con tres. En total, la movilidad internacional tuvo seis solicitudes rechazadas del 2016-1 al 2019-2, de las cuales una fue por reprobación, un rechazo por parte de la unidad receptora, tres cancelaciones por parte de los estudiantes solicitantes y una carta de aceptación que fue recibida fuera de tiempo.

Los destinos internacionales que más escogieron los estudiantes durante los cuatro años de análisis fueron España (46.6\%), Chile (13.3\%), Colombia (13.3\%) y Argentina (13.3\%), aunque también hubo participaciones en países como Portugal (3.3\%), Brasil (1.7\%), Uruguay (1.7\%), Francia (1.7\%), Canadá (1.7\%), Alemania (1.7\%) y Perú (1.7\%). Las instituciones educativas que los alumnos seleccionaron frecuentemente fueron la Universidad de Salamanca, Universidad de Burgos, Universidad de Cádiz, Universidad de Grana- 
da, Escuela Universitaria Cardenal Cisneros de la Universidad de Alcalá y Universidad Rey Juan Carlos en España. También seleccionaron la Universidad de Valparaíso, Universidad de Santiago de Chile y la Universidad de Tarapacá en Chile; la Universidad de Boyacá, la Universidad Pontificia Bolivariana en Colombia; y la Universidad de Congreso de Mendoza en Argentina.

\section{Resultados de la aproximación cuantitativa}

Datos sociodemográficos

De acuerdo con los datos sobre los 21 participantes de la fase cuantitativa, el 52.4\% tenía entre 20 y 24 años. El $76.2 \%$ son mujeres y el $23.8 \%$ son hombres. La licenciatura que registró mayor participación fue Psicología (40\%), seguido de Ciencias de la Comunicación (30\%), Ciencias de la Educación (25\%) y Sociología (5\%). El 71.4\% realizó movilidad estudiantil en el extranjero, 60\% en España, 14.3\% en Chile, 7.15\% en Portugal, 7.15\% en Alemania y $7.15 \%$ en Francia. El 28.6\% realizó movilidad nacional, principalmente a la Ciudad de México (67\%) y la mayoría (52.4\%) mencionó que cursó alrededor de tres unidades de aprendizaje.

\section{Categoría movilidad estudiantil}

Se identificó satisfacción respecto a la experiencia de movilidad estudiantil (58.8\%). En la subcategoría Desarrollo Personal, se obtuvieron puntuaciones altas en aquellos ítems relacionados al desarrollo integral del estudiante dentro del nuevo entorno (94.7\%). En la subcategoría Desarrollo Educativo y Profesional, se obtuvo menor puntuación en los ítems con relación a la movilidad estudiantil y el desarrollo profesional del estudiante (4.8\%). En la subcategoría Percepción de la Unidad Receptora hubo mayor variedad de respuesta, obteniendo puntuación alta aquellos ítems sobre la calidad educativa de la unidad receptora (86.7\%) y respuestas negativas en los ítems relacionados a la similitud del plan de estudios de la unidad receptora y la de origen (13.3\%).

\section{Categoría idioma extranjero}

El 80\% de los participantes no necesitó aprender otro idioma para realizar su estancia, debido a que la mayoría de los participantes de movilidad internacional seleccionaron destinos de habla hispana como España, Argentina y Chile. Mientras que el resto de los participantes que realizaron su estancia en un país con idioma distinto al español, señalaron no presentar ningún problema (71.4\%), e incluso en algunos casos, el idioma materno fue de utilidad para comunicarse (76.2\%), además del idioma extranjero. 


\section{Categoría contexto cultural y académico}

En estas categorías se interpreta la adaptación y desenvolvimiento en un nuevo contexto sociocultural (57.1\%). Así, se asume que los participantes aprendieron sobre una nueva cultura a través de buenas experiencias sociales, que les permitieron adaptarse a un nuevo contexto sin experiencias negativas.

\section{Categoría procesos administrativos}

En esta categoría no queda del todo claro la postura de los alumnos respecto a los trámites administrativos como un problema en la relación de su institución receptora y la de origen, debido a la diversidad de sus respuestas entre neutras (37.8\%) y positivas (49.2\%).

\section{Resultados de la aproximación cualitativa}

La entrevista se realizó a cuatro egresados de la FCH. En primer lugar, se encuentra una egresada de Ciencias de la Educación, quien realizó su movilidad en España, en el Centro Universitario Cardenal Cisneros de la Universidad de Alcalá en el periodo 2017-1. La estudiante refirió que su tutor no le mencionó la opción de participar en un programa de movilidad estudiantil, así que su participación fue por cuenta propia. Respecto al apoyo, ella mencionó que no tuvo problemas con su tutor y que le ayudó en lo que necesitó en cuanto a trámites, pero no recibió otro tipo de apoyo ni monitoreo. Respecto a la orientación, la participante dijo que tuvo mayor acercamiento con su tutor, ya que le ayudó en la selección de unidades de aprendizaje de acuerdo a su plan de estudios original y respecto al seguimiento educativo, ella expresó que no recuerda ser informada por parte de su tutor acerca de las posibles desventajas de la movilidad.

La siguiente participante es egresada de Ciencias de la Comunicación y realizó su estancia en la Ciudad de México en el periodo 2017-1, asistiendo a la UNAM. La participante dijo que el tutor le ayudó en el proceso de movilidad desde la búsqueda de las convocatorias, ya que ella había mostrado interés previamente. Le apoyó en lo que necesitaba de los trámites administrativos, pero no recibió algún otro tipo de ayuda, además explicó que tuvo buena relación con él, pero fue complicado mantener comunicación. Ella explicó que para seleccionar los cursos recibió mayor orientación por parte de docentes que del tutor y, en cuanto al seguimiento, la participante mencionó que recibió el aviso de las posibles desventajas de la movilidad como la extensión de la trayectoria educativa o las consecuencias de la reprobación de materias. 
El tercer participante es egresado de Psicología y realizó su movilidad en el periodo 2018-2, en la Universidad Rey Juan Carlos en España. Él mencionó que su participación fue por iniciativa propia. En los trámites administrativos, el estudiante dijo que no tuvo ningún otro tipo de acercamiento con su tutor más que el necesario para la realización del proceso de movilidad. Respecto a la orientación, el tutor le explicó que requería equivalencia de materias que no formaban parte de su plan de estudios original y acerca del seguimiento dijo recibir información del tutor sobre el atraso de un semestre en materias obligatorias.

La cuarta participante es egresada de Psicología y participó en movilidad nacional en el periodo 2017-2 en la UNAM en la Ciudad de México. La participante mencionó que en ese semestre recibió cambio de tutor, situación que contribuyó al interés por participar en un programa de movilidad. En cuanto a la ayuda, ella dijo que recibió mucha de parte de su tutor al momento de seleccionar la institución educativa. Respecto a la orientación, ella destacó la participación del tutor al momento de seleccionar las unidades de aprendizaje, ya que realizaron una investigación minuciosa acerca del tipo de temáticas a abordar en las materias y de qué manera se pueden ligar al plan de estudios original. Por último, al hablar del seguimiento educativo, ella señaló que recibió la información necesaria acerca de las implicaciones de la participación en movilidad estudiantil.

Tomando en cuenta las experiencias de los cuatro participantes, se advierte que la mayoría de los tutores no motiva la participación de los alumnos en la movilidad estudiantil, no ayudan en la realización de los trámites administrativos, ni en la selección de unidades de aprendizaje, ni en el seguimiento durante el proceso de dicha movilidad para anticipar posibles dificultades. Pero, según una participante, uno de los tutores motiva, ayuda, orienta y da seguimiento oportuno. Así, se cuenta con dos tipos de tutores, uno que brinda soporte para coadyuvar el proceso de movilidad estudiantil y otro que no lo hace.

\section{Discusión}

La movilidad estudiantil ha sido valorada como una experiencia positiva por los alumnos de la FCH. De manera que participar en un programa educativo de corte sociocultural, en donde se mantiene contacto directo con la realidad, resulta mayormente enriquecedor al mejorar el desarrollo integral del estudiante.

Durante su estancia, los alumnos de la FCH destacaron haber tenido un gran desarrollo personal, en donde el realizar sus actividades cotidianas en un país distinto, o al menos un ambiente diferente al de origen, les generó mayor seguridad y desenvolvimiento 
personal. Según Fiocchi y Rojas (2015), la participación en movilidad proporciona a los jóvenes la oportunidad de independizarse y, de esta forma, madurar y aprender a convivir en sociedad de manera autónoma.

Al contrario del desarrollo personal, los alumnos de la FCH han expresado que la movilidad estudiantil no tuvo un gran impacto en cuanto a su desarrollo profesional, pues no fue de mucha utilidad al momento de integrarse al ámbito laboral, esto se debe posiblemente a las diferencias entre las cualidades requeridas por los empleadores de las empresas locales y aquellas requeridas en empresas más grandes, que buscan mayor competitividad entre los candidatos. Sin embargo, de acuerdo con Santiago et al. (2019), la movilidad representa una herramienta profesional significativa, pues la variedad de experiencias académico-profesionales suman gran valor al perfil profesional de cada estudiante, lo que representará una mejor presentación sobre su currículo, por lo tanto, es posible tener mejores oportunidades laborales, así como mayores atribuciones económicas.

Un factor determinante en el impacto de la movilidad estudiantil en el desarrollo profesional del estudiante es el destino en donde se realiza la estancia. Si bien, cualquier programa de movilidad podría ser bien visto por los empleadores, una estancia en el extranjero es más llamativa en el currículo, sin mencionar aquellos que participan en programas ofertados en países de habla no hispana, pues esto deja en evidencia las habilidades y aptitudes que el alumno tuvo que desarrollar con el fin de estudiar fuera del país, en donde se tiene como primer lugar el dominio de un idioma extranjero.

No obstante, el destino foráneo más recurrente entre los estudiantes de la FCH es España que, aunque es un país que pertenece a Europa y, por lo tanto, tiene una cultura distinta a la latinoamericana, en cuestiones comunicativas no representa gran obstáculo, pues de acuerdo con los estudiantes de la FCH, compartir el mismo idioma les facilitó la adaptación y la convivencia en la sociedad.

De igual manera, los estudiantes mencionaron que no eligieron un país en donde se hablara un idioma distinto al español, ya que no contaban con el nivel suficiente para ser capaces de realizar actividades cotidianas, por lo que prácticamente sería imposible estudiar en un idioma extranjero.

Sin embargo, esto no es de extrañar, pues en México la enseñanza de idiomas está muy por debajo del promedio, teniendo al inglés como el segundo idioma a enseñar en el sistema educativo y, aun así, el país está situado en el puesto 82 de 100 en un estudio mundial sobre el conocimiento del idioma inglés (Education First, 2020), por lo que solamente alrededor del 5\% de los mexicanos dominan el inglés de manera fluida (Instituto Mexicano para la Competitividad, 2015). 
La adaptación a un nuevo estilo de enseñanza es uno de los factores que comúnmente mencionan los estudiantes de la FCH, pues incluso al realizar estancias en instituciones educativas nacionales han resaltado las diferencias entre el tipo de ambiente escolar que se vive en dichas instituciones en comparación a la UABC.

Entre las diferencias mayormente mencionadas está el tipo de estudiantes con los que se ven caracterizadas las universidades receptoras. Estos estudiantes se desenvuelven en un ambiente educativo bastante competitivo, pues estas instituciones suelen tener grupos de estudio más grandes de los que se acostumbran en la UABC y una carga y trayectoria académica más extensa, por lo que los alumnos necesitan estar a la vanguardia en cuanto al contenido académico, pues los docentes exigen el aprendizaje de los contenidos a una mayor velocidad de lo que los alumnos de la FCH están acostumbrados.

Un punto a destacar es la localización de las instituciones que eligen los estudiantes para realizar sus estudios de movilidad, ya que estas suelen estar situadas en ciudades céntricas, es decir, ciudades capitales o de las más grandes del país, por lo tanto, la concentración de estudiantes y la calidad educativa usualmente se cree que es mayor, por lo que los estudiantes prefieren seleccionar este tipo de universidades de prestigio, lo cual puede generar peso en su trayectoria académica (Santiago et al., 2019).

Sin embargo, el participar en una universidad reconocida no es de gran beneficio académico si las unidades de aprendizaje ofertadas no tienen similitud a los planes de estudios de la FCH. Entonces, el estudiante se enfrenta a una serie de complicaciones que fácilmente puede ser evitada, si se recibe una orientación educativa acertada por parte de agentes educativos tales como el tutor, los docentes y los coordinadores de los departamentos académicos correspondientes.

\section{Conclusiones}

La movilidad estudiantil en la FCH ha ido en descenso con el paso de los semestres, sin contar la situación sanitaria que se está viviendo por la COVID-19, que ha paralizado estas actividades desde principios del año 2020, lo cual ha atrasado o cancelado en su totalidad las participaciones de los alumnos en los programas de movilidad ofertados en cada periodo escolar.

Sin embargo, el índice de participantes de movilidad nacional e internacional desde el periodo 2016-1 al 2019-2 ha disminuido casi en un 90\%, sin mencionar que el flujo de los estudiantes participantes se concentra principalmente en dos de las cinco licenciatu- 
ras ofertadas en la $\mathrm{FCH}$, lo que deja en duda el manejo de esta estrategia educativa de manera institucional y su promoción al cuerpo estudiantil.

A partir de los posibles factores obtenidos en la aproximación cuantitativa, que pudieran generar una problemática durante el proceso de movilidad, no se identificó que estos mismos factores sean los posibles culpables de la disminución en el índice de participación estudiantil en programas de movilidad, pero se observó en los resultados de la aproximación cualitativa que el tutor no participa en la promoción de las convocatorias que son difundidas por el área de Cooperación Internacional e Intercambio de la FCH, pues los alumnos que han participado en movilidad comenzaron el proceso por iniciativa propia.

Sería de gran utilidad realizar una investigación de mayor profundidad sobre las causas específicas que presentan los estudiantes de la FCH y por lo que no les permiten participar en movilidad; además, tomar en cuenta no solamente la experiencia de estudiantes que ya participaron, sino también de aquellos estudiantes que no lo han hecho.

En suma, es necesario realizar un plan de acción educativo que atienda el área de oportunidad que se presenta en cuanto a la relación tutor-tutorado, que permita generar mayor comunicación en ambas partes, así como facilitar herramientas a los tutores para que conozcan el proceso completo de movilidad estudiantil y ofrezcan la oportunidad a los estudiantes para que puedan enriquecer su trayectoria académica de la mejor manera posible. 


\section{Referencias}

Aguirre, E. L., Herrera, B. R., Vargas, I., Ramírez, N. L., Aguilar, L., Arbuto, M. B., \& Guevara, R. (2017). La tutoría como proceso que fortalece el desarrollo y crecimiento personal del alumno. Revista Investigación en Educación Médica, 7(25), 3-9. http://riem. facmed.unam.mx/sites/all/archivos/A7Num25/02_AO_TUTORIA.pdf

Asociación Nacional de Universidades e Instituciones de Educación Superior. (2001). Programas institucionales de tutoría. http://www.uimqroo.edu.mx/Documentos/ Tutorias/MANUALTUTORIAS-ANUIES.pdf

Asociación Nacional de Universidades e Instituciones de Educación Superior. (2012). Movilidad Estudiantil. http://www.anuies.mx/programas-y-proyectos/cooperacionacademica-nacional-e-internacional/cooperacion-academica-internacional/ movilidad-estudiantil

Cueva, A., Van Hoof, H., Han, R., \& Eljuri, M. I. (2015). Las experiencias con programas de intercambio internacionales en la Universidad de Cuenca, Ecuador: Percepciones de participantes. Revista semestral de la DIUC, 6(2), 47-61. https://publicaciones. ucuenca.edu.ec/ojs/index.php/maskana/article/view/488

De la Cruz, G. (2017). Tutoría en educación superior: Análisis desde diferentes corrientes psicológicas e implicaciones prácticas. CPU-e, Revista de Investigación Educativa, 25, 34-59. https://doi.org/10.25009/cpue.v0i25.2537

Education First. (2020). Índice del dominio del inglés de EF. https://www.ef.com.mx/ assetscdn/WIBIwq6RdJvcD9bc8RMd/legacy/__/ /media/centralefcom/epi/ downloads/full-reports/v10/ef-epi-2020-spanish-latam.pdf

Fernández, C., Carreño, M. V., Cea, J., Santander, P., \& Yáñez, D. (2016). Motivaciones de Intercambio en Estudiantes Universitarios. Revista Global de Negocios, 4(4), 1-10. www.theibfr2.com/RePEc/ibf/rgnego/rgn-v4n4-2016/RGN-V4N4-2016-1.pdf

Fiocchi, M. C., \& Rojas, H. (2015). La experiencia de intercambio estudiantil en el extranjero: Análisis de las percepciones de chilenos que en su adolescencia participaron en programas de youth for understanding. Última década, 23(43), 207-233. https://doi. org/10.4067/S0718-22362015000200008

Fresán, M. (2009). Impacto del programa de movilidad académica en la formación integral de los alumnos. Universidad Autónoma Metropolitana. Revista de la Educación Superior, 38(151), 141-160. http://publicaciones.anuies.mx/pdfs/revista/ Revista151_S4A1ES.pdf 
García, J. (2013). Movilidad estudiantil internacional y cooperación educativa en el nivel superior de educación. Revista Iberoamericana de Educación, (61), 59-76. https:// rieoei.org/historico/documentos/rie61a04.pdf

Instituto Mexicano para la Competitividad. (2015). Inglés es posible. Propuesta de una agenda nacional. https://imco.org.mx/ingles-es-posible-propuesta-de-unaagenda-nacional/

López, M. (2010). El intercambio estudiantil como recurso promotor del desarrollo humano (Tesis de maestría). Universidad Iberoamericana, México. http://www.bib.uia.mx/ tesis/pdf/015328/015328.pdf

Maldonado, A., Bustos, M., Camacho, M., Ibarra, B., \& Rodríguez, A. (2017). Movilidad estudiantil en México hoy: preguntas y respuestas a partir de Patlani-ANUIES. XIV Congreso Nacional de Investigación Educativa-COMIE, San Luis Potosí, México. http:// www.comie.org.mx/congreso/memoriaelectronica/v14/doc/simposios/2660.pdf

Narro, J., \& Arredondo, M. (2013). La tutoría: Un proceso fundamental en la formación de los estudiantes universitarios. Perfiles educativos, 35(141), 132-151.

Pérez, A. (2004). La participación en la ayuda oficial al desarrollo de la Unión Europea: un estudio para Aragón. Prensas Universitarias de Zaragoza.

Ponce, S., Aceves, Y., \& Serna, A. (2017). Prácticas de la tutoría académica en una escuela normal de México. XIV Congreso Nacional de Investigación Educativa, COMIE. San Luis Potosí, México. https://www.comie.org.mx/congreso/memoriaelectronica/ v14/doc/2189.pdf

Ramírez, L. A., Pérez, C. J., \& Lara, R. S. (2017). Panorama del sistema educativo mexicano en la enseñanza del idioma inglés como segunda lengua. Revista de Educación, Cooperación y Bienestar Social, 12, 15-21. https://revistadecooperacion.com/ numero12/012-02.pdf

Rivera, A. (2016). Factores que influyen en el intercambio académico de los estudiantes universitarios. Revista STATUS, 1(2) 21-38. http://revista-status.uanl.mx/index.php/ status/article/view/17

Rojo, N. (2015). Análisis de necesidades de los estudiantes de movilidad internacional y diseño de acciones de mentoría y acogida. Proyectos de Innovación y Mejora de la Calidad Docente. Universidad Complutense, Madrid. https://eprints.ucm.es/34850/4/ Informe\%20Final\%20PIMCD\%20Mentoring\%202014_No95.pdf

Rodríguez, S. (Coord.). (2008). Manual de tutoría universitaria (2da). ICE-Octaedro. 
Rosas, L. M. (2014). La movilidad estudiantil una estrategia de la Educación Superior: Experiencia de estudiantes de intercambio académico en una Universidad canadiense. https://www.academia.edu/16717489/La_movilidad_estudiantil_una_estrategia_ de_la_Educación_Superior_Experiencia_de_estudiantes_de_intercambio_

Santiago, A., García, J. F., \& Ramón, P. (2019). Movilidad estudiantil...nuevas experiencias académicas, otros significados! Atenas, 1(45), 36-50. https://www.redalyc.org/ jatsRepo/4780/478058273003/html/index.html

Suárez, S. (2012). Movilidad estudiantil en México. Revista electrónica del Programa de Estudios Universitarios Comparados.

Tsokaktsidu, D. (2010). Identificación de las dificultades de los estudiantes y de los profesores en las clases de traducción. Revista Puentes, 1(9), 29-36. http://wpd.ugr. es/ greti/revista-puentes/pub9/05-Dimitra.pdf

Tuning América Latina. (2011). Proyecto Tuning. http://www.tuningal.org/

Universidad Autónoma de Baja California. (2012a). Manual de tutorías de la FCH: Fundamentación y operatividad. Facultad de Ciencias Humanas (FCH). Comité de Tutorías FCH. UABC.

Universidad Autónoma de Baja California. (2012b). Acuerdo que establece los lineamientos generales para la operación de las tutorías académicas. Gaceta Universitaria, (282). http://www.uabc.mx/formacionbasica/documentos/Acuerdo_Tutorias.pdf

Universidad Autónoma de Baja California. (2012c). Lineamientos generales para la operación de las tutorías académicas de la UABC. http://sriagral.uabc.mx/Externos/Acuerdos/ index.html

Universidad Autónoma de Baja California. (2013). Modelo Educativo de la UABC. Cuadernos de Planeación y Desarrollo Institucional. Universidad Autónoma de Baja California.

Universidad Autónoma de Baja California. (2014a). Manual de usuario: Responsable de tutores. Coordinación de Formación Básica. Sistema Institucional de Tutorías. UABC. Universidad Autónoma de Baja California. (2014b). Manual de usuario: Tutor. Coordinación de Formación Básica. Sistema Institucional de Tutorías. UABC.

Universidad Autónoma de Baja California. (2014c). Manual de usuario: Tutorado. Coordinación de Formación Básica. Sistema Institucional de Tutorías. UABC.

Universidad de Salamanca. (2018). ALFA. http://rel-int.usal.es/es/proyectos/alfa Universidad de San Buenaventura Medellín. (2017) ¿Qué es movilidad académica? https:// www.usbmed.edu.co/internacionalizacion/movilidad-academica/que-es 
Villafañe, A., Irizarry, C., \& Vázquez, R. (2011). Necesidades académicas, personales, sociales y vocacionales de estudiantes internacionales e intercambio en la Universidad de Puerto Rico, Recinto de Río Piedras. Revista Electrónica Educare, 15(2), 185-204. https://www.redalyc.org/pdf/1941/194121566013.pdf

Zúñiga, M. (2010). La movilidad internacional de estudiantes universitarios neoleoneses. Un recuento de las dificultades y las ganancias. https://core.ac.uk/download/ pdf/76598536.pdf 


\section{Capítulo 5}

La consulta de empleadores en los procesos de acreditación

de programas de estudio de nivel superior

Alonso Vega Zamorano, Evangelina López Ramírez

y Jorge Eduardo Martínez Iñiguez

La acreditación en la educación superior se ha considerado como un mecanismo para dar cuenta de la calidad del quehacer educativo por parte de las Instituciones de Educación Superior (IES) (Buendía, 2013; Rubio, 2007).

De acuerdo con Días (2007), la relevancia de la acreditación de la educación superior en los países de Latinoamérica se debe al aumento exponencial de matrículas e instituciones, la ampliación del sector privado y de sus lógicas, la diferenciación en los modelos de desarrollo organizacional, la diversificación de funciones, los cambios en el mundo del trabajo, el crecimiento de ofertas de servicios educativos desde el extranjero, el incremento en modalidades virtuales y a distancia y el surgimiento de nuevos tipos de proveedores, estimulando en los países la creación de sistemas de evaluación y acreditación.

En este sentido, los procesos de evaluación y acreditación surgen como auxiliares para asegurar que las IES, tanto públicas como privadas, cumplan los parámetros de calidad necesarios (Elizondo et al., 2014).

De acuerdo con Pires y Lemaitre (2008), en términos del fortalecimiento de la enseñanza de la educación superior, la importancia de los procesos de evaluación y acreditación recae en cinco factores: (1) la formulación e implementación de políticas públicas acorde a las necesidades de la educación superior; (2) el aumento de la calidad de los sistemas y programas de educación superior nacionales y su reconocimiento social, de manera interna como externa; (3) las políticas que consideran el incremento de la calidad 
en la producción de conocimiento científico; (4) la posibilidad de crear parámetros que permitan el reconocimiento de títulos, acreditaciones y procesos de equivalencia; y (5) la activación de programas de movilidad docente, de estudiantes y profesionales.

Perspectivas y retos de la acreditación de la educación superior en México La acreditación de la educación superior ha ganado terreno en la agenda política en México, debido a que se ha reconocido su importancia para la generación de mecanismos confiables que rindan cuenta de la calidad de las instituciones educativas (Rubio, 2007). Sin embargo, como mencionó De la Garza (2013), a pesar de los avances, se requiere continuar con los esfuerzos para lograr la generalización de la evaluación externa y la acreditación de los programas, tanto en instituciones públicas como particulares que conforman el sistema de educación superior nacional. Además, se requiere la obligatoriedad de estos procesos de evaluación y acreditación para hacer realidad la equidad de la educación superior, y hacer de conocimiento público los resultados obtenidos (Asociación Nacional de Universidades e Instituciones de Educación Superior [ANUIES], 2018; Organización para la Cooperación y el Desarrollo Económico [OCDE], 2019).

Asimismo, según Martínez (2017), existen tensiones entre la tarea política y los elementos técnicos construidos y establecidos en un marco general para la acreditación de programas académicos de nivel superior, ya que están en constante intercambio de intereses diversos actores, entre ellos, el Estado, asociaciones no gubernamentales como la ANUIES, organizaciones particulares, los propios intereses particulares de cada institución y las demandas globales, provocando una tensión entre la finalidad real de la acreditación.

Las políticas y acciones deben orientarse para revalorar la misión de las IES, afirmar la autonomía, la diversidad y la promoción de valores democráticos. La evaluación debe ser entendida como una política pública del Estado para garantizar, con calidad académica y relevancia social, la respuesta a la gran demanda de aumento de la cobertura de la educación superior. (De la Garza, 2013, p.43)

\section{Empleabilidad y educación superior}

En la actualidad, el debate en torno a los fines de la educación superior supone dos escenarios: el primero, reconoce a la educación superior como un agente primordial para el desarrollo económico de toda nación (Moreno-Brid \& Ruíz-Napoles, 2010) y, por otro lado, 
un factor importante en la formación de profesionales que requiere el mercado laboral, por lo cual, la empleabilidad supone un elemento básico de la función social de las universidades (Semchenko, 2003).

Bautista-Cero (2014) afirmó que los cambios surgidos en el mercado laboral y el campo económico han afectado directamente a las universidades, ya que estas tienen dentro de sus objetivos el formar profesionistas que puedan cumplir con las necesidades del campo ocupacional. Reforzando esta idea, Díaz (2020) afirma que las IES en México:

tienen la responsabilidad de formar personas capaces de contribuir al desarrollo económico y social del país. Esto implica que sus egresados cuenten con las competencias que demanda el mercado laboral. Cuando es así, se cumplen dos objetivos. Primero, que los nuevos profesionistas se coloquen en empleos y permanezcan en ellos más fácilmente. Segundo, que los empresarios se alleguen nuevos talentos que promuevan la competitividad y sustentabilidad de sus empresas. (párr.1)

En este sentido, es un proceso de intercambio donde ambas partes se benefician. Un estudio realizado en México, entre la población de egresados de IES, sugiere que aquellos graduados de universidades particulares logran colocarse en mejores empleos que los egresados de las IES públicas (Murillo \& Montaño, 2018). Esto a causa de una desarticulación entre las IES y las empresas, que se ve reflejada en la incongruencia entre las competencias que desarrollan los estudiantes y las necesidades de las empresas, así como de las dificultades que enfrentan los recién egresados para emplearse (Díaz, 2020). Por lo tanto, es necesario fomentar la empleabilidad de los estudiantes universitarios desde la reestructuración de la estrategia educativa, enfocándola en el desarrollo de conocimientos y habilidades que les faciliten emplearse y permanecer empleados.

Bautista-Cerro (2014) finalizó su estudio afianzando a la empleabilidad como condición necesaria de las universidades, debido a que la principal motivación de los estudiantes para matricularse en una IES es mejorar sus opciones de elegir un empleo deseado. Sin embargo, la empleabilidad debe ser analizada ampliamente para procurar el beneficio empresarial, social y personal, ya que adoptar el concepto amplio de empleabilidad supone para la universidad el formar individuos responsables, justos y capaces de integrar la dimensión ética en la toma de decisiones. En este sentido, las IES son consideradas fundamentales en las estrategias de desarrollo de las empresas en el país. Por lo tanto, es 
necesario un trabajo conjunto para fomentar las competencias para la empleabilidad de los egresados.

Por esta misma línea, Álvarez y Romero (2015) afirmaron que la educación superior no puede permanecer ajena a los problemas de la sociedad y, por lo tanto, del mercado laboral. La situación que afrontan las IES afecta directamente a los jóvenes, esto se refleja en las notables deficiencias existentes en la vinculación entre las IES y las fuentes de empleo para los egresados.

Por otra parte, la Organización Internacional del Trabajo (OIT, 2004) reafirmó la idea de que la educación superior ya no garantiza la empleabilidad y el acceso al mercado laboral se ha desvanecido. Por lo tanto, "Existe una gran contradicción entre una población juvenil más educada y la disminución de probabilidades de inserción en el mundo del trabajo" (Álvarez \& Romero, 2015, p.5).

Por su parte, Díaz (2020) señaló que, para lograr la vinculación entre la educación superior y el sector empresarial, es necesario que las IES establezcan indicadores de efectividad educativa, alineados con sus indicadores de capacidad educativa, y que las empresas sean partícipes de la definición, evaluación y cumplimiento de estos indicadores.

\section{La vinculación universidad-empresa}

Álvarez y Romero (2015) sustentaron la necesidad de realizar estudios que den cuenta de "la demanda de profesionales para que su oferta de estudios sea pertinente, deben estrecharse los vínculos entre las universidades y el mercado laboral no sólo en el proceso de formación sino también en la inserción laboral" (p.9).

No obstante, Álvarez y Romero (2015) señalaron que las universidades se enfrentan a limitaciones para realizar estos estudios debido a ciertos factores:

- Dificultad para desarrollar el seguimiento a los graduados [...] ello distorsiona la información sobre la situación laboral real de los graduados. [...]

- [Los estudios existentes] se basan en la perspectiva de los graduados y no se analiza el proceso de vinculación entre la universidad y el mundo del trabajo.

- No siempre se incluye el análisis de la realidad socioeconómica del país y territorios donde deban emplearse los graduados.

- [Los] cuestionarios no consiguen un equilibrio al tratar por un lado las variables relativas a todas las instituciones de educación superior y todas las áreas profesio- 
nales, y por otro lado las variables concretas relacionadas con el perfil específico de cada [plan de estudio].

- Se debe tener en cuenta que el mercado laboral puede variar rápidamente. (p.10)

Por lo tanto, se deben de mantener procesos continuos que permitan la vinculación de las instituciones de educación superior con el mercado laboral, de esta forma se podrán atender las necesidades sociales y proporcionar a los jóvenes una mayor probabilidad de empleo al egreso (Camarena \& Velarde, 2009; Mungaray, 2001).

Por su parte, Díaz (2020) afirmó que para lograr la vinculación de las instituciones de educación superior se deben de cumplir cuatro condiciones: (1) los directores de las IES deben de mantener una oficina de servicios para el desarrollo profesional, las actividades de esta oficina incluyen investigaciones enfocadas en egresados, empleadores y dirigentes de industria; (2) la participación de empleadores en las actividades de acopio de información de las IES sobre el desempeño de los egresados; (3) la industria y el gobierno deben facilitar recursos para que las IES Ileven a cabo estos procesos de investigación; y (4) la participación de egresados en el proceso de retroalimentación a las organizaciones que contribuyeron en su formación.

\section{Planteamiento del problema}

La educación superior en el contexto internacional se ha concebido como herramienta fundamental para el desarrollo de las naciones (Navarro, 2014). Es así, que la Organización de las Naciones Unidas para la Educación, la Ciencia y la Cultura (UNESCO, 2019), la reconoce como un elemento fundamental para erradicar la pobreza, potencializar la salud y el bienestar, alcanzar la igualdad de género, asegurar un trabajo digno y crecimiento económico, formar para la producción y consumo responsable, permitir desarrollar acciones por el clima, así como abrir paso a la paz y a la justicia. Asimismo, Fernández (2017) reconoció a la educación como un bien de carácter estratégico para las naciones, ya que esta es el vínculo indisoluble entre la generación de capital humano altamente capacitado y la producción y difusión de conocimiento, que favorece la conformación de sociedades más justas y económicamente más competitivas.

Si bien la educación superior tiene dentro de sus fines tener la capacidad de adaptarse a las necesidades contextuales e impactar de manera positiva a la sociedad, a través de la vinculación sociedad-escuela, no podemos deslindar de las IES la importancia de formular respuesta a las exigencias del campo ocupacional, ya que estas prácticas abren 
paso a la posibilidad del crecimiento y desarrollo económico del Estado. Es decir, debe de buscarse una paridad entre acciones que beneficien a la comunidad y, a su vez, mantener una estrecha relación con las necesidades del campo ocupacional.

De acuerdo con Thoilliez (2014), estos cambios en los fines de la educación superior se ven mayormente provocados por el contexto económico y político actual, señala que los cambios trascendentes en la educación superior se deben a una trasformación sin precedentes y que viene provocada por dos factores: por un lado, la internacionalización de la agenda política de la educación superior y, por el otro, el giro economicista de los debates educativos y políticos sobre la universidad (p.80).

Por ello, es impensable asumir un sistema de educación superior estático, ajeno a los cambios en la política internacional y sin la capacidad de adaptarse a las exigencias del contexto político, económico y social (Vázquez, 2015).

Como en la mayoría de los países de la OCDE, en México, el poseer un título de educación superior permite obtener mejores resultados en el mercado laboral, los egresados de educación superior tienen una mayor participación en el mercado del trabajo, disfrutan de mejores resultados en materia de empleo y perciben salarios considerablemente superiores a aquellas personas que no lo tienen. No obstante, a raíz de los cambios en el mercado de trabajo, los jóvenes con estudios superiores enfrentan dos problemas persistentes que indican un uso ineficiente de sus competencias: por un lado, la informalidad de los empleos y, por el otro, la sobrecualificación (OCDE, 2019).

En el documento Educación Superior en México. Resultados y Relevancia para el Mercado Laboral, emitido por la Organización para la Cooperación y el Desarrollo Económico (OECD, 2019), se indicó que:

En México, la educación superior se debe alinear mejor con las necesidades cambiantes de la economía. Casi la mitad de los empleadores alertan de una falta de competencias en el sector y consideran que la educación y formación de los solicitantes de empleo no es adecuada para sus necesidades. (p.3)

De igual forma, a pesar de la existencia de "políticas públicas e iniciativas institucionales para mejorar la relevancia y los resultados del mercado laboral, [...] carecen de un marco cohesionador y de mecanismos eficaces de evaluación de su impacto" (OCDE, 2019, p.3), así que se convierte en una necesidad desarrollar y coordinar la información sobre la educación superior y sus resultados en el mercado laboral. 
Aunado a esto, en México, el empleo informal aumentó del 26.9\% en el cuarto trimestre del 2010 hasta el 27.5\% en el primer trimestre del 2020; el empleo en ocupaciones laborales que no requieren un título de educación superior aumentó del 44\% en 2010 al 46\% en 2020 (Instituto Nacional de Estadística y Geografía [INEGI], 2021).

En términos globales, el $46 \%$ de los empleadores mexicanos declaraban la existencia de una falta de competencias en su sector, y la mayoría (83\%) consideraba que la educación y la formación de los solicitantes de empleo era inapropiada para su sector (Hays, 2018). (OECD, 2019, p.12)

Una fortaleza del mercado laboral en México es la presencia de una fuerza de trabajo joven, pero, a pesar de los avances en educación superior, el país aún carece de talento especializado, ya que existe evidencia de que los egresados de las universidades mexicanas no están utilizando sus competencias de forma efectiva, por lo tanto, la OCDE (2019) sugirió la existencia de un desajuste entre las competencias de los egresados y las necesidades del mercado laboral.

En torno a esto, la OCDE recomienda desarrollar una estrategia nacional sobre los resultados de la educación superior y la relevancia para el mercado laboral. Esta estrategia debe de considerar los siguientes objetivos: (1) concientizar sobre la importancia de mejorar los resultados y la relevancia de la educación superior en México para el mercado laboral; (2) proporcionar un marco para un conjunto de iniciativas políticas que garanticen la adopción de un enfoque cohesivo y sistemático para mejorar los resultados y la relevancia de la educación superior para el mercado laboral; (3) garantizar la coordinación eficaz entre niveles de gobierno, agencias y otras organizaciones a la hora de implementar iniciativas políticas; (4) ofrecer un mecanismo para monitorear y evaluar la eficacia de las iniciativas políticas (OCDE, 2019).

En cuanto al fortalecimiento de las estrategias para el aseguramiento de la calidad de la educación superior integrando la relevancia para el mercado laboral en estos mecanismos, se debe "Garantizar que los mecanismos de aseguramiento de la calidad incluyan criterios sobre la relevancia para el mercado laboral y la vinculación con agentes sociales" (OCDE, 2019, p.18), es decir:

- Incluir la relevancia para el mercado laboral y la vinculación con los agentes sociales como criterios en los procesos de acreditación de programas. 
- Promover que las instituciones privadas de educación superior incluyan estos criterios en la acreditación institucional [...] (OCDE, 2019, p.18)

Entonces, es de suma importancia reafirmar la relevancia de los factores e índices de empleabilidad de los egresados en los mecanismos de aseguramiento de la calidad de los programas de educación superior, así también se requiere reforzar esfuerzos en la exploración de las necesidades del campo ocupacional, con estrategias de investigación y seguimiento a egresados.

Por ello, el objetivo de esta exploración metodológica es analizar los procesos institucionales existentes para la vinculación del plan de estudios de la Licenciatura en Ciencias de la Educación con el campo ocupacional, así como identificar las metodologías implementadas por la institución para la obtención de información con relación a la situación del campo ocupacional y su vinculación con el plan de estudios.

\section{Justificación}

La educación superior en México se ha moldeado a las exigencias y recomendaciones de organismos internacionales. La OCDE (2019) como principal propulsor de las políticas públicas en nuestro país, señaló que "No existe tradición de vincularse con empleadores y otros agentes sociales para garantizar que la prestación de los programas satisface las necesidades del mercado laboral" (p.4).

Asimismo, menciona que "No existe ningún enfoque estratégico para mejorar la relevancia de la educación superior para el mercado laboral, al tiempo que los estudiantes, las instituciones de educación superior y los empleadores en gran parte desconocen la importancia de este tema" (OCDE, 2019, p.13). Como recomendaciones propone:

- Concienciar sobre la importancia de mejorar los resultados y la relevancia de la educación superior de México para el mercado laboral. (p.14)

- Proporcionar un marco para un conjunto de iniciativas políticas que garanticen la adopción de un enfoque cohesivo y sistemático para mejorar los resultados y la relevancia de la educación superior para el mercado laboral. (p.14)

- Fortalecer el sistema de aseguramiento de la calidad para ayudar a garantizar que los estudiantes desarrollen conocimientos y competencias relevantes para el mercado laboral. [Buscando] adoptar medidas para mejorar la calidad de la educación superior mediante una acreditación institucional y de los programas fortalecidos. (p.17) 
En México, los fines de la educación superior en el Plan Nacional de Desarrollo 20192024 se ven reflejados en el segundo eje general, Bienestar, en dicho apartado el objetivo específico 2.2 indica que busca "garantizar el derecho a la educación laica, gratuita, incluyente, pertinente y de calidad en todos los tipos, niveles y modalidades del Sistema Educativo Nacional y para todas las personas" (Universidad de Guadalajara, 2021).

En la educación superior se identifican tres grandes retos: el primero es la mejora de la calidad y la pertinencia de la oferta respecto a las necesidades sociales y económicas; en segundo plano, la articulación eficiente entre niveles, tipos y modalidades educativas; y, por último, las necesidades de financiamiento oportuno, suficiente y con la certidumbre requerida para sustentar estrategias con visión de largo plazo (Faustino, 2019).

Por esta misma línea, el Programa de Educación Superior de Baja California 2015-2019 plantea, como prioridades para la educación superior, asegurar la calidad en la oferta del nivel e incrementar la vinculación de las IES con el sector productivo y social. Como políticas para lograr lo anterior, plantea impulsar la acreditación de programas educativos por organismos externos reconocidos a nivel nacional e internacional, promover la implementación de nuevos planes y programas de estudio pertinentes, conforme a las necesidades del contexto regional, así como asegurar la vinculación con los sectores social y productivo (Sistema Educativo Estatal, 2015, p.71).

Por su parte, la Universidad Autónoma de Baja California (UABC, 2019), en su Plan de Desarrollo Institucional 2019-2023 reconoce la necesidad de asegurar la pertinencia de las modalidades y de los contenidos de los programas educativos con relación a la respuesta brindada a las necesidades del entorno regional, nacional e internacional.

Considerando lo anterior, en la política de Extensión-Vinculación, la UABC (2019) propone consolidar los esquemas de vinculación institucional con los sectores público, privado y social, fortaleciendo la inserción laboral de sus egresados a través de la vinculación de la universidad con su entorno, así como la promoción del desarrollo de esquemas eficaces para el diálogo y la vinculación con agentes y representantes de los diversos sectores de la sociedad.

En particular, la Facultad de Ciencias Humanas, en su Plan de Desarrollo 2018-2022 en el apartado de "Diagnóstico: Debilidades", enfatiza la necesidad de una mayor vinculación con egresados, asociaciones de profesionistas y bolsa de trabajo, así como la insuficiencia del seguimiento de egresados para la verificación del impacto social y económico de las profesiones (UABC, 2018). 
Por consiguiente, en la política de Calidad y pertinencia de la oferta educativa, establecida en el Plan de Desarrollo 2018-2022, señala como estrategia de aseguramiento del reconocimiento a la calidad de los programas de licenciatura y posgrado el someter a evaluación externa los cinco programas educativos para lograr el reconocimiento de calidad por parte de los organismos acreditadores. Asimismo, en la política Extensión-vinculación, se plantea como estrategia asegurar la pertinencia y la vinculación de la Facultad de Ciencias Humanas, sugiriendo realizar reuniones con egresados, empleadores, colegios y asociaciones para detectar necesidades de especialización o actualización.

En el debate sobre la relación entre mercado de trabajo y universidad se ha cuestionado en qué medida esta debe adaptarse al primero, toda vez que el crecimiento en el número de egresados limita las posibilidades de acceder a un trabajo digno. Por ende, es importante reconocer la existencia de diversos mercados y que cada uno de estos posee intereses y deseos distintos (De Vries, 2015). (UABC, 2019, p.22)

Al respecto, se debe destacar la importancia de contar con mecanismos eficientes que permitan realizar una exploración amplia a las necesidades de los empleadores con relación a las competencias de los egresados, considerando las diferentes modalidades de empleo, buscando obtener información útil para el fortalecimiento de la oferta curricular y permitir ampliar las posibilidades de empleabilidad de los egresados universitarios.

\section{Método}

Esta investigación parte de un diagnóstico cualitativo, el cual de acuerdo con McMillan y Schumacher (2005) consiste en estudiar el fenómeno a profundidad a través de la exploración directa con sujetos involucrados en el fenómeno en cuestión. Se eligió este método para analizar los procesos institucionales existentes para la vinculación del plan de estudios de la Licenciatura en Ciencias de la Educación con los empleadores en el proceso de evaluación y acreditación.

\section{Participantes}

La selección de los participantes se llevó a cabo utilizando la técnica de muestreo por juicio que, según Mejía (2014), es un procedimiento que consiste en la selección de las unidades a partir de criterios conceptuales, de acuerdo con los principios de las variables que delimitan la composición estructural de la muestra. Así, este procedimiento consiste 
en una aproximación conceptual al universo de estudio, a través de la definición precisa de las características relevantes que determinan los niveles estructurales.

Asimismo, se eligieron informantes clave; estos son aquellas personas que, por sus experiencias, pueden guiar al investigador en el proceso de investigación, ya que estos tienen una relación directa con el fenómeno en cuestión, además, estos pueden abrir acceso al investigador a otras personas y a nuevos escenarios (Taylor \& Bogdan,1996).

De acuerdo con esto, los participantes seleccionados fueron: el jefe del Departamento de Diseño Curricular de la Universidad Autónoma de Baja California (UABC), el Coordinador de la Licenciatura en Ciencias de la Educación de la Facultad de Ciencias Humanas (FCH) y un docente investigador de la Facultad de Ciencias Humanas, experto en procesos de evaluación curricular.

\section{Procedimiento}

La técnica utilizada para la recolección de los datos fue la entrevista a profundidad, la cual de acuerdo con Ruiz (2012) no es más que una conversación profesional con una o varias personas para un estudio analítico de investigación, que también pueden contribuir en los diagnósticos o tratamientos sociales.

\section{Tabla 1}

Distribución de la guía de entrevista de acuerdo con las variables

\begin{tabular}{|c|c|c|}
\hline Variable & $\begin{array}{l}\text { Número de } \\
\text { preguntas }\end{array}$ & Preguntas \\
\hline Empleadores & 2 & $\begin{array}{l}\text { - ¿Qué atributos debe tener un empleador para ser considerado } \\
\text { como fuente apropiada para ser consultado en el proceso de } \\
\text { evaluar o acreditar un programa educativo? } \\
\text { - ¿Se consideran todas las líneas terminales del plan de estudios } \\
\text { para seleccionar empleadores para llevar a cabo el proceso de } \\
\text { evaluación o acreditación del plan de estudios? }\end{array}$ \\
\hline Acreditación & 2 & $\begin{array}{l}\text { - ¿Cuál es la trascendencia de la información que deriva de la con- } \\
\text { sulta a empleadores en la acreditación de un plan de estudio? } \\
\text { ¿Se consideran todas las líneas terminales del plan de estudios } \\
\text { para seleccionar empleadores para llevar a cabo el proceso de } \\
\text { evaluación o acreditación del plan de estudios? }\end{array}$ \\
\hline $\begin{array}{l}\text { Reestructura- } \\
\text { ción curricular }\end{array}$ & 1 & $\begin{array}{l}\text { - ¿Cuál es la trascendencia de la información que deriva de la con- } \\
\text { sulta a empleadores en la reestructuración o actualización de un } \\
\text { plan de estudio? }\end{array}$ \\
\hline
\end{tabular}




\begin{tabular}{|c|c|c|}
\hline Variable & $\begin{array}{l}\text { Número de } \\
\text { preguntas }\end{array}$ & Preguntas \\
\hline $\begin{array}{l}\text { Procesos } \\
\text { institucionales }\end{array}$ & 8 & $\begin{array}{l}\text { - ¿Cuáles son las principales problemáticas o deficiencias que } \\
\text { usted ha detectado en los procedimientos metodológicos relacio- } \\
\text { nados con la categoría de "consulta a empleadores" cuando se } \\
\text { - ¿Cuáles son las principales problemáticas o deficiencias que } \\
\text { usted ha detectado en las técnicas e instrumentos relacionados } \\
\text { con la categoría de "consulta a empleadores" cuando se trata de } \\
\text { evaluar o acreditar un programa educativo? } \\
\text { - ¿Esta coordinación dispone de instrumentos diseñados exprofe- } \\
\text { so para realizar auscultación de las apreciaciones de los emplea- } \\
\text { dores? } \\
\text { ¿Cuáles son las principales problemáticas o deficiencias que } \\
\text { usted ha detectado en la redacción de informes relacionados } \\
\text { con la categoría de "consulta a empleadores" cuando se trata de } \\
\text { evaluar o acreditar un programa educativo? } \\
\text { ¿Las coordinaciones o direcciones de vinculación institucional } \\
\text { apoyan de alguna forma para establecer los contactos pertinen- } \\
\text { tes para la realización de consultas a empleadores? } \\
\text { - ¿Se dispone de una base de datos institucional de empleadores? } \\
\text { ¿Existen procedimientos especíicos para asignar el personal } \\
\text { para la organización de la información para cada una de las } \\
\text { categorías del proceso de evaluación o acreditación del plan de } \\
\text { estudios? } \\
\text { ¿Se le da seguimiento al proceso de "consulta de empleadores" } \\
\text { desde coordinación del plan de estudios? }\end{array}$ \\
\hline
\end{tabular}

Por lo anterior, se construyó una cédula de entrevista considerando las cuatro variables principales del objetivo de estudios, las cuales fueron: empleadores, acreditación, reestructuración curricular y procesos institucionales. La construcción de la cédula de entrevista se describe en la tabla 1.

Tabla 2

Categorías y subcategorías del análisis de la información recolectada

\begin{tabular}{ll}
\hline \multicolumn{1}{c}{ Categorías } & \multicolumn{1}{c}{ Subcategorías } \\
\hline & Relevancia de la consulta de empleadores \\
Empleadores & Atributos de los empleadores \\
& Seguimiento a egresados \\
\hline
\end{tabular}




\begin{tabular}{ll}
\hline \multicolumn{1}{c}{ Categorías } & \multicolumn{1}{c}{ Subcategorías } \\
\hline Acreditación & Procedimiento de asignación de actores para el proceso de acreditación \\
\hline $\begin{array}{l}\text { Reestructuración } \\
\text { curricular }\end{array}$ & Relevancia de los empleadores para la reestructuración curricular \\
\hline & $\begin{array}{l}\text { Proceso de acercamiento a empleadores } \\
\text { Instrumentos para la consulta a empleadores } \\
\text { Procesos }\end{array}$ \\
institucionales & $\begin{array}{l}\text { Seguimiento al proceso de acercamiento a empleadores } \\
\text { Vinculación institucional }\end{array}$ \\
\hline
\end{tabular}

Los resultados obtenidos de la aplicación de las entrevistas a los informantes clave, se han analizado en categorías y subcategorías. Estas categorías y subcategorías se presentan en la tabla 2.

\section{Resultados y discusión}

Se presentan los resultados obtenidos del análisis de contenido temático realizado con la información recolectada mediante la aplicación de las entrevistas a profundidad a expertos y la exploración de documentos correspondientes a las categorías de análisis. Los resultados están organizados por categorías y subcategorías de análisis.

\section{Empleadores}

La categoría de empleadores se analizó en tres subcategorías: (1) relevancia de la consulta de empleadores, (2) atributos de los empleadores, y (3) seguimiento a egresados. En la exploración y el análisis de los datos obtenidos en las entrevistas, los expertos mencionaron que la consulta de los empleadores para los procesos de acreditación del plan de estudios es de alta relevancia y alto impacto, ya que es uno de los aspectos importantes para valorar la pertinencia de los planes de estudio. Así lo mencionó el jefe del Departamento de Diseño Curricular de la UABC:

Es de alta relevancia y alto impacto porque uno de los aspectos importantes para valorar la pertinencia de los planes de estudio es el ámbito laboral, sus expresiones son muy importantes para tomar decisiones en relación a aspectos formativos para los futuros egresados ya que al final de cuentas nosotros podemos 
medir si un plan de estudios funciona o no a partir del impacto que está teniendo en el mercado laboral y quien nos puede hablar sobre eso son los empleadores. (A. Castro, comunicación personal, 13 de noviembre de 2020)

En concordancia con esto, el coordinador de la Licenciatura en Ciencias de la Educación mencionó que:

La relevancia de la consulta de empleadores debe de ser muy importante, porque son las voces de las personas que van recibiendo en sus instituciones o negocios a las personas que egresan, su opinión es muy importante, porque de alguna manera nos dicen cómo se están desempeñando los egresados, de ahí que me parece que este criterio tiene mucho peso en cuanto a entender donde se ubican los egresados y como se desempeñan. (F. Medina, comunicación personal, 12 de noviembre de 2020)

La información obtenida de la consulta de empleadores permite tomar decisiones en relación con aspectos formativos para futuros egresados y, de esta forma, medir la funcionalidad del plan de estudios a partir del impacto que está teniendo en el mercado laboral. Sin embargo, los ejercicios de consulta de empleadores realizados últimamente no han dado los resultados esperados, ya que no se cuenta con una base sólida procedimental que permita estudiar el universo de empleadores de los egresados del plan de estudios en cuestión, causando sesgos importantes en los informes de resultados.

El experto en evaluación curricular de la FCH mencionó que en el caso específico de la Facultad de Ciencias Humanas:

No hay un seguimiento sistemático principalmente, considero que esa es una problemática seria, hasta que hay movimiento de acreditación o hay cuestiones de reestructuración curricular es cuando se busca la opinión de los empleadores, pero antes, no, no hay un comité de vinculación bien definido, bien marcado para poder llevar todas esas cuestiones de seguimiento. (J. E. Martínez, comunicación personal, 13 de noviembre de 2020)

En este sentido, la OCDE (2019) propone como recomendación a las IES: 
- Concienciar sobre la importancia de mejorar los resultados y la relevancia de la educación superior de México para el mercado laboral.

- Proporcionar un marco para un conjunto de iniciativas políticas que garanticen la adopción de un enfoque cohesivo y sistemático para mejorar los resultados y la relevancia de la educación superior para el mercado laboral. (p.14)

Ya que, en la actualidad, no existe una tradición de vincular a las instituciones con las empresas.

Asimismo, consideran que el seguimiento de egresados es una herramienta fundamental para tomar decisiones en cuestión del universo de empleadores reales de los egresados del plan de estudios, ya que permiten conocer en qué áreas laborales se insertan y cuáles son los resultados en cuestión de desempeño profesional, así lo mencionó el jefe del Departamento de Diseño Curricular de la UABC:

Cada programa educativo debe de tener estudios sistemáticos de egresados, pues a partir de ahí se determinan los empleadores, entonces regularmente la comunicación la gestión de acceso al campo, esas acciones relacionadas con entrevistas, aplicación de cuestionarios hacia los empleadores pues la realizan los mismos equipos de trabajo en las unidades académicas. (A. Castro, comunicación personal, 13 de noviembre de 2020)

Afianzando esto, Palloroso y García (2019) afirmaron que "los estudios de seguimiento a graduados son de gran importancia para una adecuada gestión universitaria; contribuyen a la toma de decisiones, mejoran la calidad, retroalimentan la pertinencia de los programas académicos de la Universidad, entre otras bondades" (p.9).

Asimismo, De Vries (2015) indicó la importancia de reconocer la existencia de diversos mercados donde se insertan los egresados y que cada uno de estos mercados posee intereses y necesidades distintas. Por ello, se debe trabajar en la vinculación universidad-empresa, para lograr cubrir estas necesidades. Así, según Álvarez y Romero (2015), la educación superior no puede permanecer ajena a los problemas de la sociedad y, por lo tanto, del mercado laboral.

Sin embargo, en la institución no se cuenta con un procedimiento para llevar a cabo el seguimiento sistémico de egresados, considerando su trayectoria laboral, así lo men- 
cionó el coordinador de la Licenciatura en Ciencias de la Educación de la FCH: "no existe un seguimiento continuo, se da de manera por solicitud cuando vienen este tipo de evaluaciones es que se hace, pero no existe un seguimiento de egresados" (F. Medina, comunicación personal, 12 de noviembre de 2020).

Por otra parte, se reconoce la necesidad de perfilar las características adecuadas para la selección de empleadores que participan en el proceso de acreditación y reestructuración curricular, esto con la finalidad de determinar un universo y poder seleccionar una muestra representativa que considere las cuatro áreas de formación del plan de estudios y se pueda realizar un análisis de pertinencia y relevancia integral.

Ya que, de acuerdo con el Sistema Nacional de Acreditación de la Educación Superior (SINAES, 2019), "El proceso de acreditación exige que las carreras consulten a los empleadores sobre el desempeño de sus graduados. En ese marco, se propicia el enriquecimiento del perfil de salida de acuerdo a las necesidades del sector empleador" (párr. 3).

\section{Acreditación}

La categoría de acreditación se analizó en una subcategoría: procedimiento de asignación de actores para el proceso de acreditación. En esta, los expertos determinaron la falta de procedimientos institucionales explícitos para la asignación del personal participante en el proceso de acreditación del plan de estudios, reconociendo la necesidad de determinar el perfil adecuado para atender las categorías del instrumento de evaluación del organismo acreditador del plan de estudios. Así lo mencionó el Coordinador de la Licenciatura en Ciencias de la Educación:

La verdad en el tiempo en el que he estado no he identificado que haya algunos criterios específicos, en realidad me parece que se hace una como invitación a los maestros que tienen afinidad al tema y ellos se van sumando, porque no hay un listado como tal que diga, bueno para el área de trayectoria escolar se necesitan maestros que cumplan con ciertos criterios. (F. Medina, comunicación personal, 12 de noviembre de 2020)

De esta misma forma, concuerdan en la posibilidad de presentar resultados no adecuados a estos requerimientos por desconocer el contenido temático de las categorías del instrumento del organismo evaluador. 
Álvarez y Romero (2015) señalaron la dificultad para desarrollar estudios de egresados y de empleadores como principales problemáticas de las IES en los procesos de acreditación, ya que los estudios existentes no cuentan con el enfoque adecuado para obtener información real del proceso de vinculación entre la universidad y el mundo del trabajo.

\section{Reestructuración curricular}

La categoría de reestructuración curricular se analizó en una subcategoría: relevancia de los empleadores para la reestructuración curricular. En la cual los expertos coinciden en la doble función del proceso de acercamiento con empleadores con fines de acreditación y el seguimiento a egresados, ya que ambos procesos permiten obtener información precisa de las necesidades del campo ocupacional y permiten tomar decisiones apropiadas para la reestructuración del plan de estudios y poder adecuarlo a las necesidades sociales y del campo ocupacional, otorgando a los egresados mayores posibilidades de emplearse. Así lo indicó el jefe del Departamento de Diseño Curricular de la UABC:

Las voces de los empleadores son de alto impacto, o sea, alto impacto en el sentido de que, si son muy importantes para valorar la pertinencia de los planes de estudio, o sea, ellos son los que están dentro del mercado laboral y el mercado laboral es una parte que atendemos con los planes de estudios. (A. Castro, comunicación personal, 13 de noviembre de 2020)

Por lo anterior, se deben de mantener procesos continuos que permitan la vinculación de las instituciones de educación superior con el mercado laboral, de esta forma se podrán atender las necesidades sociales y proporcionar a los jóvenes una mayor probabilidad de empleo al egreso (Camarena \& Velarde, 2009; Mungaray, 2001).

\section{Procesos institucionales}

La categoría procesos institucionales se analizó en cinco subcategorías: (1) proceso de acercamiento a empleadores, (2) instrumentos para la consulta de empleadores, (3) informe de resultados, (4) seguimiento al proceso de acercamiento a empleadores y (5) vinculación institucional.

Los expertos coincidieron en la falta de procedimientos institucionales para llevar a cabo el acercamiento con empleadores, asimismo, reconocen que los procesos imple- 
mentados son débiles en aspectos metodológicos y no revelan una validez de la misma investigación y hace necesario el diseño procedimental con una estructura definida para la consulta de empleadores, con la finalidad de establecer un proceso sistémico y continuo del acercamiento a empleadores.

Nuevamente se destaca la importancia y necesidad de contar con una base de datos institucional de empleadores que cumplan con las características adecuadas para ser partícipes en el proceso de acreditación y reestructuración curricular. En cuanto a los instrumentos para la recolección de datos referente a la postura de empleadores utilizados en procesos de acreditación anteriores, coincidieron en la falta precisión y amplitud en las categorías de información, así como la necesidad de someterlos a procesos de confiabilidad y validez. Así lo consideró el experto en evaluación curricular:

Una problemática que yo directamente detecto es que no hay un instrumento fuerte aplicado a empleadores, hoy en día la ciencia requiere que todo sea sometido a procesos de validación y de confiabilidad, es algo que se requiere, un instrumento más consolidado, que se haya revisado por jueces expertos, que se haya revisado por pares. (J. E. Martínez, comunicación personal, 13 de noviembre de 2020)

Asimismo, mencionaron que las debilidades metodológicas tanto en el diseño metodológico del estudio como en el diseño del instrumento tiene como resultado problemas estructurales en los informes de resultados, ya que estos no brindan información precisa de las áreas de oportunidad de los planes de estudio, sino que presentan información en términos generales que pudiera presentar ambigüedades, dando importancia también al seguimiento que debe de tener el proceso de consulta a empleadores con fines de acreditación y reestructuración del plan de estudios. De acuerdo con Soriano (2015), el diseño de instrumentos y su contenido deben de pasar por el proceso de validación, para asegurar que la información que se obtenga sea válida y permita tomar decisiones. También, consideran de gran importancia realizar el acercamiento desde la postura de los enfoques metodológicos más utilizados en las ciencias sociales, para poder cubrir con los criterios de confiabilidad y validez de los estudios de investigación.

En este sentido, Álvarez y Romero (2015) sustentaron la necesidad de realizar estudios que den cuenta de la demanda de profesionales. Por su parte, Díaz (2020) señaló que, para lograr la vinculación entre la educación superior y el sector empresarial, es necesario 
que las IES establezcan indicadores de efectividad educativa y que las empresas sean partícipes de la definición, evaluación y cumplimiento de estos indicadores.

De esta misma forma, hacen hincapié en la necesidad de fortalecer los vínculos entre el departamento de vinculación institucional y las coordinaciones de los planes de estudios, ya que esto asegurará un seguimiento adecuado y continuo de empleadores y de egresados, con la finalidad de sistematizar la toma de decisiones.

\section{Conclusiones}

Los resultados obtenidos de la exploración metodológica en el contexto educativo permiten determinar la necesidad de establecer un procedimiento que mejore la instrumentación del proceso de acercamiento y consulta a empleadores. La institución debe considerar como tarea primordial el seguimiento sistémico de egresados como medio para determinar aciertos y áreas de oportunidad del plan de estudios.

Además, se deben considerar como estrategia para asegurar la pertinencia de la selección de la muestra de empleadores que se consultará como parte del proceso de acreditación del plan de estudios.

En dicho proceso de seguimiento, debe ser necesario definir las características idóneas que debe de poseer un empleador para considerarse dentro del estudio y buscar hacerlo de la manera más objetiva posible, para obtener información real del campo.

En este sentido, se debe de diseñar un perfil para el personal encargado de llevar a cabo el proceso de consulta de empleadores, en concordancia con los indicadores contenidos en el instrumento del organismo evaluador, las recomendaciones provenientes de la consulta de la literatura referente a la temática y con fuerte conocimiento de los aspectos metodológicos para la realización del estudio.

Como parte de las actividades que se deben de reforzar dentro del proceso de consulta de empleadores, se encuentra el diseño del instrumento adecuado para realizar esta tarea, ya que deben de considerarse evaluaciones de confiabilidad y validez, para que los datos recolectados puedan dar respuesta a las cuestiones más relevantes para tomar decisiones acerca del plan de estudios.

Por lo tanto, debe establecerse un procedimiento preciso para el acercamiento y la consulta de empleadores que pueda utilizarse para los procesos de acreditación y reestructuración curricular, considerándose como una actividad continua y sistémica para asegurar la pertinencia y veracidad de la información obtenida, para que sea de utilidad en la toma de decisiones institucionales. 


\section{Referencias}

Álvarez, J. E., \& Romero, A. (2015). La empleabilidad de graduados universitarios en el contexto latinoamericano. Realidades de Uniandes, Ecuador. Atenas, 4(32), 1-15. https://www.redalyc.org/articulo.oa?id=478047208001

Asociación Nacional de Universidades e Instituciones de Educación Superior. (2018). Visión y acción 2030 Propuesta de la ANUIES para renovar la educación superior en México. Diseño y concertación de políticas públicas para impulsar el cambio institucional. ANUIES. http://www.anuies.mx/media/docs/avisos/pdf/VISION_Y_ACCION_2030. pdf

Bautista-Cerro, M. J. (2014). (Re)Construction of the Concept of Employability from Universities Currículum Greening as a Key Element. Procedia - Social and Behavioral Sciences, 139, 536-542. https://doi.org/10.1016/j.sbspro.2014.08.063

Buendía, A. (2013). Genealogía de la evaluación y acreditación de instituciones en México. Perfiles educativos, 35, 17-32. http://www.scielo.org.mx/pdf/peredu/v35nspe/ v35nspea3.pdf

Camarena, B. O., \& Velarde, D. (2009). Educación superior y mercado laboral: Vinculación y pertinencia social ¿Por qué? y ¿Para qué? Estudios sociales, 17, 105-125. https:// dialnet.unirioja.es/servlet/articulo?codigo $=3176537$

De la Garza, J. (2013). La evaluación de programas educativos del nivel superior en México: Avances y perspectivas. Perfiles educativos, 35, 33-45. https://www.redalyc.org/ pdf/132/13229960004.pdf

De Vries, W. (2015). Reseña del libro Adecuar la oferta de educación a la demanda de trabajo. ¿Es posible? Una crítica a los análisis «adecuacionistas» de relación entre formación y empleo, de Jordi Planas. Scielo, 6(15), 151-154. http://www.scielo.org. mx/pdf/ries/v6n15/v6n15a9.pdf

Días, J. (2007). Acreditación de la educación superior en América Latina y el Caribe. En La educación superior en el mundo 2007. Acreditación para la garantía de la calidad: ¿qué está en juego? Global University Network for innovation. https://upcommons.upc. edu/handle/2099/7538

Díaz, E. R. (2020). Las instituciones de educación superior en México y el fomento de la empleabilidad. Revista comercio Exterior Bancomext. http://www. revistacomercioexterior.com/articulo.php?id=943\&t=las-instituciones-deeducacion-superior-en-mexico-y-el-fomento-de-la-empleabilidad 
Elizondo, M. del P., Ovando, M. A., Reséndiz, C., Mena, A., \& Castillejos, D. (2014). Los procesos de evaluación y acreditación y su impacto desde la perspectiva de los actores sociales en la Universidad Autónoma de Chiapas, México. Investigación en proceso. Atenas, 3(27), 16-27. https://www.redalyc.org/pdf/4780/478047203002. pdf

Faustino, O. Z. (2019). Los fines de la educación en el PND 2019-2024. Educación Futura. http://www.educacionfutura.org/los-fines-de-la-educacion-en-el-pnd-2019-2024/

Fernández, E. (2017). Una mirada a los desafíos de la educación superior en México. Innovación Educativa, 17, 25. http://www.scielo.org.mx/pdf/ie/v17n74/1665-2673ie-17-74-00183.pdf

Instituto Nacional de Estadística y Geografía. (2021). Directorio Nacional de Unidades Económicas. DENUE. Censos Económicos 2021. INEGI. https://www.inegi.org.mx/app/ mapa/denue/default.aspx

Martínez, O.R.(2017). Tensiones delas políticas de evaluación y acreditación de la educación superior en México. Debates en Evaluación y Currículo. Congreso Internacional de Educación, 2(2), 3858-3865. https://www.posgradoeducacionuatx.org/pdf2016/ F013.pdf

McMillan, J., \& Schumacher, S. (2005). Investigación educativa una introducción conceptual. Pearson Addison Wesley.

Mejía, J. (2014). El muestreo en la investigación cualitativa. Investigaciones Sociales, 4(5), 165-180. https://doi.org/10.15381/is.v4i5.6851

Moreno-Brid, J. C., \& Ruiz-Nápoles, P. (2010). La educación superior y el desarrollo económico en América Latina. Revista iberoamericana de educación superior, 1(1), 171-188. http://www.scielo.org.mx/pdf/ries/v1n1/v1n1a13.pdf

Mungaray, A. (2001). La educación superior y el mercado de trabajo profesional. Revista Electrónica de Investigación Educativa, 3(1), 1-12.https://redie.uabc.mx/redie/article/ view/35/1176

Murillo, F., \& Montaño, P. Y. (2018). Condiciones laborales de egresados de Instituciones de Educación Superior en México. Revista Electrónica de Investigación Educativa, 20(3), 56-68. https://doi.org/10.24320/redie.2018.20.3.1644

Navarro, M. A. (2014). Internacionalización y Educación Superior. Palibrio.

Organización de las Naciones Unidas para la educación, la ciencia y la cultura. (2019). Educación superior y objetivos de desarrollo sostenible. UNESCO. https://es.unesco. org/themes/educacion-superior/ods 
Organización Internacional del Trabajo. (2004). Recomendación R195-Recomendación sobre el desarrollo de los recursos humanos. https://www.ilo.org/dyn/normlex/es/f?p =NORMLEXPUB:12100:0::NO::P12100_ILO_CODE:R195

Organización para la Cooperación y el Desarrollo Económico. (2019). Educación Superior en México. Resultados y relevancia para el mercado laboral. Resumen/Evaluaciones $y$ recomendaciones. OECD. https://www.oecd.org/centrodemexico/medios/ educacion_superior_en_mexico.pdf

Palloroso, R. Y., \& García, I. (2019). Seguimiento a graduados: Importancia y principales experiencias internacionales. Análisis del tópico en la República del Ecuador.Caribeña de Ciencias Sociales. https://www.eumed.net/rev/caribe/2019/07/seguimientograduados-ecuador.html

Pires, S., \& Lamitre, M. J. (2008). Sistemas de acreditación y evaluación de la educación superior en América Latina y el Caribe. En A. L. Gazzola, \& A. Didriksson (Eds.), Tendencias de la educación superior en América Latina y el Caribe (pp. 297-318). Instituto Internacional de la UNESCO para la Educación Superior en América Latina y el Caribe.

Rubio, J. (2007). La evaluación y acreditación de la educación superior en México: Un largo camino aún por recorrer. Reencuentro, (50), 35-44. https://www.redalyc.org/ pdf/340/34005006.pdf

Ruiz, J. I. (2012). Metodología de la investigación cualitativa. Universidad de Deusto.

Semchenko,A. (2003). El mercado laboral yel sistema de educación y formación profesional. DVV International. https://www.dvv-international.de/es/educacion-de-adultos-ydesarrollo/ediciones/ead-612003/la-educacion-es-para-todos/el-mercado-laboraly-el-sistema-de-educacion-y-formacion-profesional

Sistema Educativo Estatal. (2015). Programa de educación de Baja California 2015-2019. http://www.educacionbc.edu.mx/see/programasectorial/PEBC20152019.pdf

Sistema Nacional de Acreditación de la Educación Superior. (2019). Para el empleador. https://www.sinaes.ac.cr/index.php/2-uncategorised/160-para-el-empleador-2

Soriano, A. M. (2015). Diseño y validación de instrumentos de medición. Diá-logos, 14, 1940. https://doi.org/10.5377/dialogos.v0i14.2202

Taylor, S., \& Bogdan, R. (1996). Introducción a los métodos cualitativos de investigación: La búsqueda de significados. Paidós.

Thoilliez, B. (2014). Universities versus employability. Some elements for analysis. Procedia - Social and Behavioral Sciences, 139, 79-86. https://doi.org/10.1016/j. sbspro.2014.08.029 
Universidad Autónoma de Baja California. (2018). Plan de desarrollo 2018-2022. Facultad de Ciencias Humanas. http://fch.mxl.uabc.mx/wp-content/uploads/2015/04/PDFCH-Versi\%C3\%B3n-Final.pdf

Universidad Autónoma de Baja California. (2019). Plan de Desarrollo Institucional 20192023. http://pedagogia.mxl.uabc.mx/transparencia/PDI/PDI_UABC_2019-2023.pdf Universidad de Guadalajara. (2019). Los apartados del Plan Nacional de Desarrollo que sirve de marco general a la planeación de las áreas relativas a las funciones del sujeto obligado. http://www.transparencia.udg.mx/apartados-plan-nacional-desarrollo

Vázquez, J. A. (2015). Nuevos escenarios y tendencias universitarias. Revista de Investigación Educativa, 33(1), 13-26. https://doi.org/10.6018/rie.33.1.211501 


\section{Capítulo 6}

La educación en el marco legal hacia la reinserción social

de las personas privadas de la libertad: un análisis documental

Eva Carolina Contreras Sánchez, Joaquín Vázquez García

y Jesús Adolfo Soto Curiel

Según el último reporte de resultados del Órgano Administrativo Desconcentrado Prevención y Readaptación Social por parte de la Secretaría de Seguridad Pública y Protección Ciudadana (SSPC), para diciembre de 2020, en México había 214231 personas privadas de la libertad (PPL), distribuidas en 289 Centros de Reinserción Social (CERESO), de los cuales 130 cuentan con sobrepoblación (SSPC, 2020). Asimismo, la última Encuesta Nacional de Población Privada de la Libertad (ENPOL) por el Instituto Nacional de Estadística y Geografía (INEGI, 2016) señaló que el $45.6 \%$ de las PPL comparten su celda con más de cinco personas, resultando en que $39.4 \%$ de ellas tengan que compartir su cama con alguien más.

A tal sobrepoblación se le conoce como hacinamiento, debido a que se considera la población total sobre la capacidad instalada en espacios determinados (en este caso, el sistema penitenciario), teniendo en cuenta la naturaleza del sitio con respecto a la fluctuación de sus habitantes que, en estas condiciones, suele ir en aumento mientras que la capacidad tiende a ser estática (Araiza \& Torres, 2019). Sin embargo, no solamente es cuestión de que cada una de las PPL cuente con un espacio para ocupar físicamente de manera individual, sino también de aquellos espacios destinados al cumplimiento de sus derechos por medio de actividades de distintas índoles como el deporte, la salud, la educación, el esparcimiento, entre otras (Comisión Nacional de los Derechos Humanos [CNDH], 2015). 
Lo anterior se puede ver reflejado en los resultados de la ENPOL (INEGI, 2016) donde se manifiesta que el 72\% de las PPL cuenta con estudios de educación básica, 19.2\% con educación media superior y $4.6 \%$ con educación a nivel superior. Igualmente, el INEGI (2020), a través del Censo Nacional de Gobierno, Seguridad Pública y Sistema Penitenciario Estatales 2020, indica que un total de 58447 PPL asisten a un programa formativo del área técnica escolar de los CERESO, resultando ser un aproximado de $27 \%$ de la población total.

Se observa que, al no contar con la infraestructura adecuada para la atención a PPL con respecto al respeto de sus derechos humanos, no se cumple con el supuesto de la promoción de una vida en dignidad humana, derecho fundamental de las PPL según las Reglas Mínimas de las Naciones Unidas para el Tratamiento de los Reclusos, también conocidas como Reglas Nelson Mandela (Organización de las Naciones Unidas Contra la Droga y el Delito [UNODC], 2015).

De lo anterior, surge la preocupación sobre las consecuencias del hacinamiento en Ios CERESO, tal como lo es el aumento de la violencia, de la reincidencia delictiva, de la tendencia a la violación de los derechos humanos, además de impactar negativamente a la capacidad de proporcionar programas dirigidos al tratamiento de las PPL (Garzón et al., 2018). Asimismo, la CNDH afirma que el hacinamiento es también una de las razones principales por las cuales el sistema penitenciario tiende a brindar un trato degradante e inhumano a las PPL, situación que entorpece y afecta el derecho a la reinserción social (CNDH, 2015).

En este sentido, cabe destacar que las bases de la reinserción social, según la Constitución Política de los Estados Unidos Mexicanos (CPEUM) en su Artículo 18 son el "respeto a los derechos humanos, del trabajo, la capacitación para el mismo, la educación, la salud y el deporte" (CPEUM, 2021). Considerando entonces que la Carta Magna señala que la educación es un derecho fundamental que ha de ser garantía de todas las personas que se encuentren en su jurisdicción sin importar su condición, con el fin de promover los derechos humanos, así como una cultura de la paz, los valores y la honestidad (CPEUM, 2021).

Además, en junio de 2016 entró en vigor la Ley Nacional de Ejecución Penal (LNEP) que surge como un medio homologado a nivel nacional para delimitar las pautas de la ejecución de las penas tanto privativas como no privativas de la libertad a causa de haber infringido la ley penal y cuya finalidad es:

1. Establecer las normas que deben de observarse durante el internamiento por prisión preventiva, en la ejecución de penas y en las medidas de seguridad impuestas como consecuencia de una resolución judicial; 
2. Establecer los procedimientos para resolver las controversias que surjan con motivo de la ejecución penal, y

3. Regular los medios para lograr la reinserción social. (LNEP, 2016, p.63)

Por consiguiente, la reinserción social es un derecho humano y la educación, además de un derecho, es una herramienta para alcanzarla y un elemento fundamental para el resguardo, promoción y garantía de la dignidad humana.

En consecuencia, el presente documento tiene como finalidad exponer el papel que reviste la educación desde el marco legal en el tratamiento de las PPL para lograr la reinserción social, así como su relevancia y naturaleza como derecho humano. Para tal efecto, se llevó a cabo un análisis documental en lo que concierne a la educación en el marco legal, la educación penitenciaria como derecho fundamental y la reinserción social. Dichos abordajes tienen la intención de llevar a la reflexión sobre la importancia de crear espacios donde se respeten y promuevan los derechos humanos de las PPL, ya que, como Añaños et al. (2013) mencionaron: "los establecimientos penitenciarios de cumplimiento de pena no sólo son entidades arquitectónicas, administrativas y funcionales del sistema penitenciario, sino que son contextos ecosistémicos, de socialización y de educación-reeducación de gran importancia" (p.15).

\section{Método}

El análisis documental se realiza para presentar datos específicos sobre un tema en particular y se le otorga un sentido o perspectiva al abordarlo según el interés particular. Así, permite describir y representar la información recabada a partir de un proceso analítico y sintético, mediante una serie de acciones que recaen en la investigación técnica (Dulzaides \& Molina, 2004). De igual manera, según Pinto (1989), el análisis documental "está constituido por un conjunto de operaciones (unas de orden intelectual y otras mecánicas y repetitivas) que afectan al contenido y a la forma de los documentos originales, reelaborándolos y transformándolos en otros de carácter instrumental o secundarios" (p.328).

Para efectos del análisis documental de interés en el texto presente, se llevó un proceso metódico en el que se establecieron distintas categorías que permiten comprender la problemática:

1. La educación en el marco legal: derecho constitucional, derecho penal, derecho penitenciario y derechos humanos. 
2. La educación penitenciaria como derecho fundamental de las PPL: derechos fundamentales y educación penitenciaria.

3. La reinserción social.

\section{Resultados}

A continuación, se abordan las categorías descritas en el apartado metodológico: derecho constitucional, derecho penal, derecho penitenciario, derechos humanos, derechos fundamentales, la educación penitenciaria y la reinserción social.

\section{La educación en el marco legal}

Derecho constitucional

El derecho constitucional surge a partir de la caída del absolutismo feudal en Norteamérica y Europa, con la intención de generar normas que concordaran con la —entonces - nueva política y visión jurídica (Bruzón, 2011). Ahora bien, Kant (2017) señaló que el Derecho, en cualquiera de sus formas, depende de leyes que determinarán cuáles acciones tiene permitida la ciudadanía y cuáles no, así como cuáles son sus obligaciones y garantías; es decir, todo derecho necesita de una ley pública en la que el Estado debe instituir los principios de libertad, igualdad e independencia ciudadana. De ahí resulta la Constitución, un documento de orden que dicta las pautas de organización de la sociedad y que convierte a México en un Estado de derecho.

Por lo referido con antelación, al clasificarse en dicha forma de gobernanza, México tiene la obligación de hacer cumplir las leyes por igual a todas las personas, entidades, instituciones que se encuentren bajo su jurisdicción, las cuales han de ser elaboradas sobre la base de los principios y normas internacionales de los derechos humanos (Organización de las Naciones Unidas [ONU], 2004). Ahora bien, el Estado mexicano y sus leyes son plasmadas en su máxima expresión en la Constitución Política de los Estados Unidos Mexicanos, un documento de orden jurídico, político, sociológico y cultural (García, 2001) y sus principios no parten de las acciones ciudadanas desde una perspectiva moral, sino desde el valor que tienen en la coexistencia y la cooperación social (Burgoa, 1984).

En este sentido, el derecho constitucional como disciplina es aquel que estudia y analiza la Constitución para comprenderla y a través de él se conocen los fines del Estado (Ramírez, 2000). Ahora bien, partiendo de este concepto se abordan las acciones que el Estado mexicano debe realizar según su función plasmada en la CPEUM sobre el ejercicio de la educación. 
Por un lado, el Artículo tercero de la CPEUM señala que la educación es un derecho del que son garantes todas las personas y que su principal fin es potenciar el desarrollo de todas las facultades del ser humano, además del fomento del respeto a los derechos humanos, intentando atender las problemáticas que el país aguarde, mejorar la convivencia, disminuir desigualdades y fortalecer la dignidad de todas las personas sin importar su condición política o jurídica (CPEUM, 2021). Por lo tanto, resulta imperante brindar educación a las PPL y no solamente por ser un derecho del que gozan, sino por ser un medio por el cual se podrán reducir las brechas de desigualdad que existen incluso antes de que las PPL fueran puestas en reclusión (Visher et al., 2008). Al mismo tiempo, como la CPEUM menciona, mediante la educación se promueve el fortalecimiento de la dignidad humana, principio que se señala fundamental para el tratamiento de PPL según las Reglas Nelson Mandela (UNODC, 2015).

Ahora bien, la CPEUM considera la educación como un elemento esencial para el tratamiento de reinserción de las PPL:

El sistema penitenciario se organizará sobre la base del respeto a los derechos humanos, del trabajo, la capacitación para el mismo, la educación, la salud y el deporte como medios para lograr la reinserción del sentenciado a la sociedad y procurar que no vuelva a delinquir, observando los beneficios que para él prevé la ley. (Artículo 18)

Aunado a ello, México se encuentra afiliado a la Organización de los Estados Americanos (OEA) de la cual surge la Comisión Interamericana de Derechos Humanos (CIDH) y que, en 2008, publicó los Principios y Buenas Prácticas sobre la Protección de las Personas Privadas de la Libertad en las Américas y que, en el Principio XIII, señala que toda PPL cuenta con derecho a recibir educación sin discriminación alguna, así como el Estado tiene el deber de proveerles de educación básica gratuita y promover, en lo posible, la educación media superior, técnica y superior (CIDH, 2008).

\section{Derecho penal}

El derecho penal se puede concebir de dos formas: subjetiva y objetiva. La primera, trata del derecho que tiene el Estado de sancionar a las personas que cometen un delito, lo cual es trabajo del Poder Legislativo; y la segunda hace referencia tanto a las normas que contienen las leyes emitidas por el Estado para la divulgación de las conductas permitidas 
(o no) en el marco de lo legal y de las medidas y penas a consecuencia de tales conductas, lo cual recae en el Poder Judicial (Díaz-Aranda, 2014).

Por su parte, Alfaro (2009) definió al derecho penal como una disciplina de carácter científico que está encargada de preservar el orden social y regular lo circundante al delito (penas y medidas de seguridad emitidas por el Estado). Ahora bien, dichas medidas son tomadas con respecto a lo que estipula el Código Penal Federal (1931), pues se delimitan las pautas para las sanciones según los delitos que han de ser especificados en este.

De tal modo que el Código Penal Federal decretó en el 2016 la expedición de la LNEP, documento que regula las acciones que se han de tomar para la ejecución de penas tanto privativas como no privativas de la libertad, resolver controversias de la ejecución penal y regular las acciones en materia de reinserción social, siempre bajo el respeto a los derechos estipulados en la Constitución y todos aquellos tratados a los cuales el país esté afiliado (LNEP, 2016).

Entonces, como ya se mencionó anteriormente, la LNEP surge del Código Penal Federal (1931) y esta retoma, en el Artículo 14 donde habla de la autoridad penitenciaria, lo que la CPEUM señala en el Artículo 18, considerando a la educación como un medio para la reinserción social del sentenciado (LNEP, 2016). Asimismo, en el Artículo 15, delimita las funciones de la autoridad penitenciaria en las cuales se encuentra "I. Garantizar el respeto a los derechos humanos de todas las personas que se encuentren sujetas al régimen de custodia y vigilancia en un centro penitenciario; II. Procurar la reinserción social efectiva mediante los programas institucionales" (LNEP, 2016, p.70). Estas dos acciones redundan en la educación pues esta es un derecho humano y un elemento del tratamiento para la reinserción social.

Por lo tanto, el derecho penal como disciplina trata del derecho que tiene el Estado de sancionar las conductas delictivas y también de las normas por las cuales dichas conductas son consideradas como delito. Pero, por otra parte, las normas van de la mano de los derechos (Kant, 2017) y uno de los cuales no se puede separar al ser humano es la educación, pues como Scarfó (2003) mencionó "quien no haga uso de este derecho pierde la oportunidad de pertenecer a la sociedad, a participar de manera real y constituirse en un ciudadano [... y cumpla con sus deberes a favor del desarrollo de la sociedad" (p.1).

\section{Derecho penitenciario}

El derecho penitenciario puede ser considerado como una rama del derecho penal, ya que tiene que ver con los procesos de ejecución de las penas consecuentes del delito (García, 
1975); es decir, se encarga de regular las normas jurídicas de los espacios de cumplimiento de las penas privativas de la libertad (Alfaro, 2009).

Sin embargo, Méndez (2008) afirmó que el derecho penitenciario tiene una mayor complejidad, ya que no solo se enfoca en las normas que rigen los espacios penitenciarios, pues lo define como "el estudio analítico, teórico y práctico de la prisión, vista como pena y como establecimiento, no sólo normativamente sino también desde una perspectiva social e integral, con la finalidad de readaptar (actualmente reinsertar) al sujeto privado de su libertad" (p.5).

Con respecto a lo anterior, el autor señala el derecho penitenciario en lo analítico, pues considera que no solo se trata de las penas y los lugares donde estas se cumplen, sino de todo lo que conlleva el sistema penitenciario, desde la infraestructura, la administración (inclúyase todo el personal), los derechos de las PPL, sus obligaciones, etcétera; con lo teórico se refiere a los abordajes del concepto y el fin del derecho penitenciario desde su naturaleza que, como se menciona en la cita anterior, es la reinserción social; y, por último, la disciplina en lo práctico, lo cual hace referencia al proceso de llevar a la práctica lo que se indica en lo teórico (Méndez, 2008).

En este sentido, Durán (2020) reafirmó la concepción de Méndez (2008), pues considera como fundamental abordar lo relacionado con la gestión y ejecución de todos los recursos que orientan al cumplimiento objetivo de la función de los espacios penitenciarios. Entonces, en México, los CERESO tienen como propósito la reinserción social de las PPL y utilizan la educación como un recurso para lograrlo. De ahí que la educación en contextos penitenciarios (que será referida como educación penitenciaria en los apartados venideros) sea considerada como el medio para la constitución del ser humano (Scarfó, 2003).

Ahora bien, los Artículos del 18 al 25 de la CPEUM (2021) indican que el sistema penitenciario (actor del derecho penitenciario) tiene la responsabilidad de ejecutar las medidas que habrán de tomarse para la reparación de los daños causados por un delito y, de ser necesario, acudir a la supervisión judicial.

Bajo tal referencia, el sistema penitenciario, en conjunto con las PPL, construye un plan de actividades personalizado para cada individuo que se encuentra recluido, donde se incluyen actividades que se llevarán a cabo durante su estancia en el CERESO con el fin de favorecer a la reinserción social. Se deberá procurar que dichas actividades sean de carácter educativo, deportivo, cultural, laboral, de capacitación y de salud, a partir de las necesidades de cada PPL y el tiempo que se destinará para cada una de las actividades estará establecido en el mismo plan (LNEP, 2016). 
Con base en lo anterior, el sistema penitenciario formaliza acciones de formulación de estrategias para la reinserción social (mismas que se ofertan para el plan de actividades) a través de la celebración de convenios interinstitucionales con diversas secretarías e instituciones de Educación Pública, Economía, Trabajo y Previsión Social, de Cultura, entre otras, lo cual las convierte en autoridades corresponsables. Por lo que a lo que educación concierne, las instituciones de educación superior también tienen la corresponsabilidad de coadyuvar al proceso de la reinserción social, brindando herramientas de distintas índoles con el fin de ampliar la oferta educativa de los CERESO y mejorar su calidad (LNEP, 2016). Para tal efecto, la LNEP (2016) señala que dichas autoridades corresponsables:

deberán prever en sus programas la adecuada y correcta implementación, y deberán establecer dentro de los proyectos de presupuesto respectivos, las partidas necesarias para atender la ejecución de esos programas, las obras de infraestructura, la contratación de personal, la capacitación y todos los demás requerimientos necesarios para cumplir los objetivos de la presente Ley. (p.117)

\section{Derechos humanos}

La Oficina del Alto Comisionado de las Naciones Unidas para los Derechos Humanos (ACNUDH, 1996) reconoció que los derechos humanos son aquellos derechos de los que somos garantes todos los seres humanos debido a nuestra naturaleza como tal y que "son inherentes a todos nosotros, con independencia de la nacionalidad, género, origen étnico o nacional, color, religión, idioma o cualquier otra condición" (párr.1). Además, afirmó que dichos derechos son:

- Universales. Es decir, todos los seres humanos gozamos de los mismos derechos humanos.

- Inalienables. No es posible despojar de estos derechos a ninguna persona, a excepción de aquellos que sean suspendidos temporalmente por causas concretas, siempre y cuando sea producto de un procedimiento adecuado. Un ejemplo sería la privación de la libertad tras un juicio legal.

- Indivisibles e interdependientes. Ningún derecho puede ser gozado de forma parcial y la privación de uno afecta el goce de los otros. Por ejemplo, el derecho al trabajo repercute en el derecho a la salud y viceversa. 
- Equitativos y no discriminatorios. Significa que no existe distinción alguna para la aplicación y goce de los derechos humanos (ACNUDH, 1996).

Aunado a ello, así como los seres humanos gozamos de derechos también tenemos obligaciones por cumplir y una de ellas es respetar y defender los derechos humanos de los demás (ACNUDH, 1996).

Por otra parte, en el ámbito nacional, la CNDH (2020) define los derechos humanos como "el conjunto de prerrogativas sustentadas en la dignidad humana, cuya realización efectiva resulta indispensable para el desarrollo integral de la persona" (párr.1). Ahora bien, tales derechos deberán incluirse y permanecer establecidos en todos los tratados y leyes nacionales e internacionales a los que se encuentre afiliado el país (CNDH, 2020).

Para efectos del presente capítulo, se abordan los derechos humanos universales que tienen relación con el tema de interés: los Artículos 1 y 2 tratan de la igualdad entre los seres humanos, todos nacen siendo libres y con los mismos derechos sin distinción por ningún tipo de condiciones, tales como el sexo, el color, la nacionalidad, la religión, la opinión política, el estatus político y jurídico; mientras que el Artículo 5 prohíbe el uso de castigos, torturas y tratos inhumanos; el Artículo 26 indica que todas las personas tienen derecho a la educación, especificando que los Estados deben proporcionar —al menoseducación básica gratuita, además, el objeto de la educación será el desarrollo del ser humano, el fomento al respeto a los derechos humanos y será en pro de la comprensión encaminada hacia una cultura de la paz (ONU, 1948).

\section{La educación penitenciaria como derecho fundamental de las PPL}

Derechos fundamentales

Los derechos humanos fundamentales son, según González (2018), "garantías que brinda la nación a todo individuo que está dentro de su límite territorial, que se ve regido por una carta magna, y que dota de facultades que debe gozar plenamente todo individuo dentro de un territorio nacional" (párr.16). Asimismo, el autor afirmó que para que puedan existir derechos fundamentales deben existir primero derechos humanos (González, 2018).

De acuerdo con Aguilar (2010), para que un derecho humano se convierta en derecho fundamental en un país este debe estar considerado en su Constitución. Los aportes tanto de González (2018) como de Aguilar (2010) son coincidentes en que los derechos humanos pertenecen al ámbito internacional (son emitidos y promovidos por organismos internacionales), mientras que los derechos fundamentales son aquellos que son recono- 
cidos por las Constituciones de cada país. Por ejemplo, un derecho humano es tener derecho a un juicio tras ser sospechoso de la comisión de un delito y un derecho fundamental es aquel que especifique las normas para el juicio, según lo que cada Estado señale en su Carta Magna.

Por lo tanto, los derechos fundamentales son distintos en cada país y los derechos humanos son universales, pues como Batista (2018) afirmó:

Tras su constitucionalización, los derechos humanos pasaron a tener un ámbito de protección dual. Es decir, los derechos humanos lograron ser consagrados en las Constituciones; sin embargo, los propios textos magnos, ampliaron la gama de derechos, hasta ese momento reconocidos a las personas, en función de su relación como ciudadanos de un Estado. (p.192)

Sin embargo, no significa que todos los derechos que se señalan en las constituciones políticas son fundamentales, sino que cada Estado deberá señalar en su Carta Magna cuáles derechos son fundamentales y cuáles no, ya sea en un apartado independiente o a lo largo del documento cada vez que aparezca un derecho de tal naturaleza (Bernal, 2009). Con base en lo anterior, la CPEUM (2021) indica que:

todas las personas gozarán de los derechos humanos reconocidos en esta Constitución y en los tratados internacionales de los que el Estado Mexicano sea parte, así como de las garantías para su protección, cuyo ejercicio no podrá restringirse ni suspenderse, salvo en los casos y bajo las condiciones que esta Constitución establece. (Art.1)

De igual manera, la educación es un derecho fundamental reconocido por la CPEUM (2021), señalando que "Toda persona tiene derecho a la educación. El Estado —Federación, Estados, Ciudad de México y Municipios - impartirá y garantizará la educación inicial, preescolar, primaria, secundaria, media superior y superior" (Art.3).

\section{Educación penitenciaria}

A partir de los abordajes teóricos, queda claro que se debe brindar educación a las PPL con motivo de tratamiento para la reinserción social, sin embargo, la formación que se ha 
de impartir en los centros penitenciarios tiene un significado distinto a la educación fuera de ellos y, por lo tanto, toda una metodología detrás de sí.

Corresponde cuestionarse, ¿qué es la educación penitenciaria? y ¿para qué sirve la educación penitenciaria?

Con base en la primera pregunta, a continuación, se aborda el significado de educación en el marco de la LNEP (2016), donde en el Artículo 83 se desglosa el derecho a la educación de las PPL:

La educación es el conjunto de actividades de orientación, enseñanza y aprendizaje, contenidas en planes y programas educativos, otorgadas por instituciones públicas o privadas que permitan a las personas privadas de su libertad alcanzar mejores niveles de conocimiento para su desarrollo personal. (LNEP, 2016, p.90)

En ese mismo artículo se indica que la educación ha de ser laica y gratuita, así como deberá incluir contenidos de tipo cultural, académico, cívico, social, higiénico, entre otros que estén dirigidos hacia el respeto a las leyes y los derechos humanos. Asimismo, la educación que se imparta en los centros penitenciarios brindará la posibilidad de obtener grados académicos, ya que serán impartidos y diseñados por los organismos de educación correspondientes, por lo que tendrán validez oficial (LNEP, 2016).

En respuesta a la segunda pregunta, la educación en penitenciarías se brinda con distintos fines. En una primera y más inmediata instancia, el fomento al respeto de los derechos humanos entre las mismas PPL y también en convivencia con la autoridad penitenciaria, de modo que es posible identificar a la educación como una herramienta que previene la violación a los derechos humanos y, por añadidura, promover espacios dentro de los centros penitenciarios donde se fomente una convivencia pacífica, respetuosa, igualitaria, justa y solidaria (Scarfó, 2003).

Sustentado en la idea anterior, Erzen et al. (2019) afirmaron que la educación en prisiones aumenta las posibilidades de que las PPL puedan prosperar como miembros de una sociedad civil, ya que les proporciona habilidades y herramientas con las que no contaban al momento de ingresar al centro penitenciario, puesto que gran parte de la población penitenciaria es víctima de las inequidades sociales desde antes de ingresar a prisión, lo cual disminuye sus posibilidades de estudiar. En este sentido, Visher et al. (2008) 
relacionaron la falta de oportunidades de las PPL incluso antes de ser puestas en reclusión al no tener experiencia laboral y bajos niveles de estudio, lo cual tiende a incrementar al cumplir con su sentencia, por lo que brindar educación puede disminuir las brechas de desigualdad y propiciar la reinserción social.

\section{Reinserción social}

Como se mencionó anteriormente, uno de los fines del sistema penitenciario y en consecuencia de cualquier CERESO es la reinserción social, la cual es definida en la LNEP (2016) como la "restitución del pleno ejercicio de las libertades tras el cumplimiento de una sanción o medida ejecutada con respeto a los derechos humanos" (p.66). De modo que, según la legislación, es la recuperación de todas las libertades de una PPL después de haber cumplido con el tiempo designado en reclusión con motivo de sanción por haber cometido algún delito. El Ministerio de Justicia de Chile (2018) definió la reinserción social como "un proceso sistemático de acciones orientado a favorecer la integración a la sociedad de una persona que ha sido condenada por infringir la ley penal" (párr.1). Por lo tanto, la definición chilena difiere de la mexicana, ya que esta se refiere a lo que pasa durante la estancia de las PPL en los espacios penitenciarios, mientras que la concepción mexicana hace alusión al momento en el que el individuo regresa a la sociedad en pleno ejercicio de la libertad.

Del mismo modo, Bravo (2017) hizo referencia a las acciones y actividades por medio de las cuales el sistema penitenciario procura evitar que las PPL vuelvan a delinquir, es decir, prepararlas para el momento en que sean puestas en libertad y que, gracias a dichas acciones y actividades, la persona pueda vivir en sana convivencia y en el marco legal. En la reinserción social también se involucra la motivación hacia el proceso de cambio para un retorno a la sociedad, donde las personas que alguna vez cometieron un delito sean capaces de respetar la ley y jueguen un papel positivo en la sociedad y en sí mismos (Enjuanes \& Morata, 2019).

Según García (2018), para efectuar la función de la reinserción social, hay que dejar de lado la idea de que los centros de cumplimiento de las penas privativas de la libertad son para efectos de castigo y que las personas que cometen delitos merecen y necesitan ser castigadas. Es decir, romper con la ideología de que las sentencias se dictan solamente como medida punitiva y reconocer que los tratamientos dirigidos hacia la reinserción social son el medio hacia una sociedad más democrática e igualitaria. 


\section{Conclusiones}

Definitivamente la educación es un elemento fundamental para el tratamiento de las PPL; es reconocida por organismos tanto nacionales e internacionales como una herramienta que favorece no solo a la reinserción social, sino la convivencia dentro de los centros penitenciarios, y promueve el derecho a la dignidad humana. Además, es considerada como un derecho humano fundamental, ya que se encuentra señalada en distintos documentos de orden jurídico como un derecho de todas las personas que residan en el territorio nacional.

Ahora bien, a sabiendas de la relevancia de proporcionar programas educativos en los centros penitenciarios, cabe reflexionar con respecto a qué acciones educativas se realizan realmente, pues los datos expuestos al inicio de este capítulo muestran la limitación de actividades de esta índole. En consideración de que la LNEP fue expedida desde el año 2016, la promoción e implementación de programas dirigidos a la reinserción social han tenido un avance paulatino que ha posicionado a la educación en una de sus prioridades. Sin embargo, aún queda un camino largo por recorrer para llegar a la celebración máxima de lo estipulado en la legislatura con respecto al propósito fundamental de los CERESO y tal situación se ve reflejada en los porcentajes de hacinamiento, pues la sobrepoblación y el incumplimiento de los derechos humanos va de la mano.

Por lo tanto, surge la necesidad de impulsar la cooperación de las diversas instituciones de carácter público y privado que se reconocen como autoridades corresponsables para la formulación de programas que favorezcan el tratamiento de las PPL. Por ende, al involucrar instituciones competentes a la educación no solamente aseguran la promoción de actividades educativas, sino que redundará en la calidad de dichas actividades brindando más y mejores herramientas a las PPL para una vida dentro y fuera de los centros penitenciarios, bajo una visión de respeto a los derechos humanos, a la ley y a la sana convivencia en sociedad. 


\section{Referencias}

Aguilar, G. (2010). Derechos fundamentales-derechos humanos. ¿Una distinción válida en el siglo XXI? Boletín mexicano de derecho comparado, 43(127), 15-71. http://www. scielo.org.mx/pdf/bmdc/v43n127/v43n127a1.pdf

Alfaro, V. M. (2009). Glosario de Términos Jurídicos. Grupo Editorial Patria.

Alto Comisionado de las Naciones Unidas para los Derechos Humanos. (1996). Qué son los derechos humanos. ACNUDH. https://www.ohchr.org/sp/issues/pages/ whatarehumanrights.aspx

Añaños, F. T., Fernández, M. del P., \& Llopis, J. J. (2013). Aproximación a los contextos en prisión: Una perspectiva socioeducativa. Pedagogía social: revista interuniversitaria, 22, 2-16. https://doi.org/10.7179/PSRI_2013.22.02

Araiza, L. J., \& Torres, M. A. (2019). Definiendo el hacinamiento. Estándares normativos y perspectivas judiciales sobre el espacio penitenciario. Revista Socio-Jurídicos, 21(2), 227-258. https://revistas.urosario.edu.co/index.php/sociojuridicos/article/ view/7632

Batista, J. (2018). Derechos humanos y derechos fundamentales. Algunos comentarios doctrinales. IUSLabor, 2, 186-213. https://doi.org/10.31009/IUSLabor.2018.i02.05

Bernal, C. (2009). Los derechos fundamentales en la jurisprudencia del Tribunal Electoral del Poder Judicial de la Federación. Tribunal Electoral del Poder Judicial de la Federación.

Bravo, A. (2017). Análisis de políticas públicas con enfoque de género en el sistema penitenciario nacional: La situación en el Centro Penitenciario Femenino de Santiago (Tesis de licenciatura). Universidad de Chile, Santiago. http://repositorio.uchile.cl/ handle/2250/144834

Bruzón, C. (2011). Derecho Constitucional: Momentos para una periodización. Algunos retos y debates actuales. Ius et Praxis, 17(1), 119-138. https://doi.org/10.4067/ S0718-00122011000100006

Burgoa, I. (1984). Derecho Constitucional mexicano (5a ed.). Editorial Porrúa. https:// bibliotecavirtualceug.files.wordpress.com/2017/06/der-mex-1.pdf

Código penal. (1931). Código penal para el Distrito y territorios federales en materia de fuero común,yparatodalarepúblicaenmateria defuerofederal.Diariooficial,DOF04-08-1931. http://www.diputados.gob.mx/LeyesBiblio/ref/cpf/CPF_orig_14ago31_ima.pdf

Comisión Interamericana de Derechos Humanos. (2008). Principios y buenas prácticas sobre la protección de las personas privadas de la libertad en las Américas. OEA. http:// www.oas.org/es/cidh/mandato/Basicos/PrincipiosPPL.asp 
Comisión Nacional de los Derechos Humanos. (2015). Uso excesivo de la pena de prisión y hacinamiento penitenciario. $\mathrm{CNDH}$.

Comisión Nacional de los Derechos Humanos. (2020). ¿Qué son los derechos humanos? CNDH. $\quad$ https://www.cndh.org.mx/derechos-humanos/que-son-los-derechoshumanos

Constitución Política de los Estados Unidos Mexicanos. (2021). Constitución publicada en el Diario Oficial de la Federación el 5 de febrero de 1917. Última reforma publicada, DOF 28-05-2021. http://www.diputados.gob.mx/LeyesBiblio/pdf_mov/ Constitucion_Politica.pdf

Díaz-Aranda, E. (2014). Lecciones de Derecho Penal para el nuevo sistema de justicia en México. Universidad Nacional Autónoma de México. https://archivos.juridicas.unam. mx/www/bjv/libros/8/3805/7.pdf

Dulzaides, M. E., \& Molina, A. M. (2004). Análisis documental y de información: Dos componentes de un mismo proceso. ACIMED, 12(2), 1-1. http://eprints.rclis. org/5013/1/analisis.pdf

Durán, M. (2020). Derecho penitenciario: Delimitación de su concepto, función y contenido desde un modelo teleológico-funcional del fin de la pena. Revista de derecho (Concepción), 88(247), 117-156. https://scielo.conicyt.cl/pdf/revderudec/ v88n247/0718-591X-revderudec-88-247-117.pdf

Enjuanes, J., \& Morata, T. (2019). Modelos penitenciarios educativos como base del éxito en la reinserción social de las personas privadas de libertad. Boletín Criminológico, 25. https://doi.org/10.24310/Boletin-criminologico.2019.v25i2019.7131

Erzen, T., Gould, M. R., \& Lewen, J. (2019). Equity and excellence in practice. A guide for higher education in prison. Prison University Project.

García, I. (2018). Ejecución Penal. Cambios de paradigma y cultura jurídica. Dfensor. Revista de derechos humanos, 16(12), 4-11. https://cdhcm.org.mx/wp-content/ uploads/2019/03/Dfensor_SJEP_reinsercion.pdf

García, J. A. (2001). Los medios de control constitucional en México. Supremo Tribunal de Justicia del Estado de Sinaloa. https://biblio.juridicas.unam.mx/bjv/detallelibro/1459-los-medios-de-control-constitucional-en-mexico?fbclid=IwAR1HqoJdn I7Fvlb2wBzMhpJLKyeLuawNpZwnH4NRH_o5d1NDIT9iQRxBqa8

García, S. (1975). La prisión. Fondo de Cultura Económica/UNAM.

Garzón, J. C., Llorente, M.V., \& Suárez, M. (2018). ¿Qué hacer con la reincidencia delincuencial? Elproblema y sus posibles soluciones. Fundación Ideas para la Paz. http://cdn.ideaspaz. org/media/website/document/5ae0ab974baff.pdf 
González, O. A. (2018). Derechos humanos y derechos fundamentales. Hechos y Derechos, 46. https://revistas.juridicas.unam.mx/index.php/hechos-y-derechos/article/ view/12589/14141

Instituto Nacional de Estadística y Geografía. (2016). Encuesta Nacional de Población Privada de la Libertad (ENPOL) 2016. https://www.inegi.org.mx/programas/enpol/2016/

Instituto Nacional de Estadística y Geografía. (2020). Censo Nacional de Gobierno, Seguridad Pública y Sistema Penitenciario Estatales 2020. INEGI. https://www.inegi.org.mx/ programas/cngspspe/2020/\#Tabulados

Kant, I. (2017). Teoría y praxis. El Cid Editor.

Ley Nacional de Ejecución Penal. (2016). DECRETO por el que se expide la Ley Nacional de Ejecución Penal; se adicionan las fracciones XXXV, XXXVI y XXXVII y un quinto párrafo, y se reforma el tercer párrafo del artículo 225 del Código Penal Federal. Diario Oficial de la Federación, DOF 16-06-2016. http://www.diputados.gob.mx/LeyesBiblio/ref/ Inep/LNEP_orig_16jun16.pdf

Méndez, L. (2008). Derecho penitenciario. Oxford University Press.

Ministerio de Justicia de Chile. (2018). Qué es la reinserción. Reinserción Social. http:// www.reinsercionsocial.gob.cl/que-es-la-reinsercion/

Organización de las Naciones Unidas. (1948). Declaración universal de Derechos Humanos. https://www.ohchr.org/EN/UDHR/Documents/UDHR_Translations/spn.pdf

Organización de las Naciones Unidas. (2004). El Estado de derecho y la justicia de transición en las sociedades que sufren o han sufrido conflictos. Informe del Secretario General. Naciones Unidas. https://undocs.org/es/S/2004/616

Organización de las Naciones Unidas Contra la Droga y el Delito. (2015). Reglas mínimas de las Naciones Unidas para el tratamiento de los reclusos (Reglas Nelson Mandela). UNODC. https://www.unodc.org/documents/justice-and-prison-reform/Nelson_ Mandela_Rules-S-ebook.pdf

Pinto, M. (1989). Introducción al análisis documental y sus niveles: El análisis de contenido. Boletín de la ANABAD, 39(2), 323-342. https://dialnet.unirioja.es/servlet/ articulo?codigo $=798857$

Ramírez, J. (2000). Derecho constitucional sinaloense. Universidad Autónoma de Sinaloa. https://biblio.juridicas.unam.mx/bjv/id/1461

Scarfó, F. J. (2003). El derecho a la educación en las cárceles como garantía de la educación en derechos humanos. Revista IIDH, 36, 291-324. http://desarrollo.uacm.edu.mx/ sitios/pescer/pdf/derecho_educacion_carceles.pdf 
Secretaría de Seguridad y Protección Ciudadana. (2020). Cuaderno mensual de información estadística penitenciaria nacional. Órgano Administrativo Desconcentrado Prevención y Readaptación Social. https://www.gob.mx/cms/uploads/attachment/ file/616688/CE_2020_12.pdf

Visher, C., Debus, S., \& Yahner, J. (2008). Employement after prison: A longitudinal study of releases in three States. Urban Institute Justice Policy Center. 


\section{Acerca de los coordinadores}

\section{Emilia Cristina González Machado}

\section{iD}

Es Doctora en Ciencias de la Educación por la Universidad Autónoma de Coahuila. Maestra en Ciencias Sociales por el Instituto de Investigaciones Sociales de la Universidad Autónoma de Baja California (UABC). Cuenta con Especialidad en Pedagogía por el Centro Regional de Educación Fundamental para la América Latina (CREFAL). Su formación inicial es Psicología en la Facultad de Ciencias Humanas de la UABC. Distinción nivel 1 del Sistema Nacional de Investigadores (SNI) del Consejo Nacional de Ciencia y Tecnología (CONACyT). Es integrante del grupo de investigación de Evaluación e intervención educativa y psicológica avalado por la Secretaría de Educación Pública (SEP). La línea de investigación que trabaja es juventudes y proyectos socioeducativos. Es profesora de tiempo completo en la Facultad de Ciencias Humanas de la UABC.

\section{Jesús Adolfo Soto Curiel}

\section{iD}

Es Doctor en Ciencias y Humanidades para el Desarrollo Interdisciplinario por la Universidad Autónoma de Coahuila, Master en Escritura para TV y Cine por la Universidad Autónoma de Barcelona, Posgraduado en Políticas Culturales y Gestión Cultural por la Universidad Autónoma Metropolitana y Licenciado en Ciencias de la Comunicación por la Universidad Autónoma de Baja California (UABC). Es miembro del Sistema Nacional de Investigadores Nivel 1. Es profesor de tiempo completo y Director de la Facultad de Ciencias Humanas de la UABC. Sus intereses de investigación se inscriben en las líneas de educación, cine documental de memoria, narrativas audiovisuales y usos sociales y didácticos del cine. 
Qartuppi, S. de R.L. de C.V. está inscrita de forma definitiva

en el Registro Nacional de Instituciones y Empresas Científicas y Tecnológicas (RENIECYT) con el número 1600052.

Qartuppi, S. de R.L. de C.V. es miembro activo de la Cámara Nacional de la Industria Editorial Mexicana (CANIEM) con número de registro 3751.

Proyectos educativos

Propuesta de gestión y procesos formativos

Esta obra se terminó de producir en octubre de 2021.

Su edición y diseño estuvieron a cargo de:

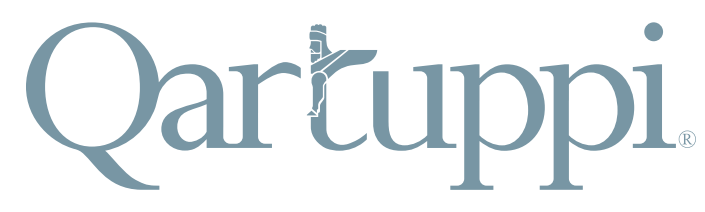

Qartuppi, S. de R.L. de C.V. http://www.qartuppi.com 
(c) (i) (): ()

Esta obra se edita bajo una Licencia Creative Commons

Atribución-NoComercial-Compartirlgual 4.0 Internacional. 
Proyectos educativos. Propuestas de gestión y procesos formativos integra las aportaciones de un grupo de estudiantes de la Maestría en Educación, realizadas durante sus estudios de posgrado en conjunto con investigadores que les acompañaron dirigiendo su trabajo terminal. En el libro se describen seis propuestas educativas que reflejan tópicos de interés para profesionales de la educación, especialmente para quienes se desenvuelven en las vertientes de la gestión educativa y los procesos de aprendizaje. Sin duda, es un libro que será de utilidad para estudiantes de pregrado y posgrado de educación, pedagogía y trabajo social.

ISBN 978-607-8694-15-0

DOI 10.29410/QTP.21.13
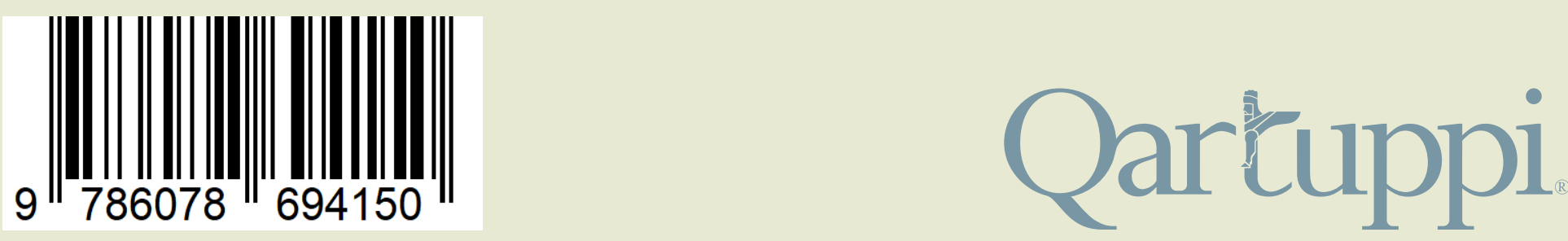